\title{
METÁTESIS DE CANTIDAD EN JÓNICO-ÁTICO Y HERACLEOTA *
}

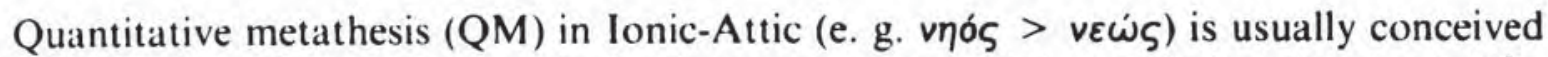
of as a phonetic process, typologically uncommon, which merely involves a transfer of length from one vowel to another. This traditional doctrine suffers from serious shortcomings. A more fruitful approach favoured by Schwyzer and other scholars views $Q M$ as resulting from synizesis (syllabicity loss) of a long vowel with simultaneous compensatory lengthening of the following vowel: e. g. vฤós $>$ vęws. This scenario is superior to the standard explanation on different counts: (a) it presents us with an internally coherent change, parallels for which may be easily found in languages other than Greek; (b) it accounts both for the systematic co-occurrence of synizesis and quantitative metathesis, and is consistent with the different behaviour of monosyllables vs. polysyllables as regards QM in Homeric epics; (c) it makes sense out of some apparent anomalies in accentuation.

The second part of the paper deals with the outcome $\iota \omega(</$ eo/) in the Heraclean Tables and in literary texts, which turns out to be another instance of QM. The lengthening of /o/ compensates for the loss of a mora caused by the synizesis of /e/ in an open syllable. Synizesis followed by the absorption of yod into /s/ explains the

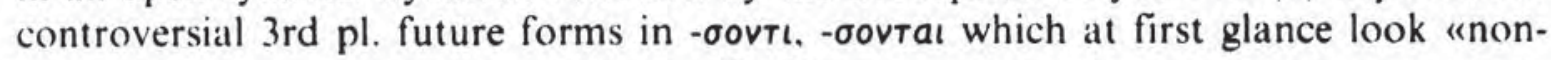
Doric"s.

* Una versión preliminar de este trabajo se presentó en el Seminario de Lingüistica Griega (Fundación Pastor, Madrid, 15-12-1990). Agradezco a E. Crespo, M. García Teijeiro, J. de $\mathrm{Hoz}$ y M. S. Ruipérez las acertadas observaciones y útiles sugerencias que allí me hicieron. A. Striano me alertó (carta del 10-1-1991) de la presencia de ciertas formas en el dialecto de Cirene que me habian pasado desapercibidas. Con su característica generosidad, Martin Peters me proporcionó valiosas indicaciones bibliográficas en el transcurso de una breve estancia en Viena (junio de 1990) y me envió más tarde una extensa carta (24-2-1991), repleta de perspicaces comentarios y críticas a una versión preliminar del artículo, que me han obligado a corregir ciertas inexactitudes y a matizar afirmaciones demasiado rotundas, y me han permitido captar algunas implicaciones de mi hipótesis de las que yo no era consciente. Por último, Albio Cesare Cassio (carta del 30-6-1991) me ha ayudado a rectificar evidentes desenfoques de interpretación de los datos transmitidos por Apolonio Díscolo. Por supuesto, el autor asume absolutamente la responsabilidad de los errores e incongruencias que permanezcan en el texto a pesar de la ayuda de las personas citadas. Este articulo se ha realizado dentro del marco del Proyecto de Investigación PB-90-0530 DGICYT. 
0. Pocos cambios en la evolución fonética del griego han recibido tanta atención como la metátesis de cantidad característica del jónicoático. Lejos de decaer, este interés ha continuado durante los últimos años en los importantes estudios de Ruijgh (1968), Miller (1976), Crespo (1977), Peters (1980: pp. 87-90, n. 40, pp. 251 ss., 301-304), Tichy (1981) y Miller (1982: pp. 103-138). Dicho esto, es preciso señalar que los trabajos citados no se ocupan del cambio por sí mismo. Su atención se centra en otras cuestiones: a) ¿Qué secuencias de vocales intervienen en la metátesis? b) ¿Qué relación se establece — bien en la cronología relativa tradicional, bien en la derivación sincrónica generativa entre la metátesis y otros procesos de la fonología del jónico ático, especialmente el cambio /a: $/>/ \mathfrak{a}: />/ \varepsilon$ :/, la pérdida de $-\underline{-}$ - y la ureversión ática»?" c) ¿Qué papel desempeñó la metátesis en la composición de los poemas homéricos?

El punto de vista que adoptaremos aqui será exactamente el inverso. Los problemas enumerados desempeñarán un papel marginal y subsidiario. Nuestro propósito fundamental es determinar cuál es el mecanismo fonético que ha provocado el cambio, una cuestión de la que, en los últimos tiempos, sólo se han ocupado autores de orientación puramente teórica (Hock 1986, Wetzels 1986).

Una revisión crítica de los dos tipos de hipótesis que se han propuesto nos llevará a la conclusión de que la solución de Schwyzer (1939), que intentaré reforzar con nuevos argumentos y con paralelos en otras lenguas, es - pese a no haber encontrado apenas seguidores la única capaz de explicar adecuadamente los datos.

Tras la metátesis de cantidad jónico-ática, examinaremos un fenómeno comparable, aunque no idéntico, en el dialecto de Heraclea. La interpretación de Schmidt (1978), aunque correcta en lo esencial, precisa algunas rectificaciones. Finalmente, revisaremos el controvertido problema de las formas de futuro atestiguadas en las Tablas de Heraclea y en textos literarios en dialecto dórico.

1. Por comodidad, mantengo la designación tradicional de «metátesis de cantidad" (en adelante MC) para referirme a la correspondencia

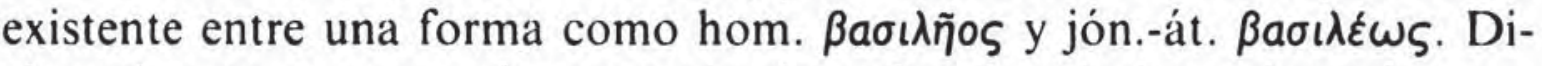
cha etiqueta no pretende tener ningún valor descriptivo, ni mucho menos explicativo, de la auténtica naturaleza del cambio, y se utiliza a lo largo de este artículo con una finalidad puramente identificativa. Bajo el mismo epígrafe quedan englobados, según es práctica habitual, los

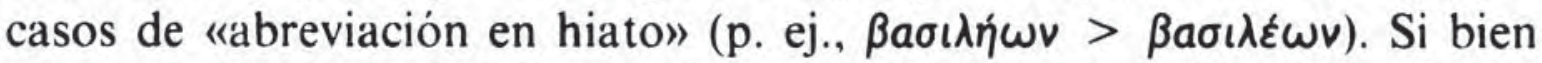
no puede hablarse de MC propiamente dicha, este cambio debe obede- 
cer a idéntica motivación: dado que el griego no contaba con vocales extralargas en su inventario de fonemas, las vocales largas $\omega, \bar{a}$ no eran susceptibles de alargamiento.

Para no interrumpir el curso de la argumentación con digresiones innecesarias, conviene exponer aquí, aunque sea de forma muy sumaria, cuál es mi posición respecto a tres cuestiones un tanto colaterales.

En primer término, si bien la $\mathrm{MC}$ de las secuencias $/ \mathfrak{a}: \mathrm{V}, \varepsilon: \mathrm{V} /$ resulta incontrovertida ${ }^{~}$, no ocurre lo mismo con el tratamiento de $/ \mathrm{e}: \mathrm{V} /$ con /e:/ larga cerrada. Pese a la escasez de ejemplos disponibles y a sus dificultades de interpretación, los argumentos de Peters (1980: pp. 87-90, n. 40) - también Crespo (1977: p. 203) - - me inclinan a creer que la MC afectó también a estas secuencias.

Por el contrario, no es verosimil la hipótesis de Ruijgh (1968:

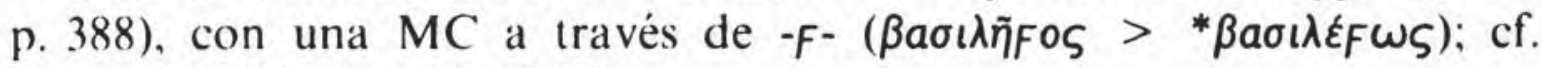
Crespo (1977: pp. 190-191) ${ }^{2}$.

Una tercera cuestión es la posibilidad de una «metátesis del grado de abertura" concomitante con la MC. Basándose en evoluciones como

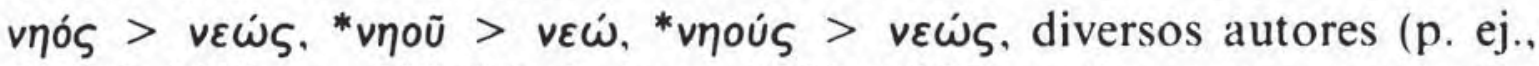
Ruijgh 1968: pp. 382-383, Lejeune 1972: $\$ 283$ ) sostienen que, en el caso

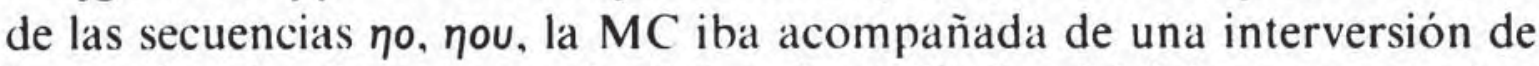
los grados de abertura: $s c .[\varepsilon: o(:)]>[\mathrm{e}: \mathrm{s}(:)]^{3}$. A mi juicio, esta «metátesis de grado de abertura» no está sufícientemente fundamentada. Por lo que se refiere a la evolución $\eta o>\varepsilon \omega$, este supuesto se basa en una idea tan arraigada entre los estudiosos como problemática (cf. Allen 1987: pp. $63,72,89-90)$ : que las vocales medias breves notadas $/ \mathrm{e} /, / \mathrm{o} /(\langle\varepsilon\rangle$, $\langle 0\rangle$ en el alfabeto clásico) se pronunciaban como [e], [o] cerradas. Si, por el contrario, se admite que /e/ y /o/ eran fonéticamente abiertas

' Para la transcripción fonética utilizo los signos del AFI, con una importante salvedad: por razones prácticas, las vocales medias breves aparecerán representadas como /e, o/ pese a que, como defenderé inmediatamente contra la opinión mayoritaria entre los especialistas, se trataba con toda probabilidad de vocales abiertas $[\varepsilon, \nu]$.

${ }_{2}$ El paralelismo con $h$, que no impide la elisión de una vocal precedente (cf. пара̀ оӥऽ [para ho:s] > пар' oüs), es ilusorio. A diferencia de /u/, la aspiración, por carecer de un gesto oral propio, puede superponerse a la articulacion de una vocal: una transcripción [para g:s] sería más adecuada a la realidad de los hechos. Por lo demás, como señala Miller (1982: p. 120), es evidente que / $\mathrm{u} / \mathrm{se}$ comporta de forma muy distinta a $/ \mathrm{h} /$, al ser capaz de impedir el hiato y formar posición tras una consonante.

${ }_{3}^{3}$ Por su parte, Wetzels (1986: pp. 335-336) opera con una resilabación parcial de la "segunda vocal" de la primera vocal larga que, por efecto del "Nuclear Fission Principle» $(s i c)$, queda asignada a la silaba siguiente: $s c$. $\eta \$ 0(=[\varepsilon \varepsilon \$ o])>[\varepsilon \$ \varepsilon 0]>$ $[\varepsilon \$ 0]$. Pero esta propuesta debe descartarse aunque sólo sea porque en griego las dos moras de una vocal larga se comportan como unidades autónomas en los procesos prosódicos (acentuación), pero no en los procesos segmentales. 
([ह], []), una hipótesis más acorde con los datos que nos ofrecen los sistemas de vocales de lenguas habladas en la actualidad, hay que postular un cambio $[\varepsilon: 0]>[\varepsilon:$ : ], lo que convierte la «metátesis de grado de abertura" en un proceso perfectamente superfluo.

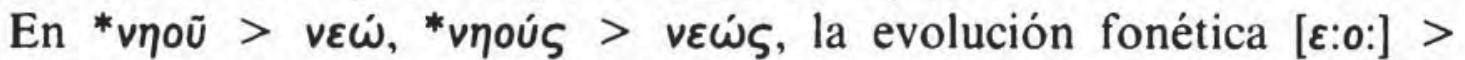
[ع:] es probablemente un espejismo. La /o:/ abierta se puede explicar por nivelación analógica con otros casos del paradigma como veẃs, $v \varepsilon \omega \dot{v}$ (ac. sg., gen. pl.), etc., donde $\omega$ es el resultado regular. A este respecto resulta sintomático comprobar que la generalización de la acentuación oxitona dentro del paradigma de la "declinación ática», con

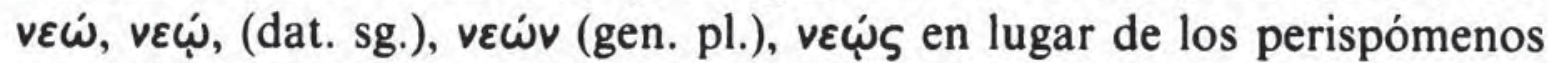

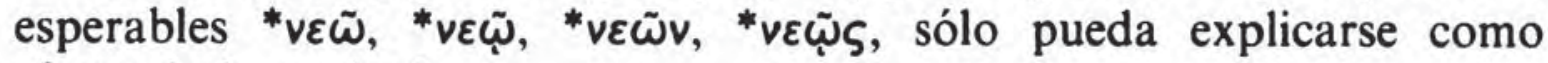
efecto de la analogía.

2. Estamos ya en condiciones de analizar críticamente las interpretaciones que se han dado a la MC.

2.1. La doctrina dominante en la actualidad concibe el cambio $\beta a$ $\sigma \iota \lambda \tilde{\eta} \circ \varsigma_{S}>\beta a \sigma \iota \lambda \varepsilon ́ \omega \varsigma$ de acuerdo con lo que parece indicar la grafia, como un proceso fonético por el que una vocal se alarga en compensación por la abreviación de una vocal precedente: $[\varepsilon: 0]>[\varepsilon \supset$ :]. Puede ser ilustrativa de este punto de vista la definición que da Lejeune (1972: \$283): “La métathèse des quantités... est limitée aux groupes $\eta a$ et $\eta$ qui aboutissent respectivement à $\varepsilon \bar{a}$ et $\varepsilon \omega$ par abrègement de $\bar{e}$ en hiatus

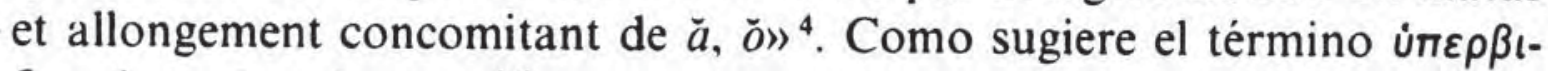

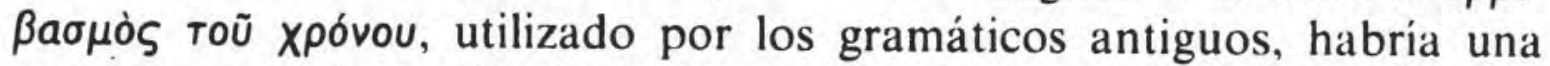
"transferencia de cantidad" de la primera vocal a la siguiente.

En adelante, reservo el término de "transferencia de cantidad» $(\mathrm{TrC}$ = metátesis de cantidad sensu stricto) para referirme a la hipótesis que ahora se discute. Por el contrario, como he indicado más arriba, utilizaré la denominación de "metátesis de cantidad» (MC) (= metátesis de cantidad sensu lato) para referirme a correspondencias como la que se

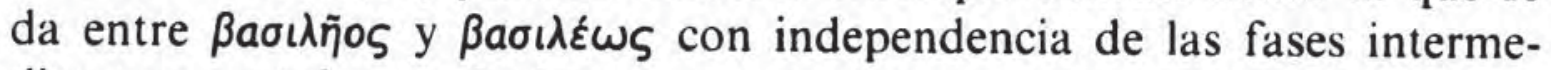
dias que postulemos. Insisto una vez más en que se trata de una etiqueta neutra sin implicaciones para la explicación del cambio.

4 Cf. también Ruijgh (1968: pp. 396-397), Rix (1976: §65). Con mayor concisión, Miller (1982: p. 103): "Quantitative metathesis is essentially the shift of $\bar{v} \bar{v}$ to $\bar{v} \bar{v}$ (certain vowels only)". Para una formalización más exacta, que engloba el proceso de la "metátesis de cantidad» propiamente dicha y el de la "abreviación en hiato" de $\eta$ ante vocal larga, cf. Peters (1980: p. 251, n. 208): $\bar{E}_{\mathrm{i}(\mathrm{QM})} \mathrm{E}_{\mathrm{j}(\mathrm{QM})}>\mathrm{E}_{\mathrm{i}(\mathrm{QM})} \overline{\mathrm{E}}_{\mathrm{j}(\mathrm{Q})}$ donde $\vec{E}_{\mathrm{i}}$ está por /a:/, / $\varepsilon$ :/ o /e:/ (vid. n. siguiente) y $\mathrm{E}_{\mathrm{j}}$ representa /a/ u /o/. Aparte su para(in)fernalia autosegmental, Wetzels (1986: pp. 331-335) no aporta nada que ayude a una mejor comprensión de la MC. 
Si hay que encontrarle alguna motivación fonética, podría pensarse que la $\mathrm{TrC}$ representaría una de las posibles manifestaciones de una restricción fonotáctica, común a todos los dialectos griegos, que tendría como finalidad eliminar las secuencias $/ \mathrm{V}: \mathrm{V} /$ (para la abreviación sin

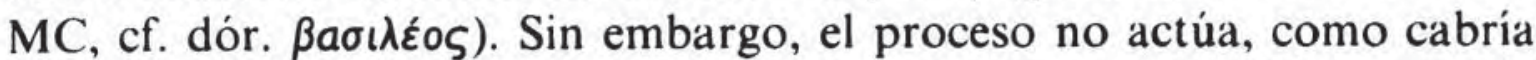
esperar, sobre todas las secuencias $/ \mathrm{V}: \mathrm{V} /$, sino que afecta sólo a un nú-

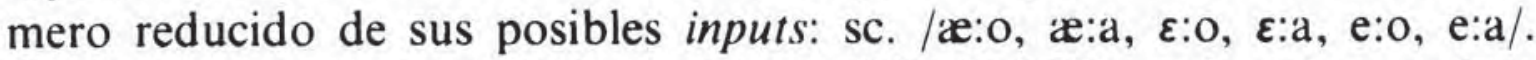
Como subraya Peters (1980: p. 251, n. 208), la MC no tiene lugar ni en

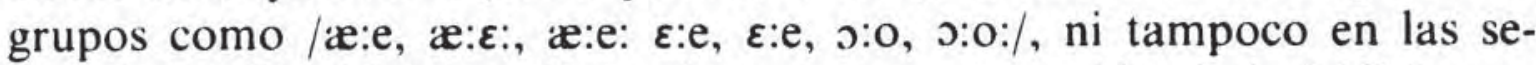
cuencias $/ \mathrm{a}: \mathrm{V} /$ del ático. También escapan a la acción de la $\mathrm{MC}$ las secuencias $/ \mathrm{i}: \mathrm{V} /$. Con tantas excepciones, la posibilidad de una restricción fonotáctica en contra de las secuencias $/ \mathrm{V}: \mathrm{V} /$ parece poco convincente.

Otro motivo para desconfiar de la $\mathrm{TrC}$ es que faltan ejemplos claros de un cambio $/ \mathbf{V}: \mathbf{V} />/ \mathbf{V V}$ :/ fuera del griego. Como admite Ruijgh (1968: p. 388), "la metathèse de la quantité [...] est un phénomène tout à fait isolé dans le cadre de la phonétique diachronique générale». El cambio del islandés antiguo que se suele citar como posible paralelo (cf. Bechtel 1924: p. 46, Lejeune 1972: $\$ 283$ ), no resulta de una mera transferencia de la cantidad vocálica (infra $\$ 4.1 .5$ ).

2.2. Una segunda hipótesis que, en mi opinión, presenta claras ventajas sobre la anterior es la que propone Schwyzer (1939: pp. 24546) 5 . Pese a que Ruijgh (1968: p. 396, n. 30) y Tichy (1981: p. 220, n. 54) la presentan como la "doctrine des manuels», lo cierto es que, si exceptuamos a Schmidt (1978) y Hock (1986) ${ }^{6}$, la hipótesis de Schwyzer, quizá por estar expuesta de forma esquemática, con una formulación poco precisa y con una argumentación apenas esbozada, no ha encontrado eco en la bibliografía posterior. Tanto es asi que sólo Tichy (1981) parece haber sentido la necesidad de refutarla de manera explicita.

Como es sabido, la MC tiene una papel secundario en la lengua de la épica homérica, donde el predominio de las formas con mantenimien-

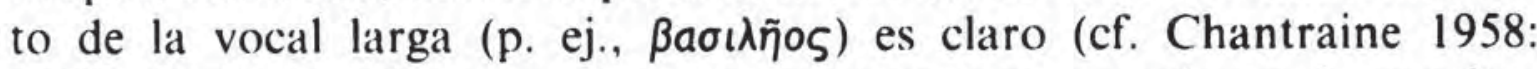
$\$$ 27-28). Esto es lo que cabe esperar en un texto, producto de una larga tradición, donde la propia técnica de composición oral favorecía la conservación de arcaísmos ${ }^{7}$. Hay, no obstante, también abundantes forclaro.

${ }^{5}$ Quizá ya antes Bechtel (1924: pp. 45-46), pero su punto de vista no queda

- Para la posición de Hock, cf. n. 25 infra.

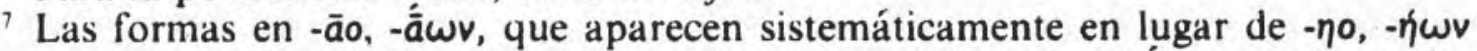

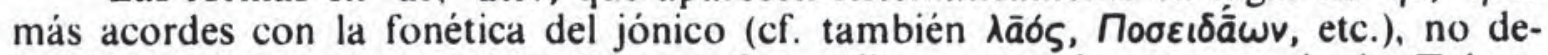
ben interpretarse como residuos de una fase eolia o, para el caso, protojonia. Tal eo- 
mas con $\mathrm{MC}^{x}$, en las que llama la atención que una abrumadora mayoría presente sinizesis, $s c$. el metro exige que $\varepsilon \omega, \varepsilon \bar{a}$ se escandan en una sola sílaba".

Como pone de manifiesto Schwyzer, resulta un hecho sorprendente y dificilmente atribuible al puro azar que la escansión monosilábica sea completamente regular en algunas categorias morfológicas como el gen.

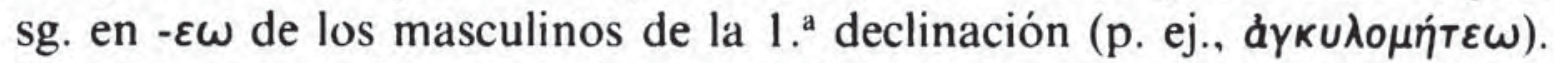
En otras categorías como el gen. pl. - $\varepsilon \dot{\omega} \boldsymbol{v}$ de los temas en $\bar{a}$, el subjuntivo, el participio de perfecto, etc., las escansiones yámbicas son rarísimas y tienden a localizarse en pasajes poco tradicionales (cf. Hoekstra 1965: p. 32), que, según diversos indicios, se pueden encuadrar en una época en la que la tradición oral había entrado en una fase de degeneración y en la que los aedos no se atenían ya a las técnicas de composición heredadas.

La sinizesis es también sistemática en las inscripciones métricas hasta fecha avanzada. Los testimonios más antiguos se registran en la célebre inscripción de Nicandra, CEG 403, 2 (Delos < Naxos, ca. 650),

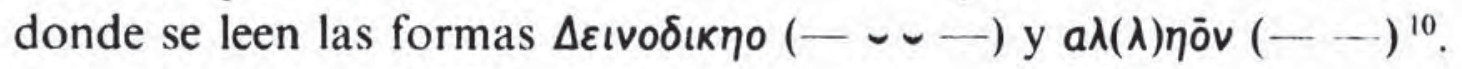

lismo (o arcaísmo) sería inorgánico ya que $-\eta 0,-\eta \dot{\omega} v$ no habrían alterado el valor métrico de -āo, -áwv. Pace Ruijgh (1985: pp. 147-148), parece más verosímil que el proceso haya operado en direcciọ́n inversa (cf. Miller 1982: pp. 120-121, Peters 1989:

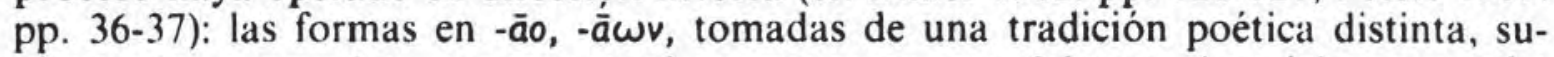
plantaron a $-\eta 0,-\eta \omega v$ porque, en el momento en que del texto homérico se estaba estabilizando, estas últimas no se usaban ya en el jónico cotidiano. Es como si los

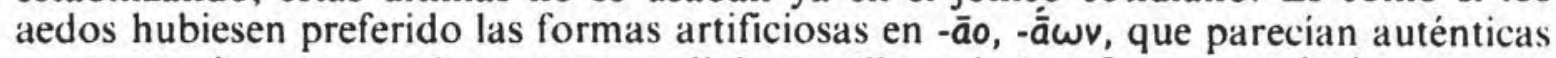
porque tenian un correlato en otros dialectos (literarios), a formas auténticas en - $\eta 0$, $-\eta \omega v v$, que parecian artificiosas porque no estaban vivas en ninguna parte.

${ }^{8}$ Hoekstra (1965: pp. 31-41) observa que las formas con MC no se han incorporado de forma orgánica al sistema de dicción formular más tradicional y, por lo tanto, deben pertenecer a los estratos más recientes de la épica.

" Empleo el término «sinizesis» ( = "formación de glide», "pérdida de silabicidad de una vocal») en un sentido muy amplio para referirme a cualquier proceso fonético por el que una de las vocales de una secuencia pierde la silabicidad: cf. esp. almohada formal [almoáða] $\rightarrow$ familiar [-møá-] $\rightarrow$ descuidado [-mwá-], hacalao [bakaláo] $\rightarrow$ [-láo] $\rightarrow$ [-láux]. Respecto al griego, no mantendré, por lo tanto, distinciones como la que establece West (1982: pp. 12-14) entre "synecphonesis" y "consonantalization of $\iota$ and u" (equivalentes grosso modo a los procesos de "diphthongal contraction" y "glide formation" en la terminología de Nyman 1978) dependiendo de que el núcleo vocálico resultante sea largo o breve. Incidentamente, resulta imposible compartir con este último autor (1978: p. 72) la idea de que la "diphthongal contraction" fuera propia del estilo "lento" y cuidado. Este tipo de procesos, que implican reducción fonética, surgen en los estilos más descuidados para difundirse más tarde a registros fonoestilísticos cada vez más formales (cf. Donegan y Stampe 1979: pp. 142-143; Dressler 1985: pp. 44-45).

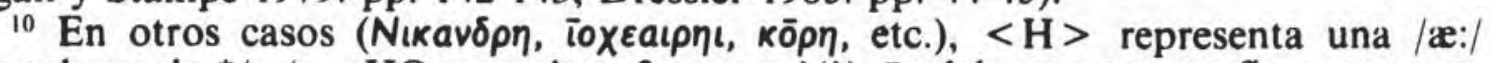
procedente de $* / a: / .<H O>$ en $\Delta \varepsilon i v o \delta ı \eta \%$ y $a \lambda(\lambda) \eta \bar{v} v$ debe ser una grafía correspondiente al estilo formal lento /a: $\lrcorner(:) /$ frente a la realización [æo:] con sinizesis, propia 
MC y sinizesis aparecen también asociadas en la lírica arcaica jónica, donde la pronunciación monosilábica de $\varepsilon \omega$ es normal (West 1974: pp. 79-83). Las escansiones yámbicas se localizan preferentemente en posición final de verso, donde la cadencia natural de la recitación tendía al rallentando ". Los primeros ejemplos de desinencia de genitivo $-\varepsilon \omega$ disilábica son tardíos y claramente secundarios (Schmidt 1968: pp. $72-74$ y 1978: p. 14 con bibliografia).

Aunque con menor regularidad, en el trímetro yámbico de la tragedia la escansión - en lugar de _- es frecuente en genitivos como $\phi$ o-

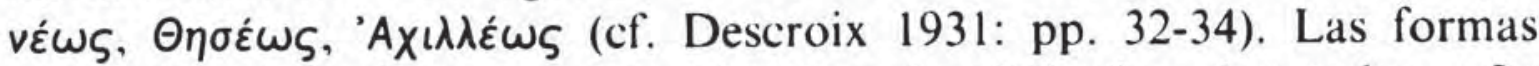
con MC y sinizesis aparecen en el primer hemistiquio sobre todo en $2 . "$ y $5 .{ }^{a}$ posición ( $1 .^{a}$ princeps y $2 .^{a}$ anceps), si bien se evitan en el segundo hemistiquio y quedan excluidas de la $100^{a}$ posición (5." princeps) ${ }^{12}$.

Pese a los intentos de disociar ambos procesos (cf. $\$ 4$ para un examen crítico), la sinizesis y la MC guardan una clara interrelación causal. La MC no constituye un proceso fonético con entidad propia: la sinizesis es condición inexcusable. El alargamiento de la segunda vocal no se produce como compensación por la abreviación de /a:, $\varepsilon$ :, e:/ como creen los partidarios de la $\mathrm{TrC}$, sino por su pérdida de silabicidad: $\eta$ o $>\varepsilon \omega^{13}$. Me referiré a esta segunda hipótesis como «sinizesis con alargamiento compensatorio» (abreviado en SINIZ. + AC).

3. Ni que decir tiene, la asociación de sinizesis y $\mathrm{MC}$ resulta inexplicable para los partidarios de la $\operatorname{TrC}$, que se ven obligados a operar con dos procesos sucesivos: (i) $\eta \circ>\varepsilon \omega$ (MC propiamente dicha), (ii) $\varepsilon \omega>\varepsilon \omega$ (sinizesis). Pero esta reconstrucción plantea dos problemas.

de un estilo menos formal, que exige la métrica (cf. Hoekstra 1965: p. 31, Gallavotti 1986: p. 232. Miller 1982: p. 106). Contra lo que da a entender Ruijgh (1968: p. $385)$, que [æ] breve (más exactamente [æx] no silábica) se haya mantenido siempre como variante contextual sin haber llegado a alcanzar el estatuto de fonema antes de confundirse con $/ \mathrm{e} /$, no presenta ningún inconveniente para nuestra interpretación.

i También en Homero un buen número de las raras formas disilábicas ocupan

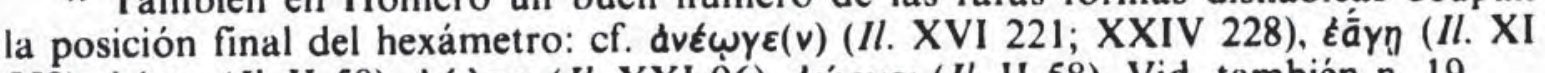

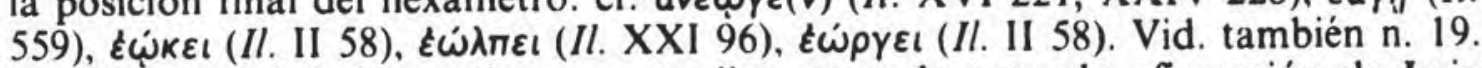

12 La realidad de los datos contradice, pues, la rotunda afirmación de Lejeune (1972: p. 278): «les textes poétiques (tragiques, comiques) indiquent que cette finale $-\varepsilon \omega \varsigma$ est normalement dissylabique; la synizèse est l'exception".

13 Tichy (1981: p. 204) arguye que los cambios $\varepsilon 0>10>1 \omega(=[i 0:])$ y $\varepsilon 0>$ દ̧ou (= [eo:]), que Schmidt (1978) postula para el laconio y heracleota y para el sira-

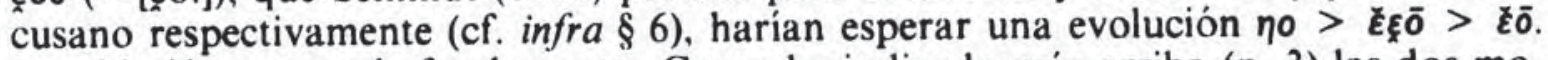
$\mathrm{La}$ objeción carece de fundamento. Como he indicado más arriba (n. 3) las dos moras de una vocal larga no actúan como unidades independientes en los procesos segmentales. Siendo esto así, es impensable la sinizesis o la contracción parcial de una vocal larga. 
Una primera dificultad deriva de la cronología de los testimonios: contra lo que cabría esperar, la frecuencia de las formas disilábicas, supuestamente más antiguas, aumenta progresivamente en los textos cuanto más recientes son éstos.

Existe otra paradoja que no ha pasado desapercibida: ¿por qué en Homero la sinizesis es tan sistemática en el caso de las secuencias $\varepsilon \omega$, $\varepsilon \bar{a}$ resultantes de la MC y, en cambio, sólo afecta de forma esporádica a las secuencias primarias del tipo $\theta \varepsilon \tilde{\omega} v$ ? En sendos trabajos de reciente publicación, Tichy (1981) y Ruijgh (1985) han tratado de dar respuesta al enigma.

3.1. Para Tichy (1981), la sinizesis es un recurso que los aedos recientes tomaban del habla allegro y que les permitía encajar dentro de patrones formulares las formas con MC que ellos empleaban en su dialecto. Podían así hacer sitio de forma expeditiva a una partícula monosilábica $(\mu \dot{\varepsilon} v)$ o a una forma pronominal $(\mu \iota v, \ddot{~} \gamma \varepsilon)$ al lado de $\varepsilon \omega \varsigma$,

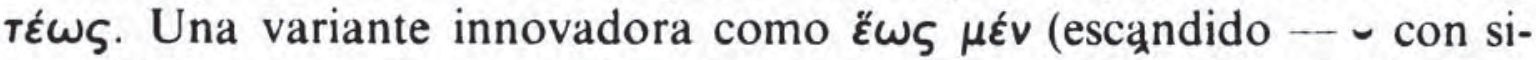
nizesis) podía suplantar a la variante tradicional * $\eta \circ$ S $^{-}(-)$sin alterar el esquema métrico (contra esta idea cf. ya Chantraine 1958: p. 12).

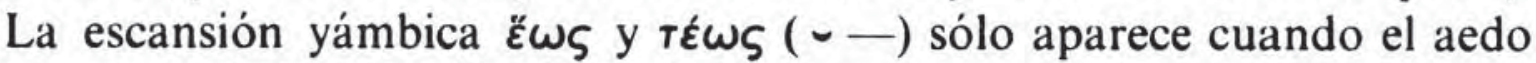
se aparta de la tradición formularia. Por razones análogas, los aedos no habrían tenido más opción que la sinizesis al sustituir la forma tradicional $\chi \rho \dot{~ p o r ~ l a ~ f o r m a c i o ́ n ~ s e c u n d a r i a ~ d e ~ s e n t i d o ~ m a ́ s ~ p r e c i s o ~ \chi \rho \varepsilon \omega ́ ~(<~}$ ${ }^{*} x \rho \eta \omega \dot{)}$.

Si esto fuera así, es dificil entender en primer lugar por qué los aedos no han dejado las cosas como estaban. A fin de cuentas, aun concediendo que las partículas y pronombres que acompañan a है $\omega \varsigma$,

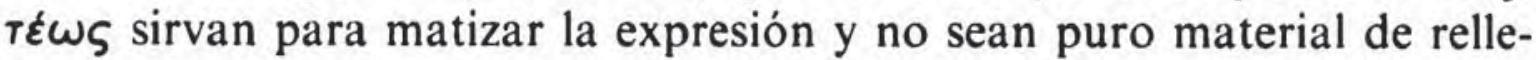
no, su uso no es absolutamente imprescindible. También queda sin explicar por qué el compositor (o compositores) de la Ilíada y la Odisea vacilan entre las variantes sin MC (p. ej., no escandido - - ) y las variantes con $\mathrm{MC}$ y sinizesis ( $\varepsilon \omega$ con la escansión - ) sin ser capaces de sacar más partido del $\varepsilon \omega$ disilábico ( - -) que presuntamente constituiría la fase intermedia entre las etapas antes citadas. Pace Tichy (1981: p. 204), si tal variante hubiese existido en su propia habla, una escansión - - no habría debido presentar dificultades para un aedo minimamente hábil.

En cualquier caso, la explicación de Tichy no sirve para justificar la ausencia de dicha escansión en los carmina epigraphica, cuya dependencia estilística de Homero es sólo relativa (cf. Mickey 1981). Mayor perplejidad si cabe produce la preferencia por $\varepsilon \omega$ monosilábico en los líri- 
cos arcaicos. Resulta increible que éstos hayan renunciado gratuitamente a la escansión disilábica _ - muy apropiada para el ritmo yámbico.

3.2. Partiendo también del supuesto de que la sinizesis es un expediente artificial, Ruijgh enfoca el problema desde un ángulo diferente. Según la hipótesis defendida en distintos trabajos, la épica homérica habría atravesado por dos etapas sucesivas, "aquea" y eolia, antes de adoptar la configuración básicamente jonia con que ha llegado hasta nosotros. Este barnizado jonio no es perfecto y deja traslucir rastros de las fases anteriores en determinadas peculiaridades fonéticas, morfológicas y léxicas ${ }^{14}$. En consonancia con estas ideas, Ruijgh (1985: pp. 164165) supone que, al menos en los casos en que aparece ante una palabra que comienza por consonante o en posición final de verso, $-\varepsilon \omega$ recubre una forma lesbia contracta - $\bar{a}$. Al transponer una fórmula eolia ( $s c$. les-

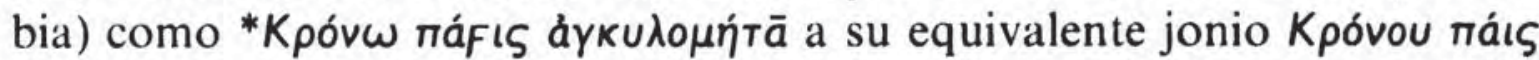
а $ү к \cup \lambda о \mu \eta ́ т \varepsilon \omega^{15}$, los aedos jonios se habrían visto obligados a pronunciar $-\varepsilon \omega$ con sinizesis para no estropear el ritmo. De la misma forma, jón.

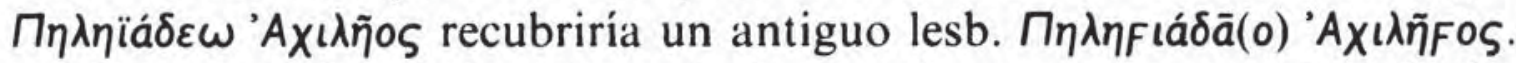

Como prueba de la existencia de una forma contracta -à en la fase eolia de la épica, Ruijgh aduce la presencia en el texto homérico del

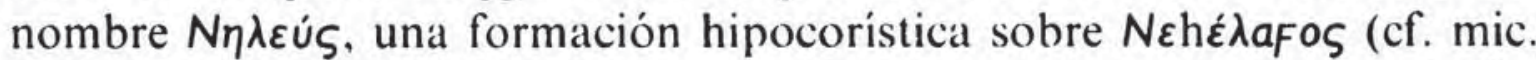
$n e-e-r a-w o)^{16}$. Dado que el elemento $\mathrm{N \eta}$ - no puede explicarse por la fonética del jonio, donde el resultado esperable es $N \varepsilon t$ - (cf. $N \varepsilon \dot{\lambda} \lambda \varepsilon \omega \varsigma$ ), el

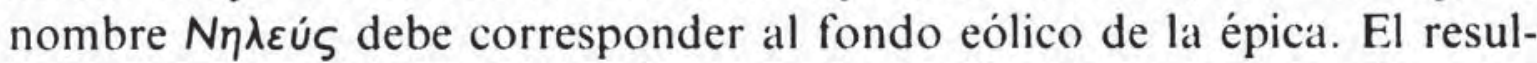
tado $\mathrm{N} \eta$ - esperable en lesbio demostraria que las contracciones de vocales se habian producido en época prejónica. Pero, aun admitiendo argu-

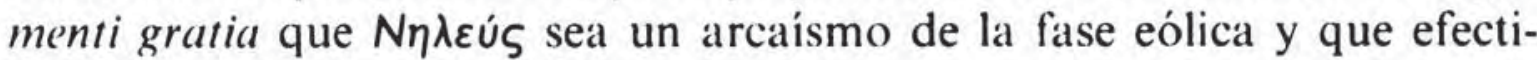
vamente la contracción $\mathrm{N} \varepsilon \varepsilon->\mathrm{N} \eta$ - deba conectarse con el dialecto de Lesbos (en contra, Peters 1989: $\$ 1.5$ y Sprache 34, 1988-1990, IC G1223, p. 671), el argumento en su conjunto constituye un non sequitur ya que la existencia de contracciones isovocálicas como $\varepsilon \varepsilon>\eta$, $\infty>$ $\omega$ (y lo mismo cabe decir para los resultados $\varepsilon \varepsilon>\varepsilon$ l,,$>>0 u$ ) no autoriza a concluir que se hubieran contraido las secuencias de vocales desiguales. Mientras que la fusión de $\varepsilon \varepsilon$ es un fenómeno panhelénico ${ }^{17}$. ào se mantiene sin contraer en distintos dialectos de época clásica. $\mathrm{Cu}$ -

${ }^{14}$ Cf. Ruijgh (1957), Wathelet (1970). Contra Miller (1982), Peters (1989: $§ 1.5$ ).

is Existen razones para suponer que esta fórmula, única en su peculiaridad de incluir una forma con MC (cf. n. 8), es una modificación reciente de la fórmula más

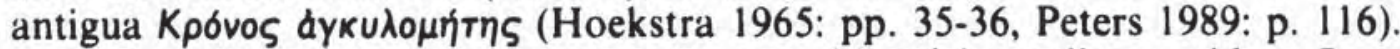

${ }_{16}$ Para la variante no contracta -āo, otro hipotético eolismo, vid. n. 7.

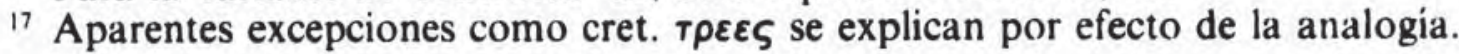


riosamente, el tesalio y sobre todo el beocio, los otros dos miembros del grupo dialectal eólico, se muestran reacios a contraer dicha secuencia ${ }^{18}$. Por lo demás, la hipótesis de Ruijgh no es aplicable a la MC en las secuencias con una $/ \varepsilon$ :/ heredada del protogriego ya que éstas no experi-

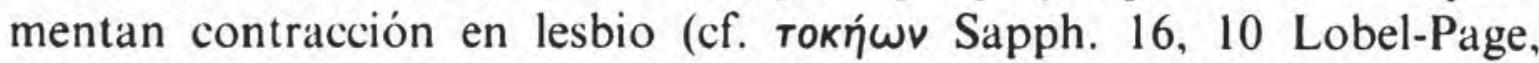
Alc. D 14, 13 Lobel-Page), ni tampoco puede dar cuenta de los datos de las inscripciones métricas y de los yambógrafos y elegíacos arcaicos que evidentemente no dependian de ninguna tradición oral lesbia.

Por último, en opinión de Ruijgh (1968: p. 396, n. 30) (1985: p. 165) - cf. también Tichy (1981: pp. 203-204) - el hecho de que en Homero la escansión disilábica sea normal cuando $\varepsilon \omega$ no es el resultado de la MC pondría al descubierto el carácter artificial de la sinizesis de $\varepsilon \omega$ primario.

Desde el punto de vista de la hipótesis de la SINIZ. + AC, el problema está mal planteado: no es lícito comparar el comportamiento de $\varepsilon \omega$ secundario producto de la MC con el de $\varepsilon \omega$ primario. El paralelismo debe establecerse entre $\varepsilon \omega$ primario y $\eta \circ$ (o bien ào) sin sinizesis y, por descontado, sin MC, por un lado, y entre $\varepsilon \omega$ primario y $\varepsilon \omega$ secundario $(<\eta o, \eta \omega)$ con sinizesis, por otro. Con este doble paralelismo se comprueba que no hay tal divergencia. Lo que prevalece en ambos casos son las formas más antiguas con $\varepsilon \omega$ y $\eta$ o sin sinizesis. Los resultados $\varepsilon \omega$ son minoritarios cualquiera que sea su origen. Los yambógrafos y elegiacos arcaicos, que reflejan un estado de lengua más reciente que los poemas homéricos, presentan $\varepsilon \omega$ con sinizesis tanto como resultado de $\varepsilon \omega$ como de $\eta \circ, \eta \omega$.

En conclusión, la sinizesis no es un expediente artificial para encajar formas con MC. Muy al contrario, existen razones de peso para considerar que la escansión _ , muy minoritaria en Homero, es el resultado de una diéresis metri gratia propia del estilo hiperformal de la épi$\mathrm{ca}^{19}$. No cabe, pues, hablar de una evolución lineal $\eta 0>\varepsilon \omega>\varepsilon \omega$,

${ }_{18}$ Nótese, por otra parte, que el genitivo no contracto 'Aíōo (Alc. 48,15 LobelPage) puede ser un arcaísmo conservado en la lírica lesbia y no necesariamente una forma tomada en préstamo de la épica (cf. Bowie 1981: p. 112).

${ }_{19}$ Otro indicio de este carácter artificial es que el nombre $\Pi \eta v \varepsilon \hat{\varepsilon} \varepsilon \omega \varsigma$ escandido

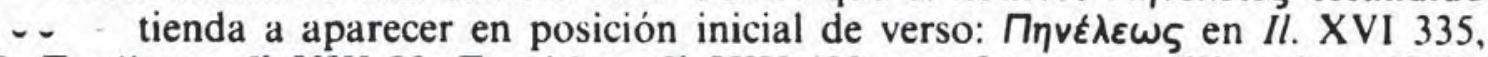

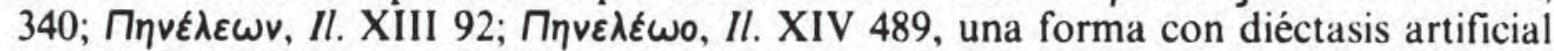
(cf. Ruijgh 1968: pp. 390-391, Peters 1980: p. 256; pace Miller 1982: pp. 131-132);

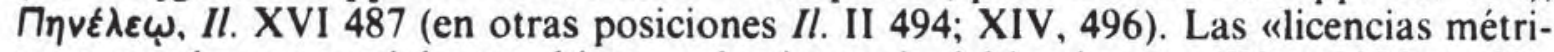
cas" se toleran especialmente bien en el primer pie del hexámetro (West 1982: p. 39). En el caso de otros dos nombres en - $\varepsilon \omega \varsigma$, la escansión disilábica se disimula situándolos en posición final de verso, que favorecía una retardación del tempo o asociándolos a una particula enclitica, que dificultaba la sinizesis: $O d$. VIII 111 'Aкpóveẃs

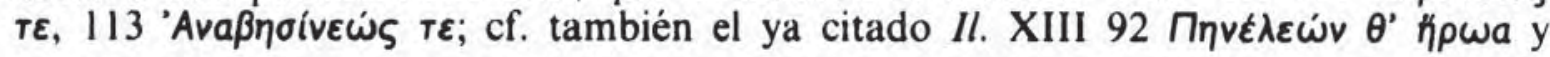


sino de dos cambios de naturaleza contraria: $\eta \circ>\varepsilon \omega$, restringido en un primer momento al habla coloquial y generalizado más tarde a estilos cada vez más formales hasta penetrar en fecha relativamente reciente en la épica, y $\varepsilon \omega>\varepsilon \omega$, surgido en el registro literario hiperformal en fecha tan reciente que apenas se encuentra representado en el texto homérico.

4. Como corroboración de los argumentos desarrollados en la sección precedente, vamos a considerar ahora otros aspectos de la MC que plantean dificultades para la $\operatorname{TrC}$, pero son perfectamente explicables en el marco de la SINIZ. + AC.

4.1. Hemos señalado más arriba que uno de los puntos débiles de la hipótesis de la $\operatorname{TrC}$ es la ausencia de paralelos de este pretendido proceso fuera del griego. No es, en cambio, tan dificil encontrar en las lenguas más diversas ejemplos de procesos fonéticos en los que la pérdida de silabicidad de una vocal viene compensada por el alargamiento de la vocal siguiente. Para que un proceso de esta naturaleza pueda tener efecto en una lengua, parece condición ineludible que la cantidad vocálica sea relevante fonológicamente. Las características prosódicas propias de cada lengua acento melódico (pitch accent) o acento de intensidad (stress accent) por el que la oposición de cantidad suele quedar restringida a la sílaba tónica explican que el proceso se manifieste con características distintas en cada caso ${ }^{20}$.

4.1.1. En luganda, una lengua de la familia bantú hablada en Uganda, en una secuencia de una vocal cerrada (/i, u/) y otra vocal, la primera se convierte en una semivocal $\left(\left[i, u_{n}\right]\right)$ y la segunda experimenta un alargamiento compensatorio (Clements 1986). El proceso actúa con plena regularidad en contextos de fonética sintáctica. Los siguientes ejemplos ilustran este fenómeno (en su mayoria, se trata de combinaciones de sustantivos con los clasificadores prefijados caracteristicos de la

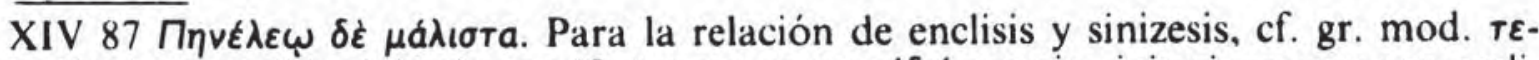

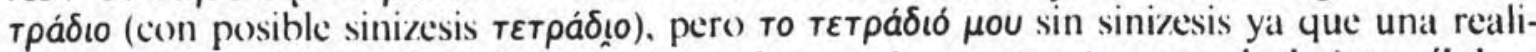

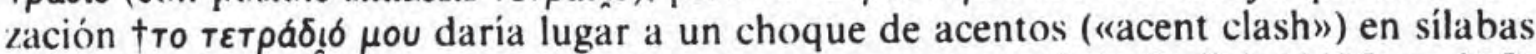
contiguas de una misma palabra. Por otra parte, como señala Ruijgh (1985: p. 165), pero extrayendo una conclusión a mi entender errónea, los nombres propios enumerados corresponden a personajes secundarios introducidos tardiamente en la tradición. Una vez más, la escansión disilábica se asocia a un elemento atípico no tradicional. Para la noción de estilo hiperformal, cf. Dressler (1985: p. 87).

2. Conviene dejar bien sentado para evitar posibles malentendidos que el alargamiento compensatorio puede ser un efecto colateral del mecanismo de la sinizesis. En ningún caso, se trata de una consecuencia inevitable. Sin salir del griego, cf. los ejemplos de siı. zesis de /eo/ en ático citados más abajo (\$ 4.2). 
familia bantú; las vocales largas aparecen notadas como secuencias de vocales iguales):

/li ato/

/ki uma/

/mu iko/

/mu ojo/

/o mu limi o mu lala/

/o mu limi a gend i $\mathrm{e} /$ [liaato]

[kiuuma]

[müiiko]

[müoojo]

[omuliminoomulala]

[omulimiaageenze] 'barco"

'objeto de metal'

'paleta'

'alma'

'otro granjero'

'el granjero se ha ido'

Hay que subrayar dos hechos que cobrarán importancia más adelante. Por un lado, el glide es absorbido automáticamente si le precede una consonante homorgánica. Así, [u] desaparece tras las labiales /f, v, $\mathrm{u} /: /$ e N kofu e zi o/ $\rightarrow$ [eenkofeezo] 'esas gallinas de Guinea'. Lo mismo sucede con [i] tras las palato-alveolares $/ \mathrm{s}, \mathrm{z}, \mathrm{c}, \mathrm{t}, \mathrm{n}, \mathrm{i} /: / \mathrm{e} \mathrm{N}$ buzi e $\mathrm{N} \mathrm{fu} / \rightarrow$ [eembuzeenfu] 'cabras muertas', /o mu geji o mu/ $\rightarrow$ [omugenoomu] 'un huésped'. Las vocales largas de estas realizaciones fonéticas sólo pueden explicarse a partir de ${ }^{*}$ [eenkofueezo], ${ }^{*}$ [eembuzıeenfu], etc.

Por otro lado, en secuencias de vocales iguales /ii/, /uu/, no hay alargamiento. Por razones que indicaremos más abajo $(\$ 4.2)$, en este contexto no tiene lugar la formación de glide, sino una contracción: cf. $/$ mi iko/ $\rightarrow$ [miiko] 'paletas' (no +[miiiko]), /lu uii/ $\rightarrow$ [luuii] 'lado' (no $\dagger$ [lunuuiii]).

4.1.2. Procesos semejantes se han repetido en distintos momentos de la evolución diacrónica del japonés (Poser 1986: pp. 178-183). En primer lugar, los testimonios escritos disponibles y determinadas alternancias morfofonológicas del japonés actual permiten reconstruir un cambio histórico de SINIZ. + AC: cf. karibito $>$ kariudo $>$ karjuudo 'cazador', kunibito $>$ kuniudo $>$ kunjuudo 'compatriota', kefu $>$ keu $>$ kyoo 'hoy', me + oto > mjooto 'matrimonio'. El sufijo $(k) u$, que hoy apenas sobrevive en el estilo formal con la función de derivar adverbios de adjetivos, da lugar a alternancias como adj. ooki 'grande' / adv. ookjuu, kawai 'mono' / adv. kawajuu, utukusi 'bonito' / adv. utu$k u \int u u$. Vale la pena destacar que, a diferencia del luganda donde las únicas vocales capaces de perder la silabicidad eran las vocales cerradas, en japonés también la vocal media /e/ puede convertirse en /i/.

En época reciente, la SINIZ. + AC se manifiesta en la adaptación de préstamos: ingl. aluminium $>$ jap. aruminjuumu, barium $>$ barjuumu, planetarium $>$ puranetarjuumu, geranium $>$ zeranjuитu, linoleum $>$ rinorjuuтu, computer $>$ konpjuuta $(a)$. Adaptaciones como calcium $>k a$ ruјuumu, magnesium $>$ magune $\int u u m u$, radium $>$ radzuumu, stadium $>$ 
sutadzuumu indican que, tras provocar la palatalización de una dental precedente, [i] queda absorbida por las consonantes $/ \mathrm{J} /, / \mathrm{d}_{3} /$ resultantes.

Por último, en el estilo coloquial, el proceso fonético actúa sobre los hiatos producidos por la pérdida de una consonante en determinados sintagmas (Poser 1988). Así con los pronombres kore 'este', sore 'ese' seguidos de la partícula pospositiva de topicalización wa: /kore + wa/ $\rightarrow$ [koriaa], /sore $+\mathrm{wa} / \rightarrow$ [soriaa]. También en el "provisional» en $-(r) e b a$ de las raíces verbales $i k$ 'ir', $t i r$ 'esparcir': /ikeba/ $\rightarrow$ [ikiaa], /tireba/ $\rightarrow$ [tiriaa].

4.1.3. En inglés, en distintas épocas y dialectos, se atestigua una inversión de silabicidad entre los componentes de un diptongo, que lleva aparejada la inversión de sus cantidades. El fuerte acento de intensidad del inglés hace que la oposición entre vocales largas (tensas) y breves (laxas) sea posible únicamente en posición tónica. La inversión de silabicidad no puede producir una inversión de cantidad en posición átona, de la que por definición las vocales largas quedan excluidas.

El diptongo /i: $/(<$ ingl. med. /i: $/ /, / \varepsilon: \mathrm{v} /$, originalmente decreciente ${ }^{21}$, evolucionó al diptongo creciente/iu:/ del inglés actual (Donegan y Stampe 1978: p. 34): cf. few [fiu:], feud [fiu:d], spew [spiu:], sleuth [slu: $\theta$ ], new [nia:], beauty [bin:tı], cube [kinu:b], etc. En posición átona, donde el núcleo del diptongo era breve [ıu], el cambio de silabicidad no se traduce en ningún alargamiento: cf. issue [ısiu], [1 $\left.\int \mathrm{U}\right]$.

En dialectos del sur de Inglaterra (Wells 1982: pp. 154-155) el diptongo (12/ es susceptible de una realización [iə:]. El nuevo núcleo tiende

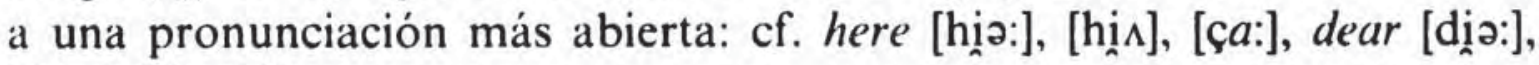
[di $\Lambda:]$, [dia: ${ }^{22}$.

4.1.4. En latín vulgar, /e/, /i/ en hiato se convirtieron en las semivocales [e], [i], más tarde confundidas en [i]. Cuando /e/, /i/ eran tónicas, esta pérdida de silabicidad iba acompañada por un desplazamiento del acento a la vocal adyacente. Grafias como Puteólls, CIL X 1889, en

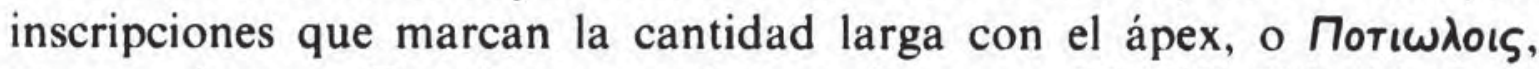
una vez junto a Пoriodois en ocho ocasiones en $I G$ XIV 830, 26 (Pozzuoli, 174 d.C.), en inscripciones griegas, parecen indicio de una evolución [éo, ió] > [éó, ịó:] > [ió:] (vid. Schulze 1934: p. 424).

Confirmando estos testimonios, una amplia zona del sur de Italia ofrece resultados propios de /o:/ larga para lat. clás. -iŏlum, -eǒlum (cf.

${ }^{21}$ Esta característica se revela aún hoy en la grafia histórica $e w$ (ingl. med. / $\varepsilon: \underline{x} /$ ).

${ }^{22}$ Para otros ejemplos en dialectos del inglés, cf. Donegan (1985: p. 206). 
Rohlfs 1966: § 126): filiolum < salent. fighiulu, nap. figliulo, linteolum $>$ nap. lenzulo, Puteolis $>$ nap. ant. Pezzulo, con metafonía de /o/ cerrada en $/ \mathrm{u} /$ en todos los casos ${ }^{23}$. También en el caso de $i e$, ciertos resultados suponen una etapa [(i)e:] cf. parietem $>$ it. parete, fr. paroi, esp. pared; abietem $>$ it. abete; arietem $>$ rum. arete, fr. ant. aroy ${ }^{24}$.

4.1.5. En islandés antiguo las vocales palatales /i(:)/, /e(:)/ (largas o breves) perdieron su silabicidad ante una vocal no palatal y confluyeron en la semiconsonante/i/. Como en los casos antes citados, la pérdida de silabicidad provocó el alargamiento de la segunda vocal de la secuencia (Donegan 1985: p. 205, Hock 1986). En los ejemplos siguientes, el acento es marca de cantidad larga:

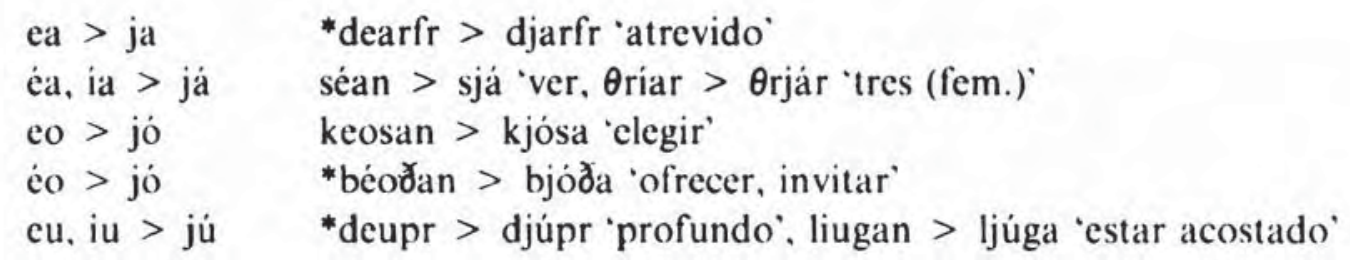

Resulta curioso que este cambio haya figurado reiteradamente en la bibliografia sobre la MC sin que los especialistas se hayan percatado de que, en el paralelismo entre isl. ant. *béoðan, séan > bjóða, sjá y jón.-

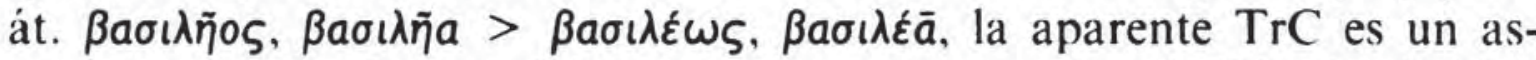
pecto accesorio. Lo crucial en ambos procesos es la pérdida de silabicidad de una vocal en hiato ${ }^{25}$.

${ }^{23}$ Pero cf. puteol- $>$ it. Pozzuoli, esp. Pozuelo, filiolum $>$ it. figliuolo, fr. filleul, esp. hijuelo con resultados de /o/ breve (lat. vulg. / / /) en otras zonas de la Romania.

${ }^{24} \mathrm{La}$ vocal larga /e:/ parece guardar relación con la pérdida de yod: $\mathrm{cf}$. mulierem $>$ tosc. ant. mogliera, fr. ant. moillier, esp. mujer (esp. ant. mugier), fr. ant. moillier, donde la yod se mantuvo, con resultados de /e/ breve (lat. vulg. / $/$ /).

${ }^{25}$ La presentación de Hock (1986: pp. 442-443) -en un trabajo, por lo demás, modélico - resulta confusa en lo que respecta a la MC jónico-ática. Por un lado, remite simultáneamente a Miller (1976) y a Schwyzer (1939) pese a que los puntos de vista de estos autores son dificilmente conciliables. Por otro, si bien Hock pone de relieve la circunstancia de que los resultados de la metátesis son generalmente monosilábicos («the mora transfer commonly operates within a single mora-counting unit»), el hecho de clasificar por separado la metátesis y los procesos del luganda y del islandés antiguo antes analizados sugiere que Hock los considera cambios intrínsecamente distintos y no manifestaciones diversas de la SINIZ. + AC. Es posible que Hock haya establecido esta distinción basándose en la idea tan extendida como errónea de que la sinizesis lleva aparejado el paso a los glides prototipicos /i/ y / $\mathrm{u} /: \mathrm{p}$. ej., Hiersche (1970: p. 48): "In metrischen Texten werden $\varepsilon \omega$ und $\varepsilon \bar{a}$ meist einsilbig gemessen (Aussprache j $\omega$, jā)»; cf. también Nyman (1978: p. 69). La implicación es excesiva. Una cosa es comprobar que la pérdida de silabicidad de $e([\mathrm{eV}] \rightarrow[\mathrm{eV}])$ puede $y$, de hecho, suele -... conducir al cierre de la semivocal ([ęV] $\rightarrow[j V])$. Este es el caso del japonés, del latín y del islandés antiguo. Otra cosa muy distinta es establecer un determinismo absoluto entre ambos procesos 0 , lo que viene a ser lo 
4.1.6. J. I. Hualde (1990) señala un fenómeno análogo en el dialecto vasco (alto-navarro septentrional) hablado en Arbizu: vasco unificado (batua) gero 'luego' > Arbizu [gioo], berotu 'calentar' > [biootu], esperatu 'esperar' $>$ [espiaatu $]^{26}$. Es importante destacar por su interés para los hechos del griego que la inserción de una yod antihiática (pronunciada con fricción) impide que [i] antevocálica pierda su carácter silábico; en consecuencia, no se produce alargamiento compensatorio: /mendi + a $/ \rightarrow$ [mendiia] 'montaña' (absol. sg.).

4.1.7. La principal peculiaridad de la MC jónico-atica frente a los procesos fonéticos analizados en esta sección es que el alargamiento se produce exclusivamente cuando la sinizesis es de una vocal larga. Dicho de otro modo, se compensa parcialmente la pérdida de las dos moras de la vocal larga: $e: V(3$ moras $)>e V:(2 \text { moras })^{27}$. En las otras lenguas, la sinizesis de una vocal breve (una mora) basta para producir el alargamiento de la vocal antigua: $i V$, e $V(2$ moras $)>i V$ : ( 2 moras).

4.2. Otra zona de sombra en la hipótesis de la $\operatorname{TrC}$ es, como indiqué más arriba, que el cambio afecte a un número muy limitado de secuencias: /a:o, æ:a, $\varepsilon: 0, \varepsilon: a$, e:o, e:a/; es decir, las secuencias formadas por una vocal anterior, no cerrada seguida de una vocal no anterior y no cerrada.

Desde la perspectiva de la SINIZ. + AC, en cambio, este hecho cobra sentido ya que el dominio de la MC se deriva de las propiedades naturales de los glides. La esencia de un glide reside en ser un gesto dinámico - un "deslizamiento» rápido . hacia o desde una articulación vocálica distinta y más prolongada, que constituye el núcleo del diptongo (Catford 1977: p. 131). Según esto, por definición, un glide no puede aparecer en contacto con una vocal con idéntico punto de articulación: un movimiento sin desplazamiento es un absurdo lógico. Muchas lenguas proscriben incluso las secuencias con un glide y una vocal articulados en áréas muy próximas (como ingl. wood, yeast). Esta aversión parece mayor en el caso de [e $\varepsilon$ ], [oo] con glides de abertura media.

Normalmente, en un diptongo el glide es más cerrado o, todo lo

mismo, fusionar estas dos etapas, sucesivas e independientes, en un único proceso $[\mathrm{eV}] \rightarrow[\mathrm{iV}]$.

${ }_{26}$ La situación real es más compleja. La regla parece no actuar en determinadas categorias morfológicas: cf., p. ej., allegatu 'llegar' > [aKaatu] con simple asimilación (contracción). Por otra parte, el alargamiento compensatorio tiene también lugar cuando la vocal que pierde la silabicidad es la segunda de una secuencia: txori "pájaro" < [t fooi]. laun 'amigo" > [laaun]. Nótese, por otra parte, que J. I. Hualde (1990: pp. 279-280) opera con un discutible cierre de /e/ en /i/previo a la fase [i].

27 Para [ęo] sin alargamiento compensatorio en ático, cf. \$ 4.2. 
más, tiene el mismo grado de abertura que la vocal contigua. Por tratarse de un gesto momentáneo (no prolongable), los glides más adecuados son [i] y [u] - recuérdese que, cuanto más cerrada es una vocal, menor es su duración intrínseca. Por esta razón, los glides [e] y [o] tienden a cerrarse en [i] y [ụ] y, a la inversa, queda descartada la existencia de un glide $+[a]$ correspondiente a una vocal [a] completamente abierta cuya duración es intrínsecamente más prolongada que la de las otras vocales ${ }^{28}$.

Si proyectamos estas reflexiones sobre los hechos del jónico-ático, se comprende fácilmente que no haya sinizesis - y, por tanto, MC en

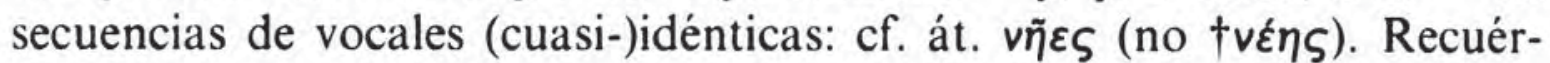
dese a este propósito que en luganda no había formación de glide en las secuencias de vocales iguales /ii/, /uu/.

El hecho de que la vocal más abierta /a/ no pueda perder su silabicidad, también explica por qué las secuencias $/ a: V /$ del ático han escapado a la MC.

Por último, no hay $\mathrm{MC}$ en las secuencias /V:i, V:u/ porque la tendencia natural es la consonantización de la vocal más cerrada /V:i V:ü/:

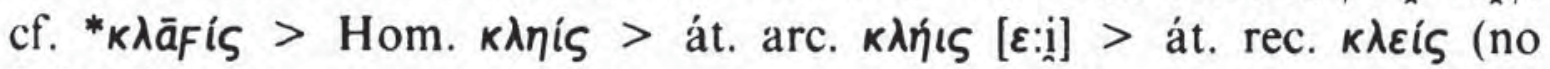
$\left.\dagger_{\kappa} \lambda \varepsilon \bar{i} \varsigma\right)$.

A primera vista, algunos datos no encajan en el esquema general. Hemos observado que los glides prototípicos eran los de abertura cerrada y que, en conformidad con este principio, las lenguas donde había pérdida de silabicidad de /e(:)/ antevocálica (japonés, islandés), también /i(:)/ se convertía en un glide en idénticas condiciones. En luganda, había sinizesis de /i/, pero no de /e/ antevocálica.

Según esto, esperariamos que una secuencia como to hubiese evolucionado a $\dagger \omega \omega$ de la misma forma que $\eta 0>\varepsilon \omega$. Pero estas expectativas no se cumplen en formas como íarpós, át. ítevat. Ya hemos tenido ocasión de señalar (vid. § 2) que la ausencia de sinizesis y la ausencia de

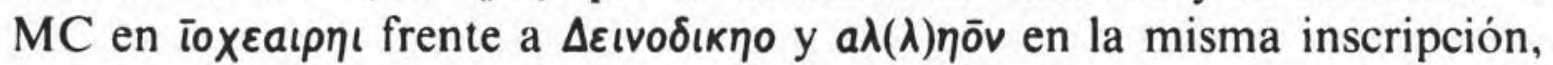
son fenómenos que no pueden desligarse uno del otro. Esta anomalía en el comportamiento de /i:/ antevocálica debe ponerse en relación con un hecho observado desde hace tiempo: en griego antiguo, contra lo que parece ser la tendencia habitual en otras lenguas, la sinizesis con las vocales cerradas 1 y $u$ es muy infrecuente en comparación con la de $\varepsilon$ (cf. Christ 1879: § 39, West 1982: pp. 12-14).

Para explicar esta situación paradójica, hay que tomar en considera-

${ }^{28} \mathrm{La}$ "vocalización" de /r/ (cf. pronunciaciones como vier [fi: $\left.\mathrm{f}\right]$, nur [nu:p] frecuentes en variedades del alemán) da lugar a una semivocal centralizada. 
ción otra circunstancia que limita en cierta medida el alcance del principio general. En muchas lenguas, las vocales cerradas $/ \mathrm{i}, \mathrm{u} /$ en posición antevocálica desgajan un glide de transición que contribuye a mantener el hiato: cf. fr. pied [pie] en contraste con prier [priie], plier [pliie] (no $\dagger[$ prie], $†[$ plie]), donde la diéresis tras $\mathrm{Cr}, \mathrm{Cl}$ evita un ataque silábico complejo. Que en griego, como en el vasco de Arbizu (cf. § 4.1.6), existía una tendencia a realizar /i(:)/ antevocálica como [i(:)i] es un hecho innegable a la vista de grafias con $\langle\|\rangle$ geminada atestiguadas en di-

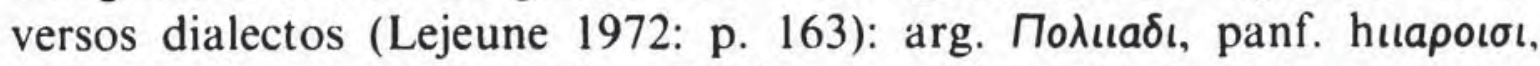

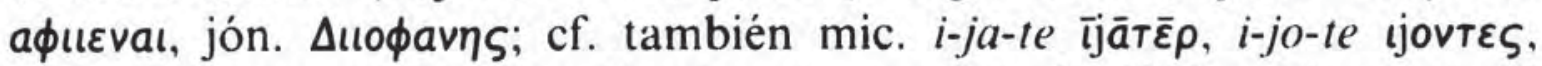
chipr. $i$-ja-te-ra-ne ìjārē $\rho a v$. En el caso concreto del jónico-ático, esta [i] de transición impedía la sinizesis de /i:/ y, en consecuencia, la MC.

Las vocales medias no ofrecen esta propiedad: en fr. no hay una realización préau †[preeeo] comparable a [priie]. Las vocales cerradas son más proclives a la sinizesis, pero tienen la posibilidad de bloquearla desgajando un glide antihiático (cf. Mühlestein 1956: p. 96 a propósito del micénico). Las vocales medias son por naturaleza menos propicias a la sinizesis, pero también se encuentran más desprotegidas ante ella.

A diferencia de lo que vamos a encontrar en heracleota, la sinizesis del grupo /eo/, con /e/ breve, no se traduce ni en jónico ni en ático en un alargamiento ${ }^{29}$. Para el jónico la razón es obvia: mientras que en las secuencias $/ \varepsilon: o(:)$, es:/ la sinizesis hace que el primer elemento pierda la silabicidad, la sinizesis de la secuencia /eo/ con dos vocales breves desemboca en un resultado [eo] (más tarde [eun]: cf. Hom. $\mu \varepsilon u, \phi(\lambda \varepsilon u ̃ v т a \varsigma)$, en el que no se perdía ninguna mora ${ }^{30}$. Es posible, pero no demostra-

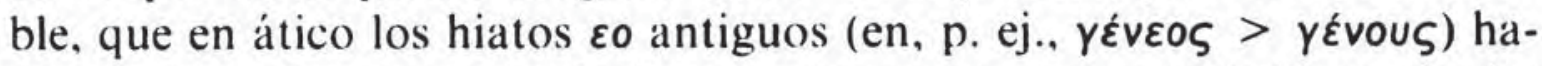
yan atravesado una etapa [eo] antes de contraerse en /o:/. En cualquier caso, está fuera de toda duda que en formas residuales como el bisílabo

${ }^{29}$ Martin Peters (per litteras) me indica la posibilidad de que la sinizesis de una /e/ breve sea la causante de la anómala vocal larga en formas verbales del tipo $\varepsilon \dot{\varphi} \hat{k \varepsilon}$

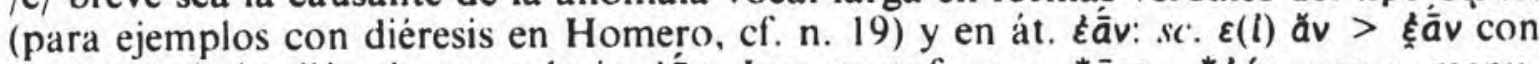

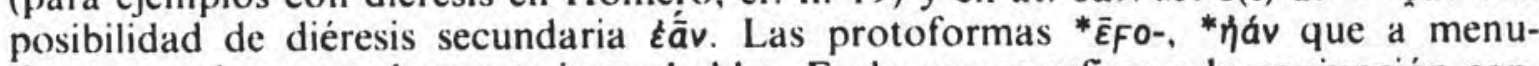
do se postulan, son altamente improbables. En lo que se refiere a la conjunción condicional, esta hipótesis puede encontrar apoyo en la forma tav ( $s c$. ‘ $\bar{a} v<\xi_{\bar{c}} \bar{a} v$ ) que se atestigua en el euboico de Eretria (IG XII 9, 1273-1274, ¿550-525?) y en una inscripción muy fragmentaria atribuida a la colonia siciliana de Leontinos (SEG IV 64; ¿ica. 525?).

${ }^{30}$ No comparto el juicio de Szemerényi (1956: p. 256), quien ve en $\langle\varepsilon \omega\rangle$ con escansión monosilábica la representación gráfica de un diptongo [eux] $(<$ [eō]. El paso directo de [es:] a [eo] es poco verosímil ya que una vocal breve, sobre todo siendo la primera de la secuencia, está siempre más expuesta a perder su silabicidad que una vocal larga. Ello obliga a postular una etapa intermedia [eo] dificilmente justificable como resultado de una evolución fonética (para otros argumentos en contra de la equivalencia $\langle\varepsilon \omega\rangle=$ [eu]], vid. Scherer 1959: §311a). 


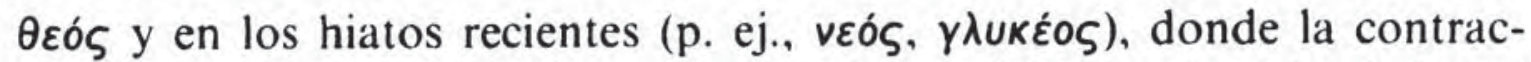
ción es excepcional (p. ej., voupquía), la pérdida de silabicidad de /e/

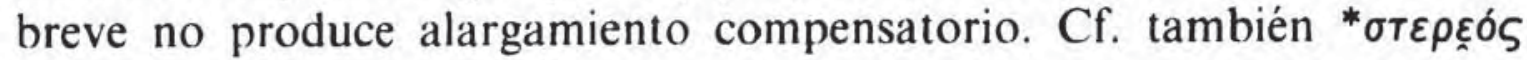

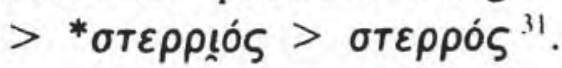

4.3. Según la doctrina comúnmente aceptada (cf. Lejeune 1972:

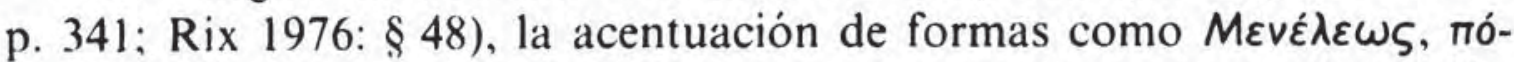
$\lambda \varepsilon \omega \varsigma$, $\pi \delta ́ \lambda \varepsilon \omega v$, etc., constituiría una excepción a la regla de limitación del acento que prohibía los proparoxitonos con vocal fina larga $(z-$

). En palabras como las citadas, la MC habría respetado la posi-

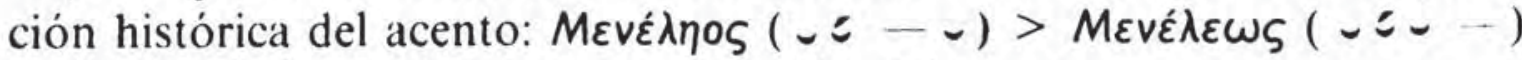

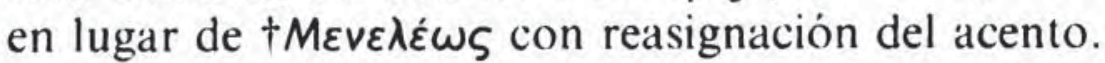

Tales formas no plantean, en cambio, ningún problema si explicamos la hipótesis de la MC como SINIZ. + AC. Un esquema prosódico

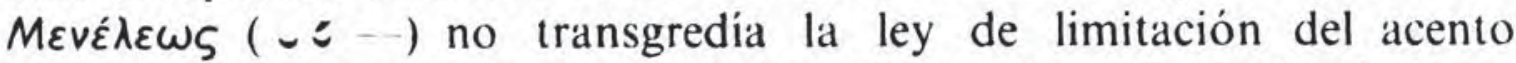
puesto que este caía sobre la penúltima sílaba; cf. ya Descroix (1931: p.

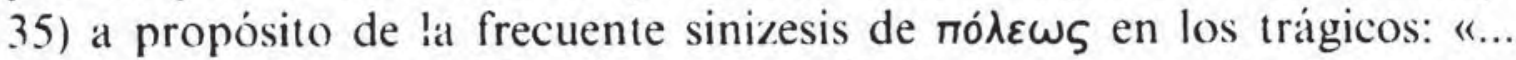
à considérer l'accentuation de ce terme [...], on est mis en éveil: le groupe $\varepsilon \omega \varsigma$ doit former une sorte de diphtongue" ${ }^{32}$.

4.4. Hace ya tiempo que en los poemas homéricos se ha observado un curioso contraste (Chantraine 1958: p. 72). Las formas de la flexión

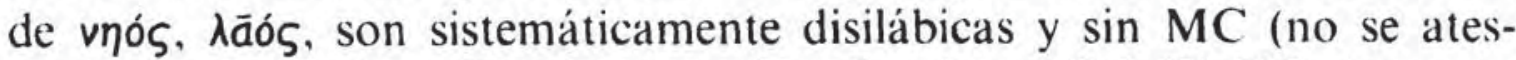

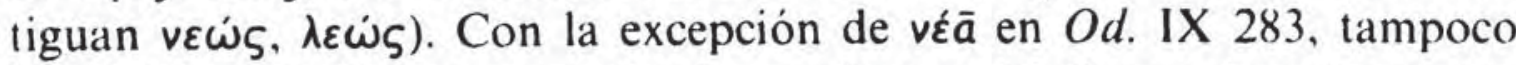

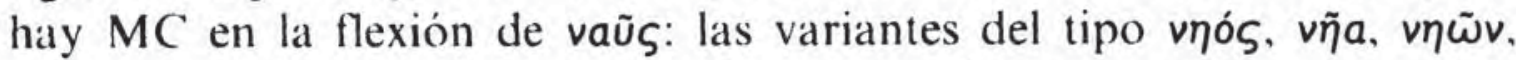

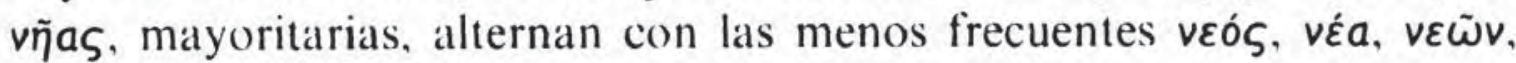
véas, con abreviación.

${ }^{3}$ Curiosamente, la sinizesis de /e/ ante vocal breve (tipo $\theta \varepsilon \iota_{\delta} \varsigma$ ) es bastante infrecuente en el trímetro yámbico de la tragedia por comparación con la sinizesis ante vocal larga (tipo $\theta \varepsilon \bar{c} \tilde{\omega} v$ ); cf. Descroix (1931: p. 32). Es significativo que la sinizesis de

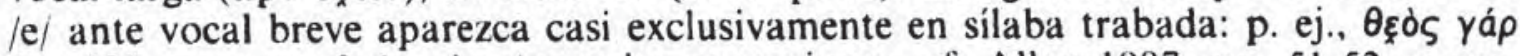

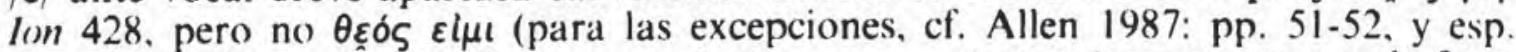
Nyman 1978: pp. 68-72). Esto parece indicar que se intentaba enmascarar el efecto alargante de la sinizesis de /e/ sobre la vocal siguiente haciendo que el núcleo silábico fuera fonológicamente largo o que la silaba fuese larga por posición. Martinet (1969: p. 215) observa un efecto análogo para la sinizesis de /i/ en la métrica francesa y comenta sobre las posibles realizaciones del hemistiquio Ariame ma so'ur: "... Sans prononcer une voyelle [i], on traînera un peu sur une réalisation non syllabique [i]. et le second [a] acquerra une durée insolite. On n'aura donc [...] l'insistant et scolaire [a-ri-a-nz], mais [aria-n], c'est-à-dire deux syllabes qui valent quatre pieds».

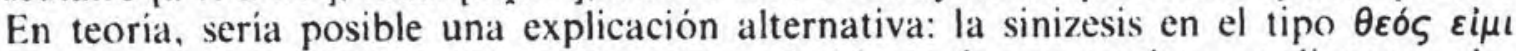
seria del tipo jónico (sc. $\theta \varepsilon \delta ́ s$ ). Pero (a) no había razón para evitar un diptongo decreciente de un tipo bien establecido en griego; (b) las evoluciones del tipo gr. clás.

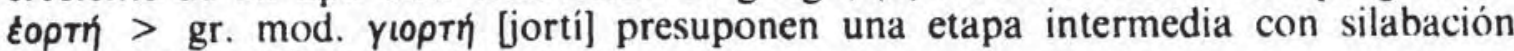
Ėoprí (Méndez Dosuna, en prensa).

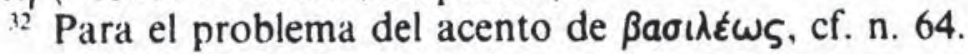


Por el contrario, cuando estos elementos forman parte de un com-

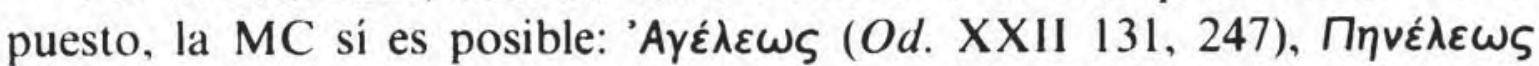

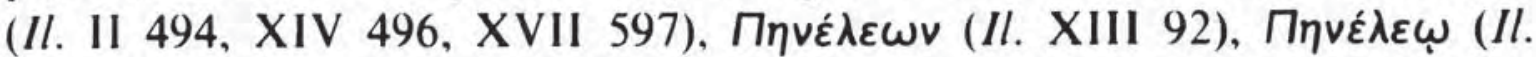

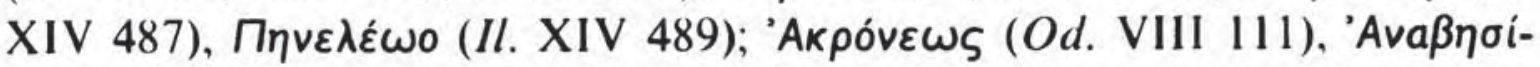

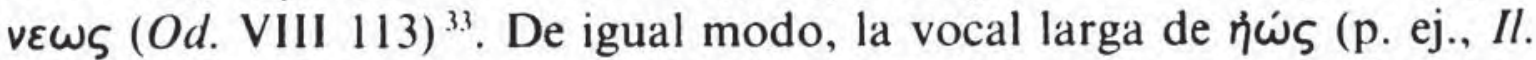

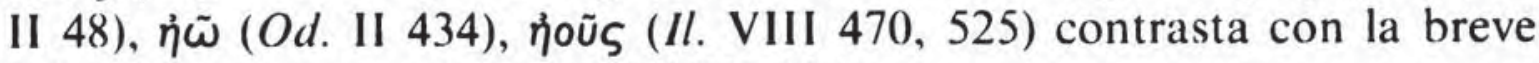

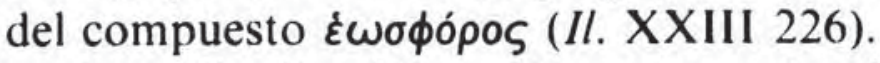

Una distribución análoga se puede observar en Hesíodo, en los líricos arcaicos, en Heródoto e incluso en inscripciones dialectales del área

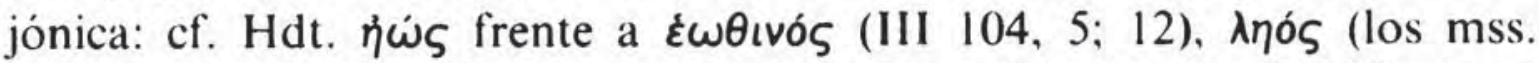

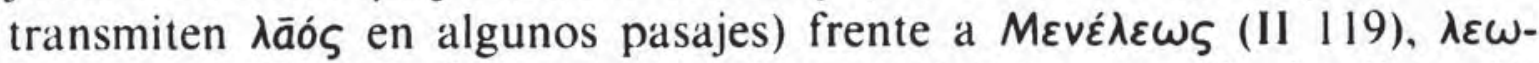

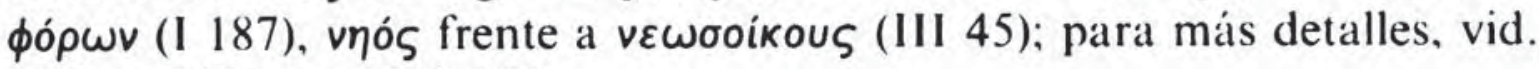
Miller (1982: pp. 130-132).

Los datos de Heródoto y de las inscripciones jonias en prosa, donde la disparidad de tratamientos no puede justificarse por necesidades métricas, invitan a creer que tampoco en los poemas homéricos puede ser artificial el contraste entre las formas simples con conservación de la vocal larga y los compuestos con MC (Miller 1982: p. 137). Miller critica con razón las soluciones tradicionales que explican las formas con MC como aticismos, elementos de mixtura dialectal o formas posthoméricas, pero su propia solución no resulta más convincente.

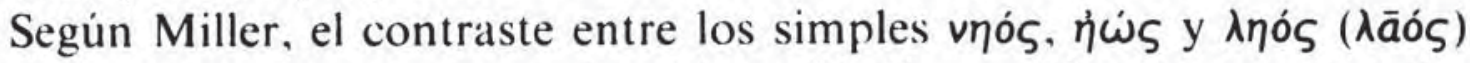

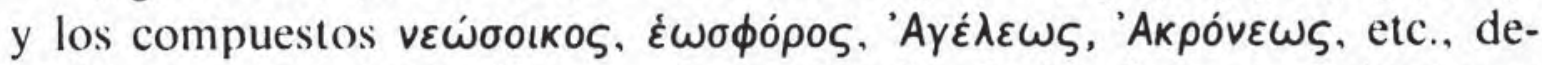
beria ponerse en relación con la tendencia de las formas derivadas a perder rasgos excepcionales («exceptional features»), tendencia que este autor ejemplifica con datos del inglés y del dialecto cubano de Miami: en inglés los plurales irregulares en formas básicas como féet, leaves, lives contrastan con los plurales regulares en derivados lexicalizados como flatfoots, the Lightfoots; Maple Leafs; still-lifes; en el cubano de Miami - en general, en hablantes incultos de todas las variedades dialectales del espanol -... mientras que los pretéritos como dijo, puso son sistemáticamente irregulares en los verbos simples, las formas equivalentes en los compuestos maldijo, impuso pueden sustituirse por formas regularizadas como maldició, imponió.

Sin embargo, el paralelo entre ingl. feet / flatfoots, esp. dijo/maldició

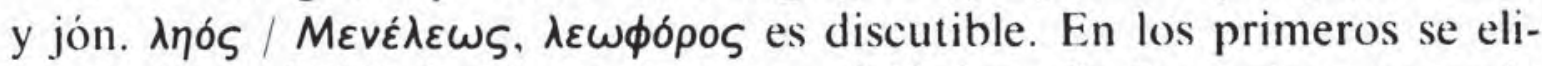
minan irregularidades de carácter morfológico: flatfoots sigue la regla general ("default rule») de formación del plural en inglés (cf. books), esp. maldició encaja en el paradigma regular de partió. Por el contrario,

${ }^{33}$ Para la escansión yámbica de $\varepsilon \omega$ en estos nombres propios vid. n. 19. 
si una forma como ג̄ós constituye una excepción desde el punto de vista de la regularidad "neogramática» de la difusión del cambio (con independencia de cual sea la explicación que le demos), no es menos cierto que, desde el punto de vista de la morfo(fono)logía, la anomalia reside precisamente en la MC, cuya aplicación regular vuelve más opaca la

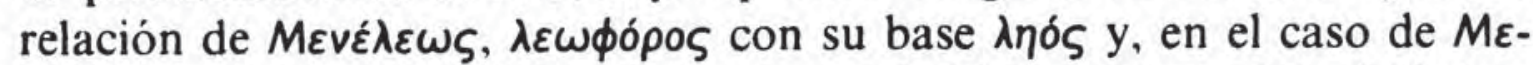

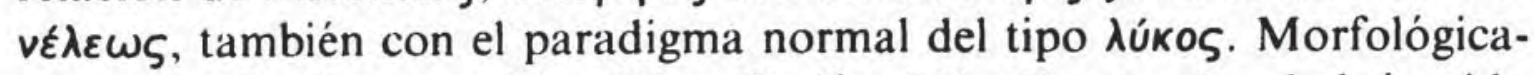
mente hablando, una hipotética flexión ${ }^{*} M \varepsilon v \varepsilon \varepsilon \lambda \eta \varsigma$, ,

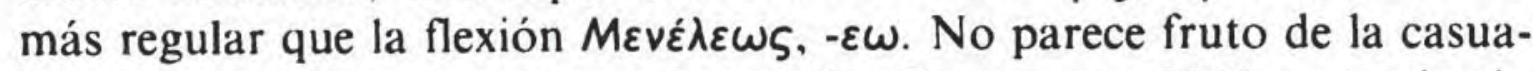
lidad que se haya tendido a eliminar las formas con MC: en territorio

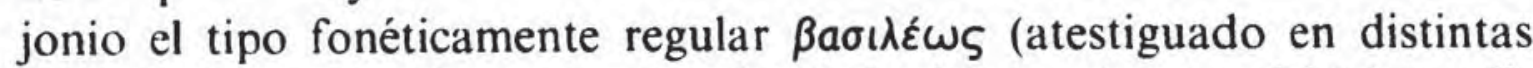
localidades en una época en que el influjo ático es impensable) ha cedi-

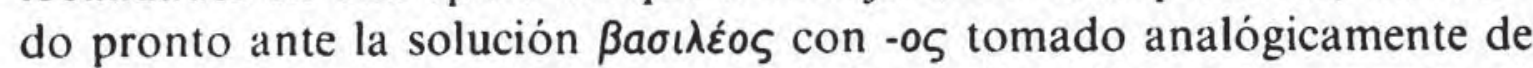

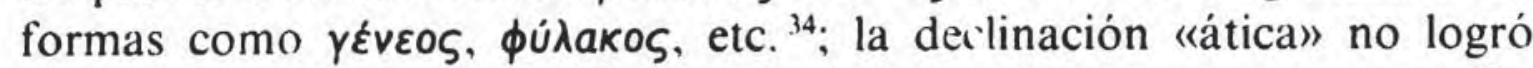
imponerse en la koiné, donde jón.-át. $\lambda \varepsilon \omega \dot{s}$, véús desaparecieron en fa-

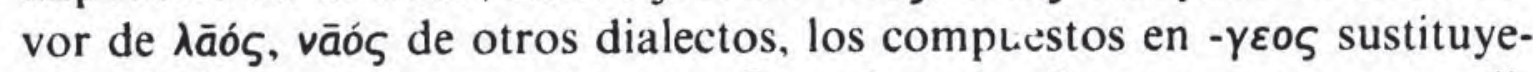
ron al tipo $-\gamma \varepsilon \omega \varsigma$, etc. Aunque formalmente diversos, estos procedimientos comparten una función común: eliminar los efectos indeseables de la MC.

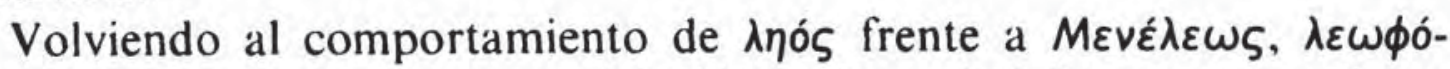
pos, para que el paralelo con el inglés y el español fuera exacto, deberíamos encontrar una distribución diametralmente opuesta a la atestiguada, con regularidad fonética en las formas básicas $(\lambda \varepsilon \omega \dot{\zeta})$, pero

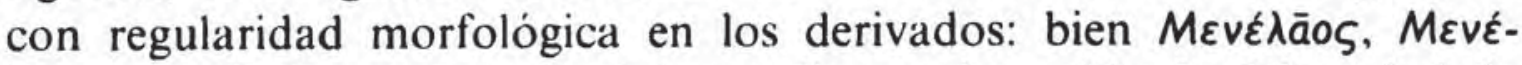
$\lambda \eta \circ$, donde la "resistencia del paradigma al cambio fonético" habría operado con carácter profiláctico para bloquear la MC, bien *Mevé$\lambda \varepsilon o \varsigma$, donde la nivelación analógica habría actuado con efecto terapéutico ${ }^{35}$.

La disparidad de resultados de las formas básicas con $\eta_{0}(\bar{a} 0)$ y los derivados con $\varepsilon \omega$ está motivada por el distinto volumen fónico de las palabras en cuestión ${ }^{36}$. En efecto, la palabra constituye una unidad bá-

${ }^{34}$ En este punto Ruijgh (1968: p. 391) y Peters (1989: pp. 132, 156-157) llevan indudablemente la razón frente a, p. ej., Schwyzer (1939: p. 246), Lejeune (1972: p. 284) que piensan en la posibilidad de la abreviación en hiato como tratamiento alternativo a la MC.

${ }_{35}$ Un paralelo más ajustado a los hechos del inglés y del español es el contraste que el propio Miller (1982: p. 137) observa en distintas localidades jonias entre el genitivo con MC de la forma base $\pi \delta \lambda \varepsilon \omega \varsigma$ y el analógico en $-\pi \delta \lambda_{\lambda}$ os de los nombres compuestos (p. ej., Avał̌ınoגıs), morfológicamente más regular.

${ }_{36}$ Una sugerencia en este sentido puede encontrarse ya en Wackernagel (1916: p.

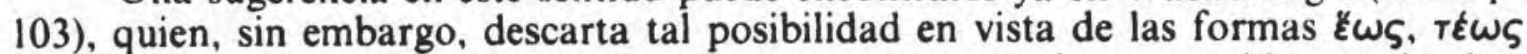
abundantemente atestiguadas en Homero (nos ocupamos de este problema más abajo). Cf. también West (1974: p. 79) a propósito de los líricos arcaicos: «Disyllables 
sica en la organización rítmica del lenguaje. Estudios de fonética experimental realizados con informantes de distintas lenguas han demostrado que para disimular en lo posible la diferencia en el tamaño de las palabras, los hablantes tienden a abreviar o prolongar la duración intrínseca de los distintos segmentos en proporción directa al volumen de la palabra a la que pertenecen. En la evolución histórica, este principio de isocronía se traduce en una mayor predisposición a la erosión fonética en los polisilabos y una mayor resistencia en los monosilabos ${ }^{37}$.

Como todo el mundo admite, la aversión a la excesiva reducción del volumen de una palabra ha impedido la contracción de vocales en áti-

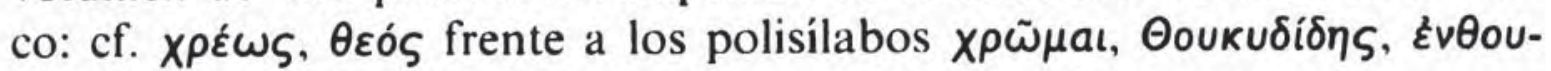

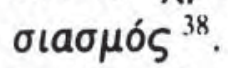

Desde este punto de vista, la divergencia entre los bisílabos como

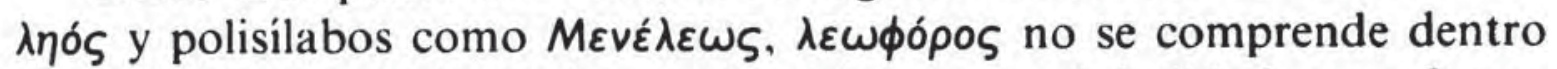
de la hipótesis de la TrC: considerada en su globalidad, una forma como $\lambda$ nós $(2+1=3$ moras) tiene el mismo volumen que el hipotéticamente bisílabo $\lambda \varepsilon \dot{\omega} \varsigma(1+2=3$ moras). Únicamente varia la distribución. Lo mismo cabe decir a propósito de la cantidad vocálica de $M \varepsilon$ -

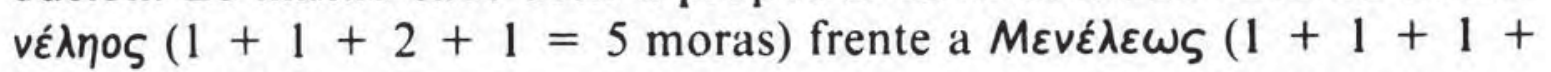
$2=5$ moras).

Por el contrario, el volumen de $\lambda$ nós $(2+1=3$ moras) no es el mismo que el del resultado monosilábico $\lambda \varepsilon \hat{\varepsilon} \omega \varsigma$ ( 2 moras) que presupone la SINIZ. + AC. Con el mantenimiento de Anós no se trataba tanto de evitar la MC como de bloquear la sinizesis que producia automáticamente un monosílabo $\lambda દ ૂ \omega \omega \varsigma$. La situación no difiere en esencia de la que

show some resistance [sc. to quantitative metathesis, J.M.D.]". Nótese que, pese a tener puntos de vista divergentes entre sí y pese a mantener posiciones muy diferentes de las aquí defendidas, tanto Tichy (1981: p. 207) como Miller (1982: p. 137) admiten que las diferencias en el volumen de las palabras han podido influir como elemento coadyuvante en la distribución de las formas con MC y sin ella. Alternativamente podría pensarse en la posición del acento como factor determinante: con-

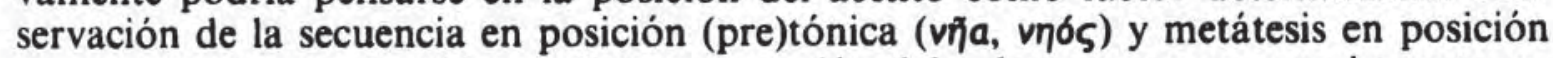

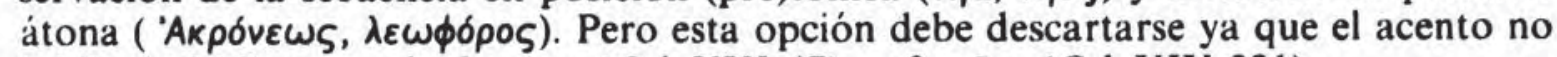

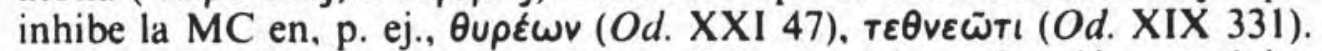

${ }^{37}$ En hindi, una vocal larga en sílaba inicial se abrevió en palabras de más de cuatro moras; en idénticas condiciones, el alargamiento compensatorio de una vocal resultante de la simplificación de un grupo consonántico no tuvo efecto (Miranda $1990)$. Por contraste, en las lenguas romances, la $-m$ latina, que se perdia regularmente en palabras de más de una sílaba (portam $>$ it. porta, fr. porte, esp. puerta, etcétera), se mantuvo en los monosílabos quem $>$ esp. quien, rem $>$ fr. rien, sum $>$ it. sono.

${ }_{38}$ En estos casos se suele hablar de aversión a los monosilabos. Sin embargo, si mi interpretación de la MC es correcta, las formas žw nos habían pasado por una etapa de) monosílabos. 
se advierte en diversos dialectos dorios, entre las formas básicas disilábicas no contractas $\lambda \bar{a} 0 \varsigma$, vāos y los compuestos, polisilábicos, con con-

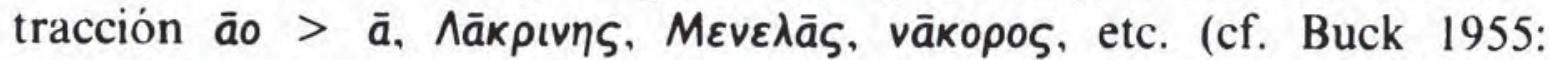
$\S 41.4)$.

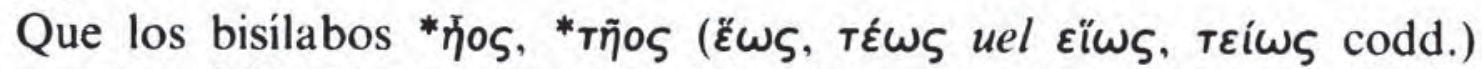
sean susceptibles de experimentar sinizesis (aproximadamente $6 \times$ y 4 ó $5 \times$ monosilábicos respectivamente frente a $c a .39 \times$ y $5 \times$ disilábicos), no es ningún obstáculo para nuestra explicación. A diferencia de los bi-

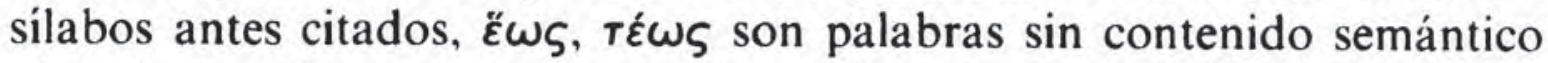
pleno y, por lo tanto, muy proclives a la erosión fonética (cf. también Peters 1989: pp. 148-149) ${ }^{39}$. Por otra parte, como observa Tichy (1981: p. 189), aunque sacando una conclusión a mi juicio incorrecta (cf. supra

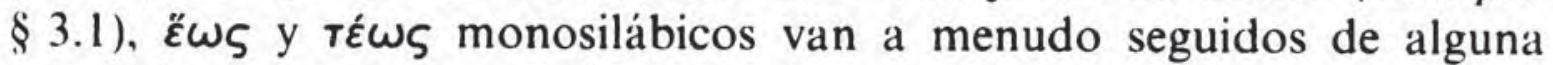
partícula o pronombre $(\mu \dot{v} v, \mu \iota v)$. Al combinarse con estas partículas

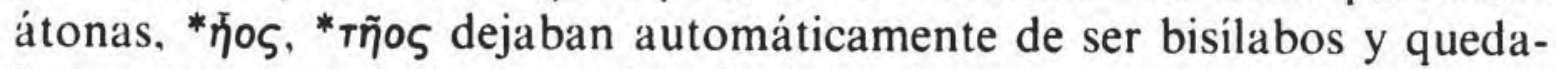
ban sujetos a la regla general de la sinizesis.

4.5. Bechtel, SGDI II 5, p. 690 , sugiere que $\langle\omega\rangle$, resultado que se atestigua abundantemente en inscripciones del área jónica ${ }^{40}$, es una simple grafia por [e्x:], en la que se ha prescindido de la notación de [e] no silábica. Implícitamente esta sugerencia de Bechtel presupone que [e्र:] no puede haber evolucionado a [0:].

En primer lugar, no resulta evidente que $\langle\omega\rangle$ refleje mejor que $\langle\varepsilon \omega\rangle$ una realidad fonética [ę:]. En segundo lugar y más importante, sinizesis y contracción no son procedimientos antitéticos e incompatibles. Como hemos indicado más arriba (n. 25), es importante no confundir 'pérdida de silabicidad' $([\mathrm{eV}]>[\mathrm{eV}])$ y 'formación de yod' $([\mathrm{eV}]>[\mathrm{iV}])$. La etapa [es:] con pérdida de silabicidad de la $[\mathrm{e}(:)]$ parece un eslabón probable entre $[\mathrm{e}(:) \mathrm{x}(:)]$ y [0:]. Cf. las evoluciones tri-

${ }^{39}$ Otros ejemplos en que la erosión fonética (generalmente asociada a una pérdida del acento propio) refleja icónicamente la desemantización experimentada son: las particulas $\mu \varepsilon v v, \delta \varepsilon$, variantes reducidas semántica y fonéticamente de $\mu \eta \dot{v}, \delta \eta \dot{j}$; la psilosis del artículo en dialectos (locr. occ., colonias aqueas) donde $h$ - normalmente se mantiene; en beocio la secuencia /a:o/ (normalmente conservada) se contrae en el gen. pl. fem. del artículo ${ }^{*} T a ̄ \omega v>$ tāv y en la conjunción āos $>$ ās (!). Para la reducción de palabras átonas en griego, cf. Lejeune (1972: § 301).

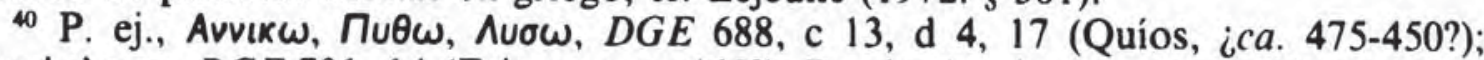
$T \omega v \phi u \lambda \varepsilon \omega v, D G E 701,14$ (Eritras, ¿ca. 465?). Por lo demás, la contracción es regular en ático en, p. ej., $\delta \rho a \chi \mu \tilde{v} v$, donde la comparación con el jonio hace probable

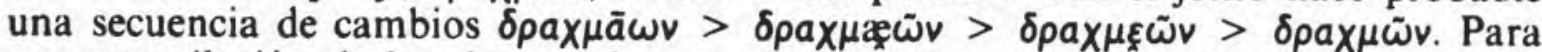
una recopilación de los datos sobre $\langle\omega\rangle$ por $\langle\varepsilon \omega\rangle$ y las grafias ultracorrectas $\langle\varepsilon \omega\rangle$ por $\langle\omega\rangle$ en las inscripciones jonias, así como para una discusión de las diversas explicaciones que se han propuesto, cf. P. Hualde (1989). 
viales $[$ ei] $>$ [ei $]>$ [e:], [ai] $>[a]$ a $]>$ [ae $]>[\varepsilon:]$, etc., en que la pérdida de silabicidad preludia la contracción.

5. Pasamos ahora a ocuparnos de otro cambio fonético, atestiguado epigráficamente en Heraclea, colonia fundada por Tarento y Turios en el $433 / 432$ a.C.

Las célebres Tablas de Heraclea (fin. s. IV) nos ofrecen distintos resultados para las secuencias /eo(:/), /ea(:)/. La distribución depende en buena parte de su origen.

En primer lugar, $\langle\varepsilon 0\rangle,\langle\varepsilon \omega\rangle,\langle\varepsilon a\rangle$ aparecen de forma invariable en los hiatos recientes producto de la pérdida de -w-: cf. Kuveas (I

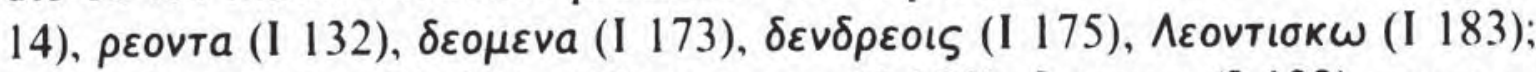

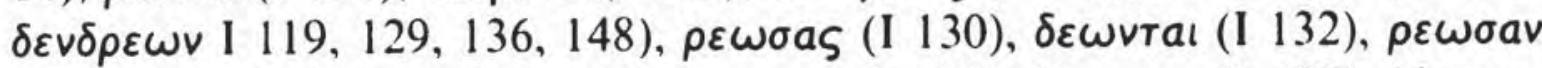

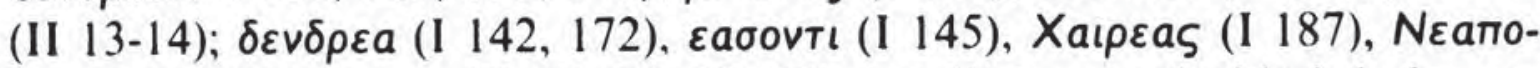

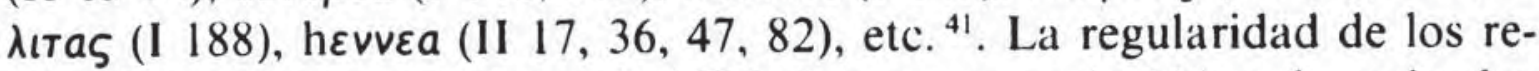
sultados indica con toda probabilidad que, como /eo(:)/ en laconio, los hiatos recientes habian permanecido intactos en Heraclea ${ }^{42}$. Cf. también $\varepsilon \kappa \pi \lambda \varepsilon$ ov (II 31), resultante de la abreviación de ${ }^{*} \varepsilon \kappa \pi \lambda \eta$ ov $\left(<{ }^{*} \text { pleh }{ }_{1} \text { io- }\right)^{43}$.

Aunque no de forma sistemática, esas mismas grafias se utilizan también para notar el resultado de hiatos más antiguos producidos por

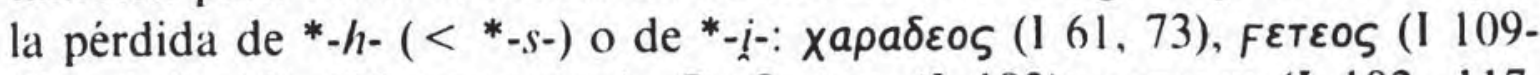

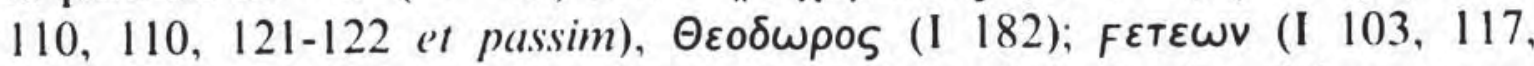

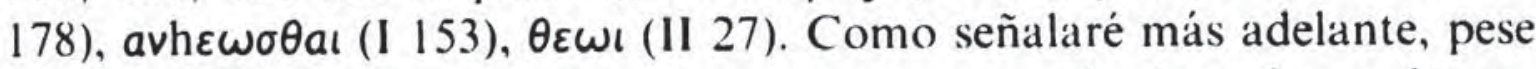
a las apariencias, $\langle\varepsilon 0\rangle,\langle\varepsilon \omega\rangle$ no son una prueba inequivoca de que en /eo(:)/ el hiato se hubiera mantenido.

Para los hiatos antiguos, junto a $\langle\varepsilon 0\rangle,\langle\varepsilon \omega\rangle$, se registran ejem-

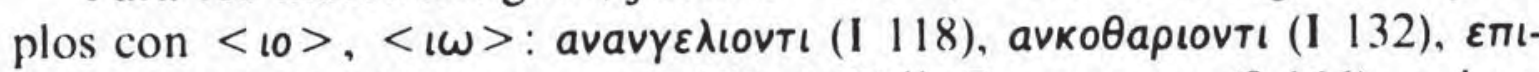

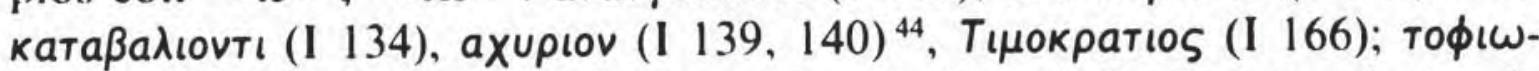

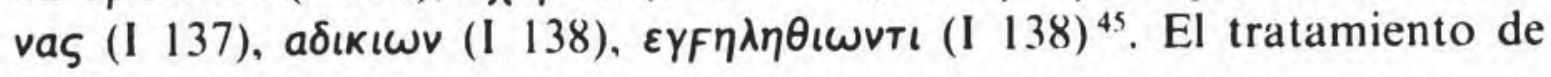

${ }^{41}$ Para el - $w$ - en los nombres en -tas, asegurado documentalmente por mic. $a-u$-ke-wa Auyefas (PY An 192, 4; Jo 438, 23; Ta 711, 1) y ahora por chipr. $k u$-pe-rewa Kumpefas en una inscripción silábica de Kouklia-Pafo (Masson y Mitford, 1986, n." 48), cf. Peters (1980: p. 301, n. 251), Sprache 32, 2 (1986 [1988]), IC 722a, p. 545) y Masson (1990: pp. 149-150) con bibliografia.

${ }^{42}$ Para Tarento, cf. las formas veav y $\operatorname{coc}_{0} \delta[\varepsilon \lambda \bar{\varsigma} \varsigma]$ en un texto fechado en la primera mitad del s. vi, recientemente publicado por Lo Porto (1987), inscripción n..$^{\circ} 1$, II. 5 y $10-11$.

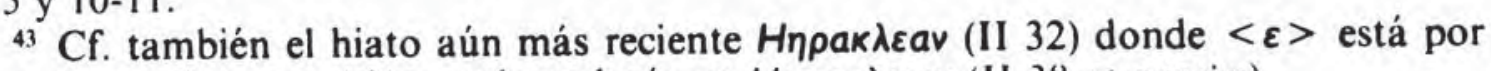

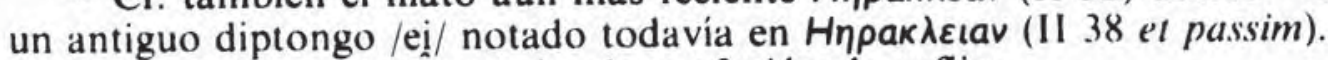

44 Puede tratarse de una simple confusión de sufijos.

45 Los ejemplos de $\langle ı \mid\rangle$ son de interpretación más incierta. Pese a fern (I 111),

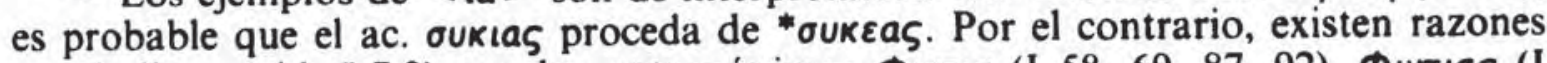
que indican (vid. \$ 7.2) que los antropónimos Фivtıa (I 58,69, 87, 92), Фıvrıas (I 168) y חeı。as (I 183) son formaciones con el sufijo -tas, distinto de -Eas, que aparece en los ya citados Kwveas, Xaipras. 
Heraclea concuerda con el de Laconia: cf. lac. avıoxı̄ov (IG V 1. 213, 8, 14, etc.; Esparta, ¿ca. 450-431?). Los investigadores al unisono ven aquí una prueba del cierre de /e/ antevocálica.

Los resultados $\langle 0\rangle,\langle\omega\rangle$ se atestiguan en dos grupo de palabras.

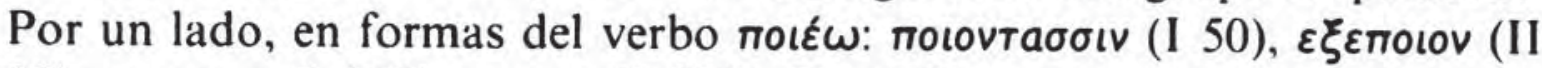

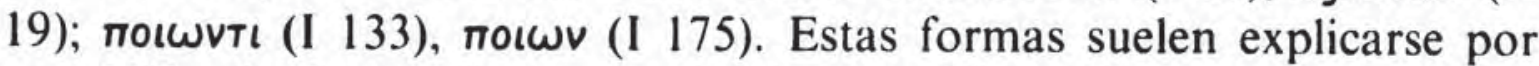
una hiféresis de la /e/ en posición intervocálica (cf. Schwyzer 1939: p. 253, Uguzzoni 1968: p. 34), pero veremos que ésta no es la única solución posible.

Más controvertida resulta la aparición de $\langle 0\rangle$ en la $3 .^{a}$ pers. pl. del futuro, tanto en la voz activa como en la voz media (más de treinta

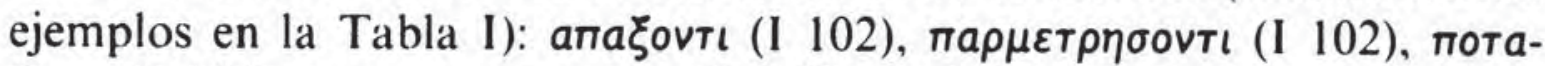

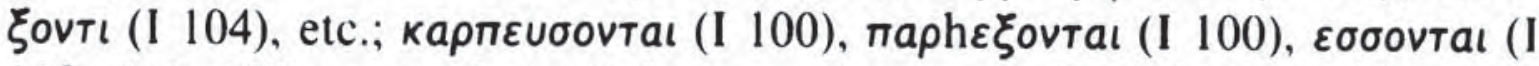
$112,145,179)$, etc.; cf. también $\mu \varepsilon \mu 1 \sigma \theta \omega \sigma \omega v т a$ (I 106), probablemente un futuro perfecto de subjuntivo (Buck 1955: § 146.5). En principio, por tratarse de un dialecto del grupo dorio, sería esperable que las desinen-

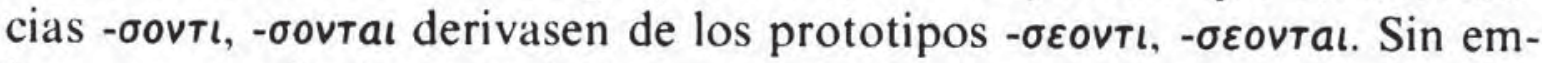
bargo, no todos los especialistas son partidarios de una solución fonética del problema. Volveremos sobre la cuestión a su debido tiempo.

Por último, el resultado $\langle\omega \omega\rangle$ con una /o:/ larga no etimológica se repite en dos palabras con una sistematicidad que excluye la posibilidad de un error gráfico: $\mu \varepsilon т \rho ı \omega \mu \varepsilon v a i ~(I ~ 18,22,28,33), \varepsilon \mu \varepsilon т \rho ı \omega \mu \varepsilon \varsigma$ (II 17$18,45,73)^{46}$. Es este resultado $\langle\iota \omega\rangle$ el que por el momento va a centrar nuestra atención.

Los textos literarios dialectales nos proporcionan otros posibles ejemplos de $\langle\boldsymbol{\omega} \boldsymbol{\omega}\rangle$, en su gran mayoría identificados ya por Ahrens (1843: p. 211). Los códices son unánimes en transmitir la forma $\delta \mu \omega \dot{-}$ $\mu \varepsilon \theta a(<\delta \mu \varepsilon o ́ \mu \varepsilon \theta a)$, que aparece en boca de la espartana Lampitó en la Lisistrata de Aristófanes, v. $183^{47}$. Es muy probable que Ahrens tuviera

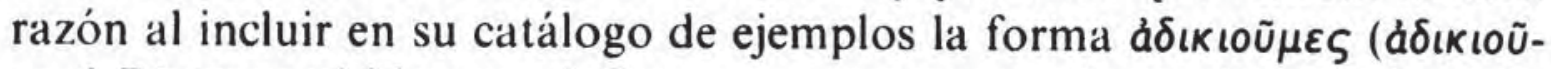
$\left.\mu \varepsilon \sigma^{\prime} \mathrm{R}\right)$ transmitida por el Rauennas en otro pasaje en dialecto laconio de la misma comedia (v. 1148). Esta forma no es forzosamente conta-

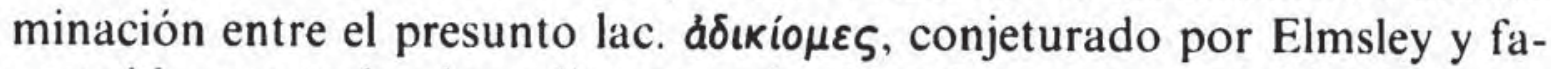

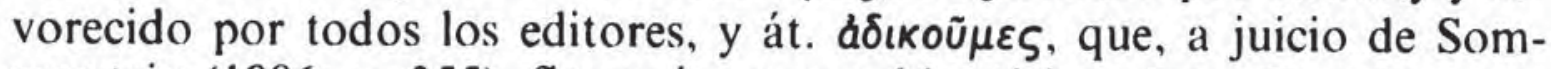
merstein (1986: p. 355), figuraría en una hipotética glosa. Es más verosímil que, por un error trivial de los copistas, que tienden a introducir

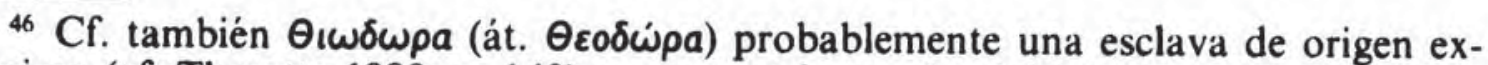
tranjero (cf. Threatte 1980: p. 143) en una estela sepulcral ática, Hesperia 23 (1954), p. 278, n. ${ }^{\circ} 154$ (s. iv/ui a. C.).

${ }_{47}$ Desdichadamente esta forma coincide con una laguna en el fragmentario Pap. Col. 3 (fr. 43 CGFP) que transmite este pasaje. 
el vocalismo ático en los pasajes dialectales de Aristófanes ${ }^{48}$, a $\delta\llcorner เ\llcorner\tilde{u} \mu \varepsilon \varsigma$ haya suplantado a una forma ${ }^{*} \dot{d} \delta \iota \kappa \iota \tilde{\omega} \mu \varepsilon \varsigma$, más acorde con la fonética del laconio. Como se verá más adelante, otras razones apoyan esta conjetura ${ }^{49}$.

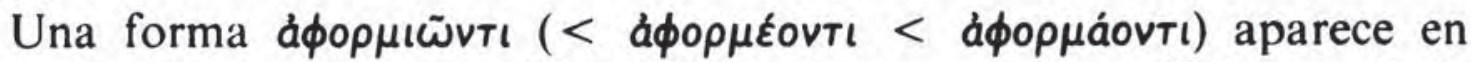
una carta del filósofo Arquitas de Tarento (s. Iv) transmitida por Diógenes Laercio, III $22^{50}$. Idéntico resultado se repite en varias glosas del

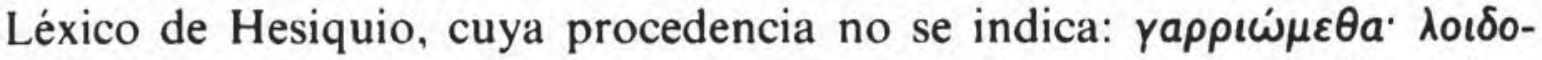

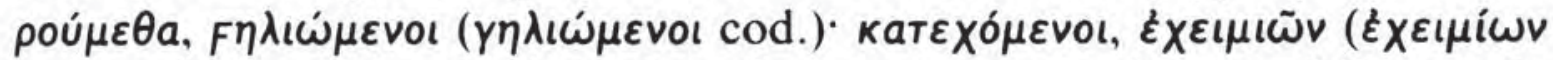

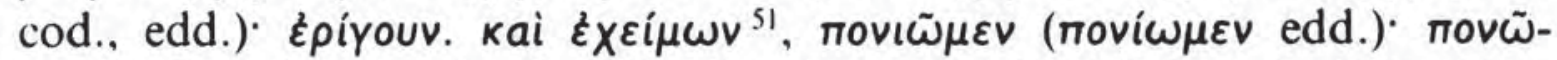
$\mu \varepsilon v^{52}$. Por fin, Apolonio Díscolo, Pron. 95 B, 96 C (ed. Schneider, p. 74 , 11. 17-18; p. 75, II. 24-25) atribuye las formas pronominales

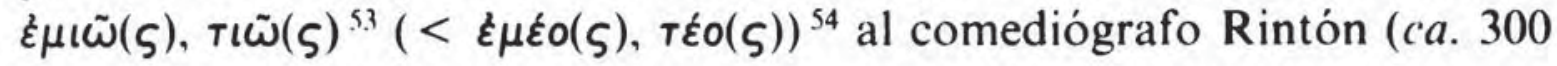

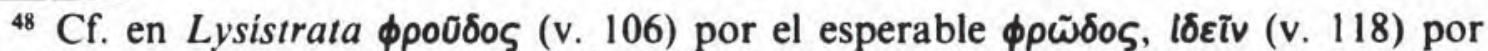

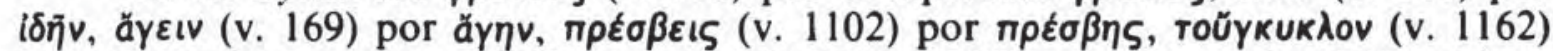

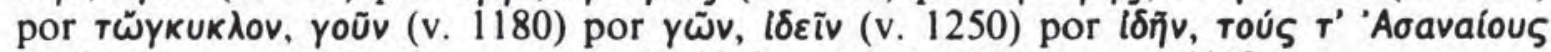

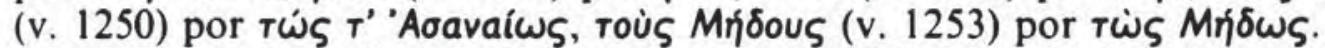

${ }^{44} \mathrm{La}$ forma $\dot{\mu} \mu i \omega \mu \varepsilon \varsigma$ Elmsley (U் $\left.\mu v \varepsilon i \omega \omega \varepsilon \varsigma \mathrm{RB}\right)$ en Lys. 1305, que cita Ortega Villaro (1990: p. 21), es en realidad un subjuntivo.

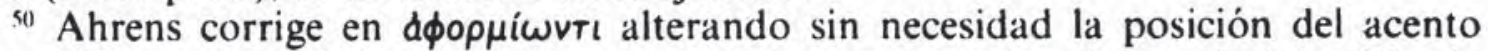
transmitida (probablemente de forma correcta) por los mss. Aún más injustificado es el proceder de Hicks (ed. Loeb) quien propone dфорнíovtı. Sobre este problema, cf. infra $\S 6$.

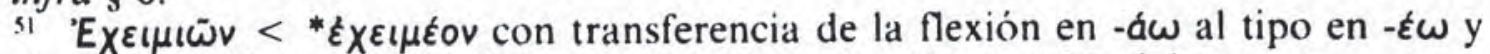
con la acentuación "dórica" de la 3." pers. pl. en los tiempos históricos.

${ }_{52}$ Curiosamente, tal como señala Arena (1971: p. 112, n. 11), no hay $\langle\omega \omega\rangle$ en la glosa $\kappa \lambda a u \mu u \rho\llcorner\delta \mu \varepsilon v o v \cdot \kappa \lambda a i o v т a$ atribuida explicitamente a los tarentinos.

${ }_{53}$ Los mss. transmiten las lecturas $\varepsilon \mu \varepsilon i \omega$ en $95 \mathrm{C}$ y $\varepsilon \mu \varepsilon \omega$, $\varepsilon \mu \varepsilon \omega \varsigma$ en $96 \mathrm{C}$. La acentuación $\varepsilon \mu i \omega(\varsigma)$, тí $\omega(\varsigma)$ que adopta Schneider siguiendo los manuscritos es probablemente inadecuada (cf. $\S 6$ ). $T(\tilde{\omega}(\varsigma)$ dificilmente puede remontarse a un prototipo *teue-so. Tampoco es probable una reconstrucción *teuo-(s) ya que, por tratarse

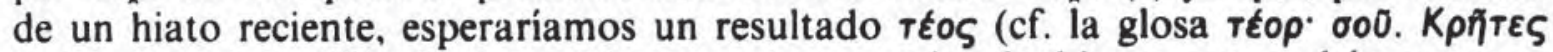
en Hesiquio); la dificultad que plantea rıós no es insalvable ya que podría pensarse en la acción analógica de la $1 .^{\mathrm{a}}$ persona o en un tratamiento especial generalizado a partir de la variante enclítica más proclive a perder el hiato. De todos modos, parece más razonable suponer con $\operatorname{Rix}(1976: \$ 191)$ que dór. TÉos (> Tı́́) se ha creado directamente sobre el acusativo $T \hat{\varepsilon}$.

${ }^{54}$ Uguzzoni (1968: p. 34, n. 45) sugiere relacionar las formas de Heraclea con

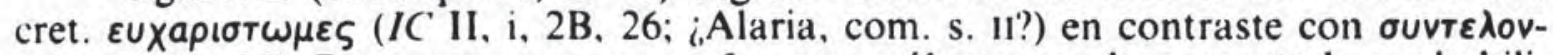
$\tau \varepsilon\langle\varsigma>(1.15)$. Pero $\varepsilon \cup x a p ı \tau \tau \omega \mu \varepsilon \varsigma$ y formas análogas resultan con toda probabilidad de la adaptación de formas de la koiné a la fonética del dialecto a partir de equivalencias como $\beta$ ouגí de la koiné $=\beta \omega \lambda a$ del dialecto (vid. Brixhe y Bile 1991: $\S 2.3 .4)$. Tampoco parece convincente la evolución $-\lambda \varepsilon o v>-\lambda \varepsilon \omega \omega v$ [«vielleicht mit (im Text nicht bezeichnetem) mouillertem $\lambda$ »] que Harlow (1972: p. 24) postula para

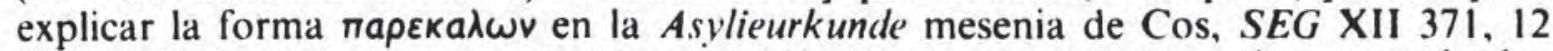
(242 a.C.). En la misma inscripción y en idénticos contextos se atestiguan resultados

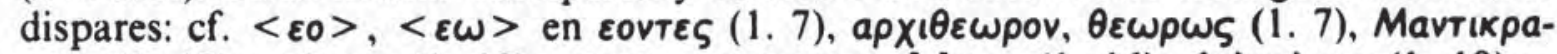

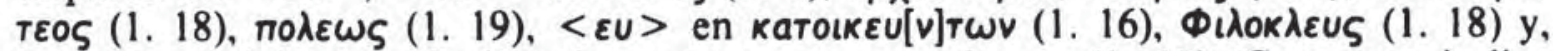
lo que especialmente significativo, <ou $>$ en ouvtedouvtı (1. 10). Como me indica 
a.C.) quien, aunque natural de Siracusa, desarrolló su carrera en Tarento.

En una importante contribución, Volkmar Schmidt (1978) ha sido capaz de ampliar el dossier de Ahrens al identificar un fenómeno análogo en el dialecto siracusano de un fragmento papiráceo de Epicarmo

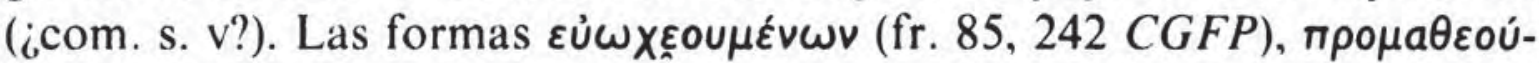

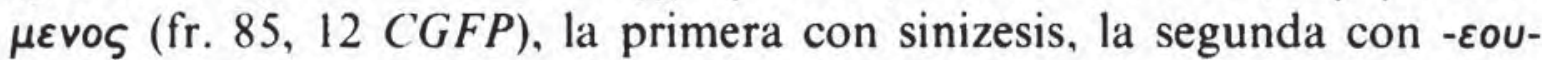
escandido como un yambo, corroboran la atribución a Epicarmo de un

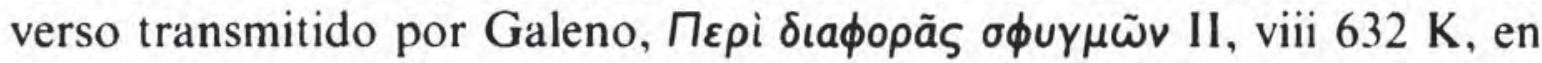

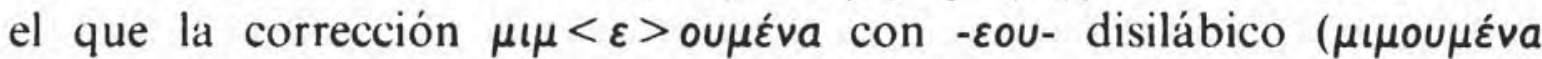
codd.) se hace necesaria para poder escandir un trímetro yámbico. Este resultado $\langle\varepsilon \circ u\rangle$ es el equivalente siracusano con vocalismo de la $D o$ ris mitior del tipo heracleota $\langle\iota \omega\rangle$ con vocalismo de la Doris seuerior.

En otro fragmento papiráceo (fr. 83,9 CGFP), Austin lee una forma $\varepsilon \mu \varepsilon \tilde{\text { [c }}$. La lectura cuenta con la autoridad de Apolonio Díscolo, Pron. 95 A (ed. Schneider, p. 74, 11. 15-17), quien registra la forma $\varepsilon \mu \varepsilon u \tilde{S}$ como característica del dórico de Epicarmo (cf. también la variante $\varepsilon \mu \varepsilon \tilde{u}$ referida a Sofrón en $82 \mathrm{C}$ y el genitivo de la $2 .{ }^{a}$ persona $\tau \varepsilon \tilde{\varsigma} \varsigma$ en otro fragmento de Epicarmo citado en 96 A, ed. Schneider, p. 75, 11. 36). Pese a las dificultades de interpretación que plantea un dialecto literario donde pueden convivir variantes estilísticas y dialectales de origen diverso (sc. [eo] $>$ [eu ] $\langle\varepsilon u>$ y [eno:] $\langle\varepsilon \circ u>$ ), no es impensable que $\langle\varepsilon \cup\rangle$ en $\varepsilon^{\prime} \mu \varepsilon \tilde{u} \varsigma$ haya surgido por una mala interpretación de una grafia $<\varepsilon o u>{ }^{55}$. El propio Apolonio Discolo comenta un poco más adelante el genitivo $\tau \varepsilon o \tilde{~(\tau \varepsilon o u s ~ c o d . ~ A ~ e n ~} 96 \mathrm{~B}$ ) en relación una vez más con Sofrón y/o Epicarmo (Pron. 95 C y 96 B-C, ed. Schneider, p. 74, 1. 24 y p. 75 , Il. 16-23). Si esta interpretación es correcta, tales ejemplos deberían añadirse a los señalados por Schmidt.

Martin Peters (per litteras), la forma napeкaגwv tiene todo el aspecto de ser una ultracorrección por napekałouv, forma regular en la koiná dórica; la ultraccorrección ha surgido a partir de otros casos en que había una vacilación entre $\langle\omega\rangle$ resultado genuinamente mesenio y $<o u>$ de la koiná: cf. en la misma inscripción to $\varepsilon$ pov

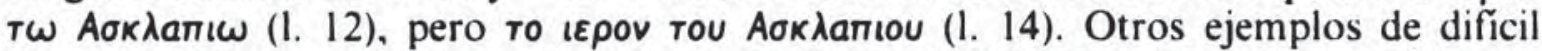
interpretación se registran en la "Stele dei Patti" (SEG IX 3; Cirene, s. IV), donde

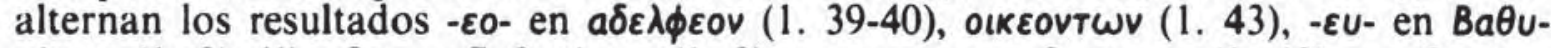

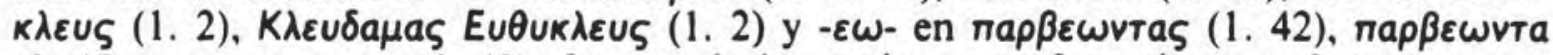

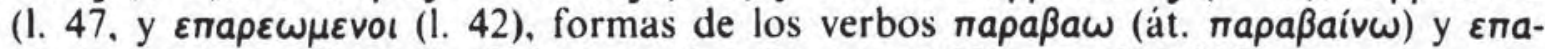
paopai con transferencia al tipo en $-\varepsilon \omega$. Devoto (1928: pp. 391-392) ve en $-\varepsilon \omega-$ un hibrido de $-\omega$-, resultado regular de la contracción de -ao- (cf. $\eta \beta \omega v$ ras 1. 29), y-80-, esperable en la flexión en $-\varepsilon \omega$.

35 A este respecto parece revelador el hecho de que, como observa Lobel, Oxy.

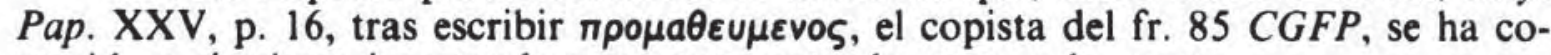
rregido a si mismo insertando una $\langle 0\rangle$ entre la $\langle\varepsilon\rangle$ y la $\langle u\rangle$. 


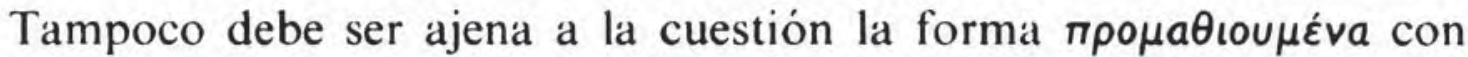
$\langle ı$ lou $\rangle$ escandido _ - , que figura en un tetrámeto trocaico en dialecto dórico, transmitido sin indicación de autor por Apolonio Díscolo, Pron. 61 B (ed. Schneider, p. 48, 1. 27) ${ }^{56}$. Aunque ni Kaibel (1899), ni Demiańczuk (1912), ni Olivieri (1930) parecen haber considerado tal posibilidad, ni tampoco existen ejemplos de $\langle 1\rangle$ por $\langle\varepsilon\rangle$ antevocálica en otros fragmentos de Epicarmo ${ }^{57}$, el paralelo con las formas antes mencionadas apoya la atribución al comediógrafo siracusano propuesta por Bergk, PLG III 3, 4, p. $1359^{\text {sk }}$.

6. Siguiendo una explicación que se remonta a Ahrens (1843: p. 211$)^{59}$, Schmidt (1978: p. 14) interpreta las grafias $\langle\iota \omega\rangle$ de las Tablas de Heraclea, Aristófanes, etc. y $<\varepsilon \circ u>$ de Epicarmo como resultados de un proceso de sinizesis en el que la pérdida de la mora correspondiente a la primera vocal de la secuencia se compensa mediante el alargamiento de la segunda ${ }^{\text {t0 }}$.

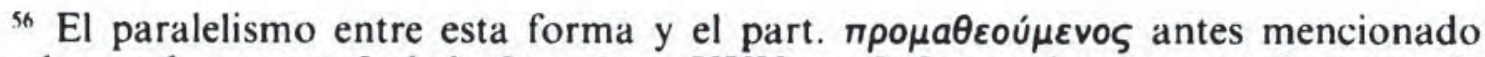
fue observado ya por Lobel, Oxy. Pap. XXV, p. 5. La conjetura $\pi \rho \mu_{\mu} \theta \imath \omega \mu \varepsilon ́ v a$ de

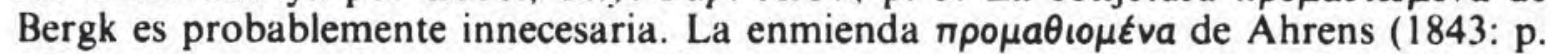
208) es incompatible con el metro. Tampoco parece tener fundamento la atribución a Alcmán que propone Ahrens (1839: p. 234). Como indica Lobel, loc. cit., y contra lo que da a entender Gentili (1961: p. 337), estas formas del siracusano no guardan

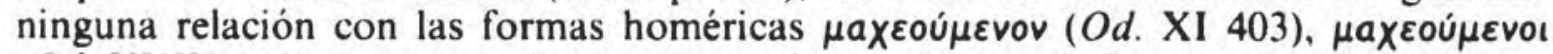
$(O d$. XXIV 113), que se explican por un alargamiento métrico (Chantraine 1958: p. 101).

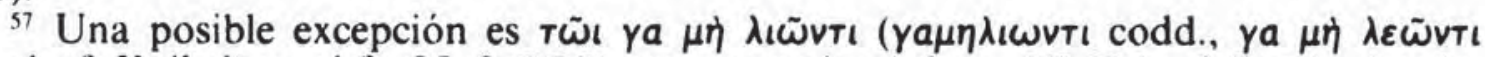
Dindorf, Kaibel) en el fr. 35, 2 ( $G F$, que transmite Athen., VI 235 e-f. Por lo demás, salvo los casos apuntados y los ejemplos con contracción (?) (cf. § 7.2), encontramos

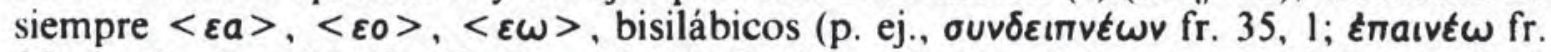

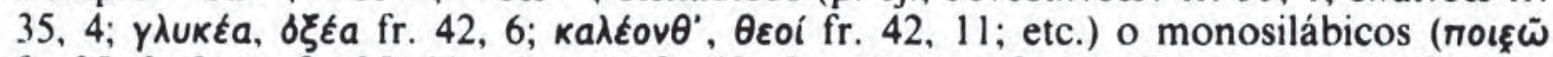

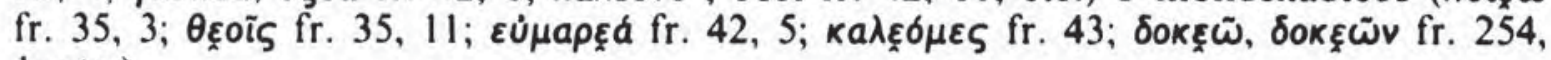
1; etc.).

${ }^{5 k}$ El genitivo tıoũ que Apolonio, Pron. 95 C (ed. Schneider, p. 74, 11. 27-28), introduce a continuación de sendas citas de Sofrón y Corina donde se ejemplifica el

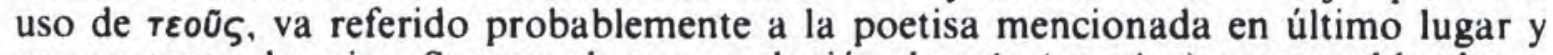
es, por tanto, beocio. ¿Se trata de una evolución de riós $(<$ TÉs) comparable al tra-

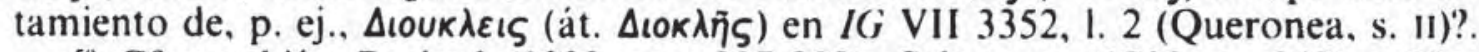

${ }^{59}$ Cf. tambièn Bechtel (1923: pp. 307-308), Schwyzer (1939: p. 242) y Harlow (1972: p. 24). Uguzzoni (1968: p. 34, n. 45) y Ortega Villaro (1990: p. 205) han entendido mal el pasaje de Schwyzer y hablan de una evolución $\varepsilon 0>10>1$ o $>1 \omega$.

${ }^{60}$ Lejeune (1972: $\$ 275$ y 283, n. 3) sugiere que con el alargamiento de $/ 0 /$ se trataria de compensar la reducción en duración intrínseca ("durée absolue») que llevaría aparejada el hipotético cambio [eo] > [io] - la vocal cerrada [i] es intrínsecamente más breve que [e]. Pero esta explicación - que, por otra parte, no puede dar cuenta de los ejemplos de $<\varepsilon o u>$ en siracusano - es inverosímil: la duración fonética (por oposición a la cantidad fonológica) no desempeña ningún papel en este tipo de procesos. Por la misma razón no es probable que $\langle\iota \omega\rangle$ note una [o*] semilarga como sugiere Schwyzer (1939: p. 242). 
Se trata, pues, de un proceso equiparable a los procesos de SIN. + $\mathrm{AC}$ analizados en secciones precedentes, pero hay que poner de relieve dos importantes diferencias respecto de la MC jónico-ática:

(a) En jónico-ático, sólo hay alargamiento cuando la sinizesis afecta a una vocal larga. En siracusano y en heracleota (laconio, tarentino), la /e/ que ha perdido la silabicidad y ha provocado el alargamiento es breve.

(b) Como ya observó Ahrens, en estos dialectos - con las posibles

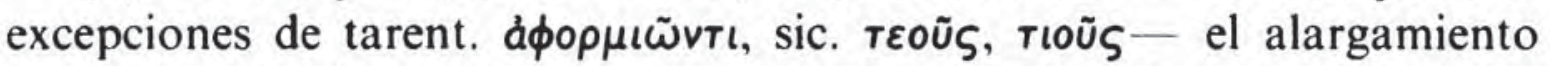
tiene lugar en sílaba abierta (heracl. $\mu \varepsilon т \rho \iota \omega \mu \varepsilon v a l)$ pero no en sílaba ce-

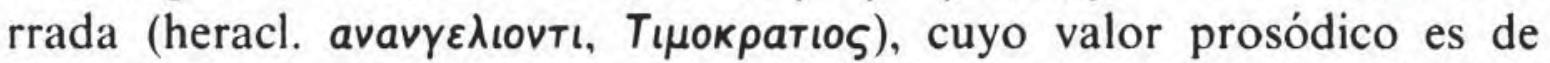
dos moras. En otras palabras, mientras que lo que cuenta aquí es la cantidad silábica, el proceso jónico-ático se rige por la cantidad puramente vocálica y actúa con independencia de la estructura silábica: cf.

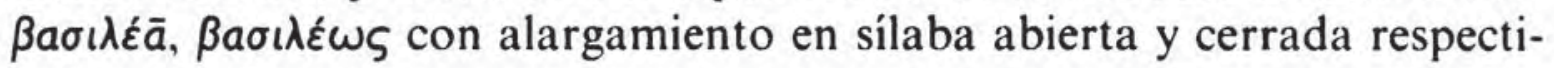
vamente.

Por lo que se refiere a las formas del siracusano de Epicarmo,

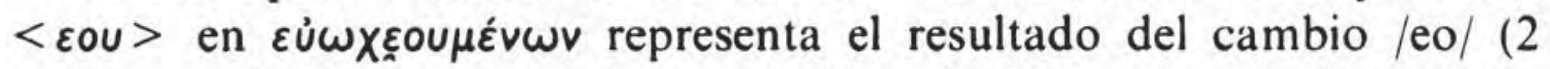

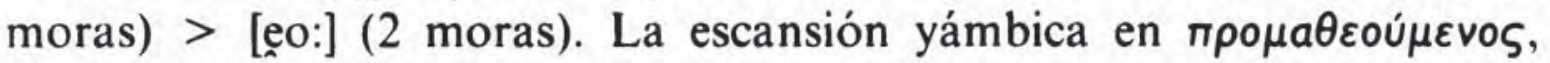
$\mu \iota \mu \varepsilon>$ ou $\varepsilon_{\varepsilon} v a$ debe considerarse secundaria como los ejemplos de $\varepsilon \omega$ disilábico en el caso de la MC jónico-ática.

No estamos, en cambio, plenamente de acuerdo con la reconstrucción que Schmidt propone para el heracleota, según la cual $\langle\imath \omega\rangle$ sería el resultado de una secuencia de cambios [eo] $>$ [io] $>$ [io:], donde la SINIZ. + AC de [i] vendría precedida por un proceso fonético de «Anhebung von $\varepsilon>$ । vor dunklen Vokalen (ausser wenn $F$ dazwischen geschwundet war)». Como es bien sabido, un cierre de /e/ de características análogas al del heracleota se postula también para otros dialectos (tesalio, beocio, panfilio, cretense, argólico occidental, laconio, áreas de Sicilia) en los que con mayor o menor profusión se atestiguan grafias del tipo $\theta$ เos por $\theta \varepsilon \circ \varsigma$.

Sin embargo, pese a tratarse de una de las creencias con más firme arraigo entre los estudiosos de los dialectos griegos desde que Solmsen publicó en (1893) su celebrado artículo sobre el problema, la existencia de un cambio $[\mathrm{eV}]>[\mathrm{iV}]$ en griego es cuestionable (para una argumentación pormenorizada, vid. Méndez Dosuna, en prensa).

Una solución más satisfactoria es postular un proceso de SINIZ + AC en sílaba abierta, [eo] > [eo(:)], común a los dialectos de Siracusa y Heraclea. En este último dialecto, es con toda probabilidad esta fase

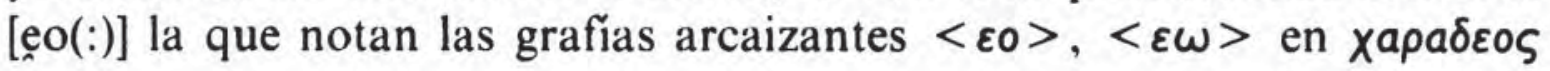




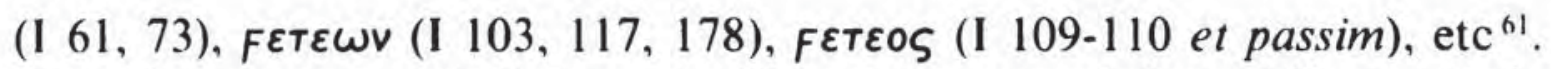
Posteriormente, en el dialecto de Heraclea - y quizá también en el de

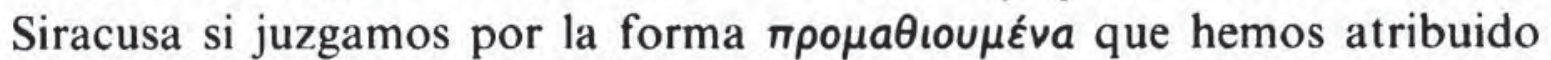
a Epicarmo - , la [e] no silábica, siguiendo una tendencia natural a la que nos hemos referido más arriba $(\S 4.2)$, tendió a cerrarse en [i] (notada $\langle\iota 0\rangle,\langle\imath \omega\rangle,\langle\iota \mid\rangle^{62}$.

Además de la grafia $\langle\iota \omega\rangle$, existen otros argumentos en los que no parece haber reparado Schmidt (1978), que avalan las hipótesis de la

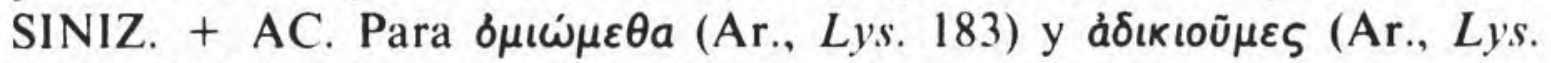
1148), la sinizesis que explica el alargamiento de /o/ encuentra apoyo en la métrica. En el caso de $\delta \mu \iota \dot{\omega} \mu \varepsilon \theta a||$, si bien la escansión _- con un anapesto en el quinto pie de un trimetro yámbico no es imposible (cf. West 1982: p. 88), la escansión $\delta \mu \iota \dot{\omega} \mu \varepsilon \theta a$ con sinizesis _- , que da un metro yámbico perfecto, es claramente preferible (cf. Henderson 1987: p. xlvi). Por lo que se refiere al comienzo de verso ॥ ả $\delta\left\llcorner\left\llcorner\left\llcorner о \tilde{u} \mu \varepsilon \varsigma^{\circ}\right.\right.\right.$ à $\lambda \lambda^{\prime}$, la sinizesis parece ineludible ya que una escansión _. - transgrede el esquema métrico ${ }^{6.3}$.

${ }^{61}$ Por lo expuesto en $\S 4.4$, es probable que el deseo de evitar la creación de un monosilabo bloqueara la sinizesis y, por consiguiente, el cierre de $\langle\boldsymbol{\varepsilon}\rangle$ en $\theta \varepsilon \omega$ เ (II 27) (cf. también $\theta \varepsilon o[s]$ en una consulta de los tarentinos al oráculo de Dodona, $S G D I 4620,1$, ss. IV-III) y analógicamente en su derivado $\Theta \varepsilon o \delta \omega \rho o s$ (I 182); una analogía semejante ha producido la restauración de la secuencia en át. $\theta \varepsilon \delta \delta \omega \rho o \varsigma$ frente

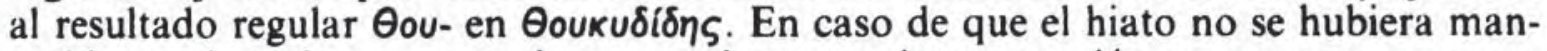
tenido, en heracleota esperaríamos --si nuestra interpretación es correcta - un resultado $\dagger \theta \varepsilon \omega$ - con alargamiento. De igual modo, la ausencia de alargamiento en $\delta \varepsilon о \mu \varepsilon v a(I$ 173) parece indicar que el hiato se mantenía en las secuencias [eo] recientes $\left(>^{*}\right.$-euo-). Arena (1971: p. 1112) sostiene que en el dialecto de Heraclea pugnarian dos tendencias contradictorias: "una (arcaica?)... di evoluzione di $\iota$ ad $\varepsilon$, ed una (più recente?) di conservazione o di restaurazione di $\varepsilon$ ". Esta hipótesis, indemostrable en el mejor de los casos, deja sin explicar el resultado $\langle\omega \omega\rangle$. La idea de una mezcla dialectal que proponen Thumb (1909: $\S 103.2=$ Kieckers 1932: $\S 103.3$ :

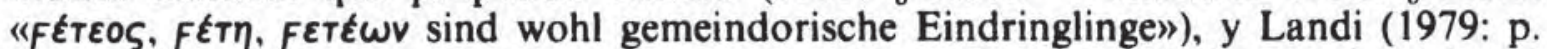
95: una "conservazione di $\varepsilon$ davanti ad $a$, o" característica del dórico nordoccidental (?) frente al "passaggio in i del dorico") adolece de idénticos defectos.

${ }^{62}$ Como en los cambios meoto > mjooto del japonés y *béoðan > bjóða del islandés antiguo, el cierre de /e/ en heracleota es un proceso independiente, pero asociado a la SINIZ. + AC: [eo] > [ęo:] > [jo:] (cf. n. 25). En el laconio de las inscripciones y en los otros dialectos enumerados más arriba donde se atestiguan las grafias del tipo $\theta$ เos, la sinizesis no producia ningún alargamiento: [eo] $>$ [e्xo] $>$ [io]. Cf. también en español de forma más o menos general dependiendo de los dialectos y de los niveles de habla Mediterránęo $\rightarrow$ Mediterranío, vidęo $\rightarrow$ vidio y ultracorrecciones como historęografia, fólęo y espúreo admitido por la Academia.

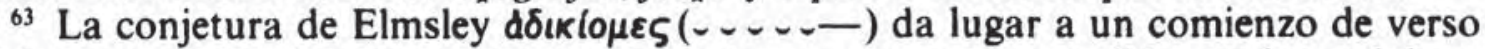
doblemente anómalo en cuanto que presenta un anapesto escindido en dos palabras y precedido inmediatamente por una resolución. Para eliminar esta anomalía, Sommerstein (1986: pp. 355-356), que adopta la conjetura en cuestión, propone con Wi-

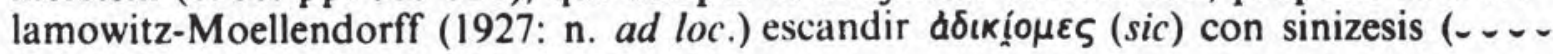


Una segunda prueba a favor de la sinizesis es la acentuación transmitida por los manuscritos para la forma ádıкıõ $\mu \varepsilon \varsigma$, acentuación que obviamente no puede remontarse a la época de Aristófanes, para el ta-

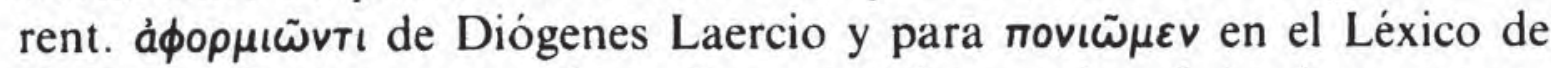
Hesiquio. Dado que en griego el acento (el tono elevado) solamente podía ir sobre un elemento silábico, la pérdida de silabicidad de una vocal tónica suponía la transferencia automática del tono a la vocal contigua

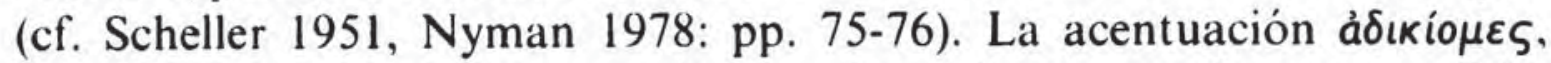

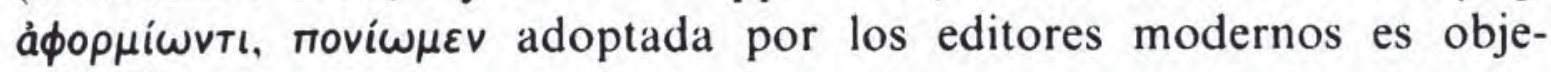
table ${ }^{64}$.

Las formas de futuro atestiguadas en heracleota constituyen el tercer argumento a favor de la sinizesis. De esta uexata quaestio nos ocupamos en la sección siguiente.

7. Uno de los rasgos más llamativos del dialecto de Heraclea es el polimorfismo apreciable en la flexión del futuro, para cuyo estudio la Tabla I nos ofrece abundante material. Si nos dejamos guiar por las apariencias, la conclusión que parece imponerse en que en heracleota conviven las tres principales formaciones del futuro: el futuro "sigmático" en $-\sigma \omega$, el futuro "contracto" en - $\varepsilon \omega$ y el futuro "dórico" en $-\sigma \varepsilon \omega^{65}$.

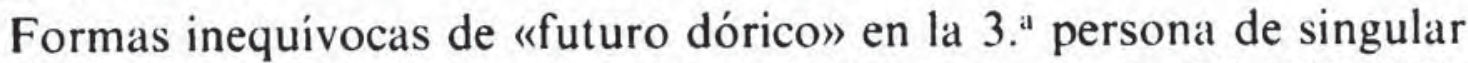

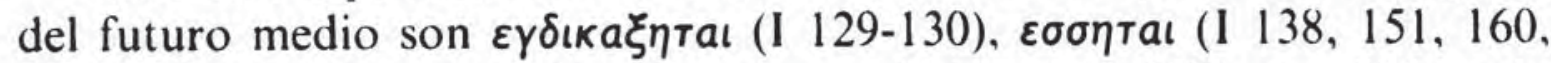

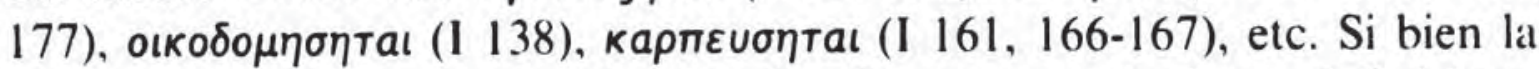
falta de marcas acentuales no permite alcanzar conclusiones definitivas, los investigadores coinciden en interpretar las formas correspondientes de la voz activa como "futuros dóricos" y no como simples futuros sig-

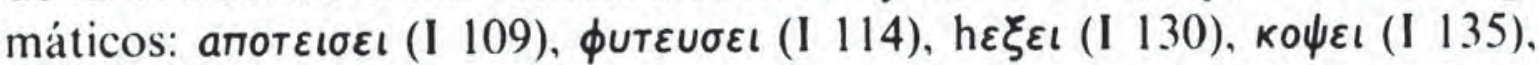

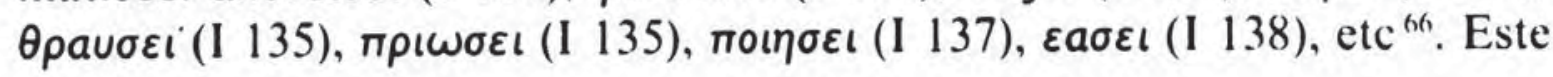

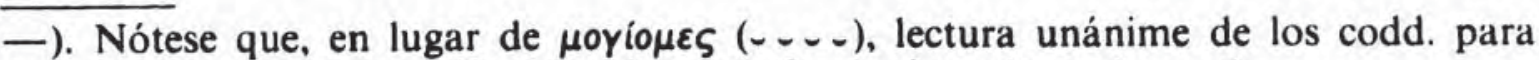

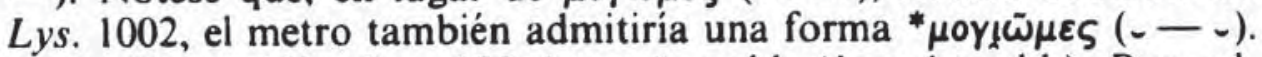

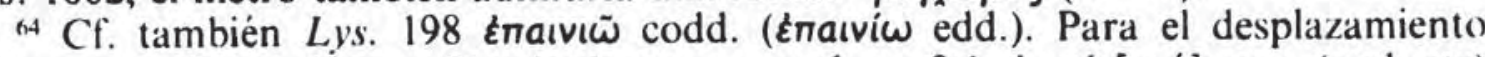

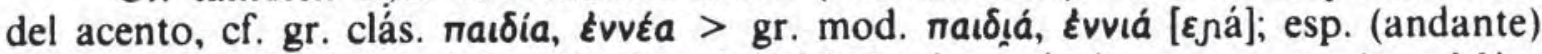
el pas[éo]del Prado $\rightarrow$ (allegro) el pas[eó]del Prado, éstándar creo que si $\rightarrow$ Méx. [krió ksi] y las formas latinas citadas en $\$$ 4.1.1. Nótese que, desde este punto de vis-

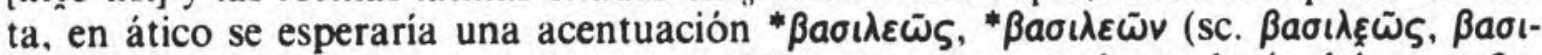
$\lambda \varepsilon \tilde{\omega} \tilde{\omega})$ en lugar de $\beta a \sigma \iota \lambda \hat{\varepsilon} \omega \varsigma$, $\beta a \sigma i \lambda \varepsilon ́ \omega v$. ¿Hay que pensar en la analogía del nom. $\beta a-$ $\sigma i \lambda \varepsilon u ́ s$ (sc. [-éuss]? ¿Se impuso una diéresis secundaria con dislocación acentual como en esp. med. judio > esp. mod. judio?

${ }_{65}$ Recurro a estas tres cómodas etiquetas a sabiendas de que resultan inapropiadas: el futuro "contracto», originalmente también sigmático, presenta secuencias $-\varepsilon 0-,-\varepsilon \omega$ - sin contraer en numerosos dialectos; el futuro "dórico", que es por definición "sigmatico" y "contracto", puede aparecer en el mismísimo ático (p. ej., $\pi \lambda \varepsilon v \sigma o u ̃ \mu a \imath)$.

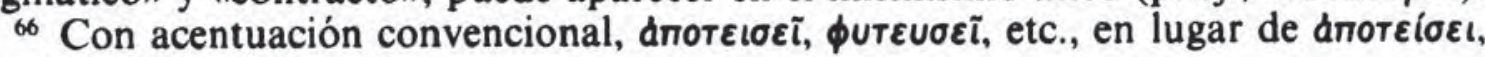

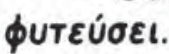


tipo de formación no puede causar la menor extrañeza en un dialecto dórico.

Tampoco sorprende la desinencia de 3 . $^{\text {a }}$ persona de plural -ıovTı $(<$

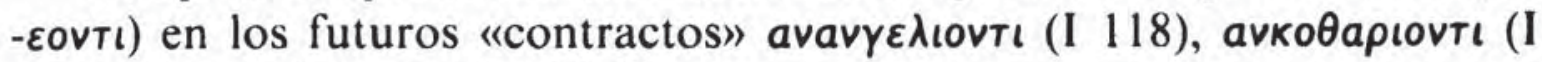

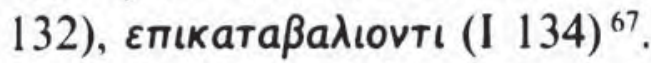

Por el contrario, no responden a nuestras expectativas las desinen-

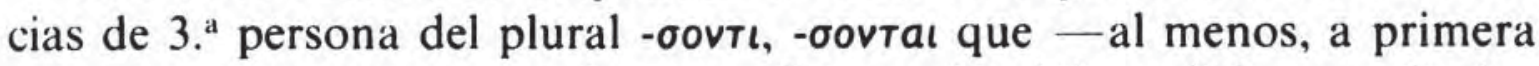
vista - parecen corresponder a un futuro sigmático: cf. los ya citados

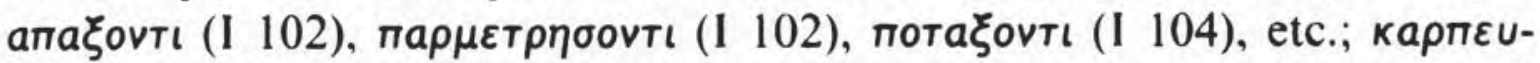

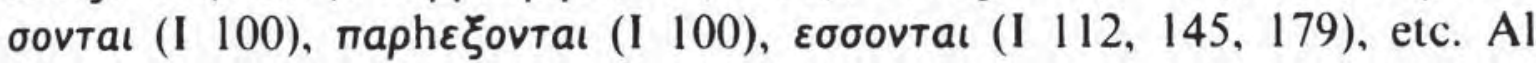
mismo tipo pertenece $[\varepsilon] \sigma \sigma o v t a l, I G$ V 1. 3, 7 (Esparta, ifin. s. IV - com. s. III?), único ejemplo de futuro atestiguado en las inscripciones laconias.

Algunos autores (Page 1951: pp. 123-125, Risch 1954: p. 27, Ruijgh 1986: pp. 456-457, 1989: p. 168) han tratado de establecer una conexión entre los datos de Heraclea y los que proporcionan los fragmentos de Alcmán, donde las formas dóricas en - $\sigma \varepsilon \dot{\omega} \omega$ también alternan con las formas en - $\sigma \omega$. Así, en el Partenio del Louvre (fr. I PMG) aparecen los

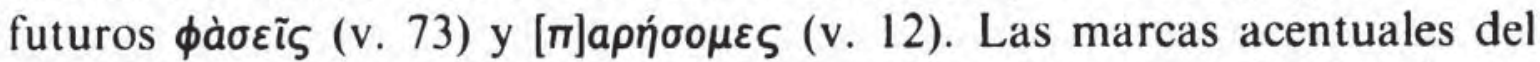
papiro muestran sin lugar a dudas que el copista entendía el primero como un futuro dórico y el segundo, donde a juicio de Page (1951: p. 123) "metre protects the form», como un futuro sigmático. Formas no dóricas recurren en otros fragmentos, en su mayor parte citas en obras de otros autores antiguos transmitidas a través de la tradición manuscrita: $\tau \iota v a ́ \xi \omega$ edd. ( $\tau \iota v a \xi \omega$ pap.) en el segundo Partenio (fr. 3, $9 P M G$ ),

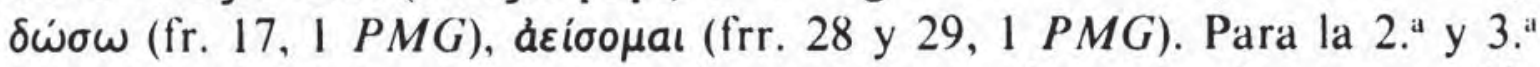
pers. sg., los códices transmiten formas acentuadas como futuros no dó-

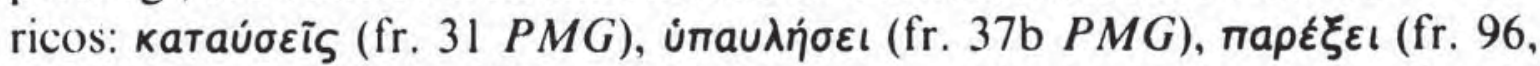
$1 P M G)$. Aunque la diferencia de interpretación no tiene trascendencia para la métrica, Page $(P M G)$ y Calame (1983) llevan sin duda razón en

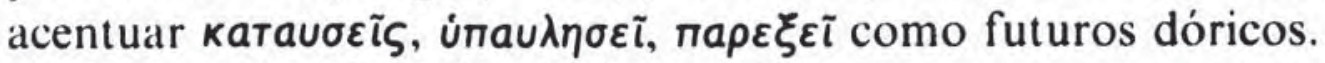

Junto a los ejemplos de futuro dórico con $\langle\iota \omega\rangle,\langle\iota 0 u\rangle$ ya discutidos, los manuscritos de Aristófanes son unánimes al transmitir una forma no dórica $\pi \varepsilon i ́ \sigma o \mu \varepsilon \varsigma$ en Lys. 168, que parece avalada por la métrica ${ }^{6 x}$.

${ }^{67}$ Para la 3." pers. sg., cf. $\varepsilon \mu \beta a \lambda \varepsilon ı$ (I 115).

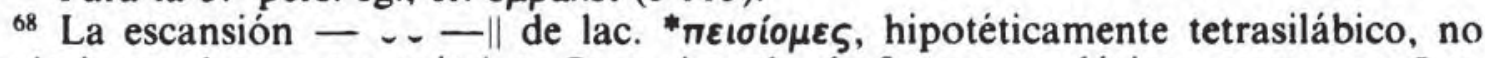
encajaría en el esquema métrico. Otro ejemplo de futuro no dórico aparece en Lys. 1013, donde algunos edd., siguiendo una sugerencia de van Herwenden, corrigen en

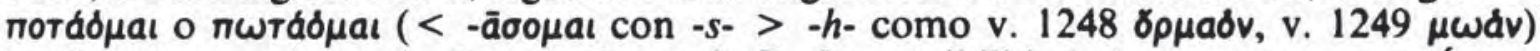

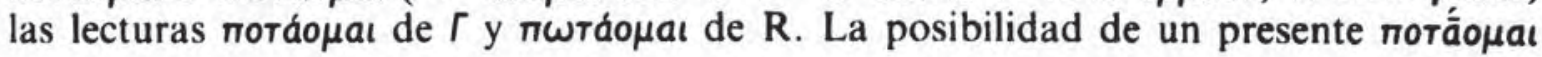


7.1. Una serie de estudiosos encabezada por Solmsen (1893: p. 545) - cf. también Bechtel (1923: pp. 353, 407-408), Kieckers (1932: $\S 80.5$ ), pero no Thumb (1909: $\S 80.5$ ), y Schwyzer (1939: pp. 785786) - admite que efectivamente en Heraclea el futuro seguía un para-

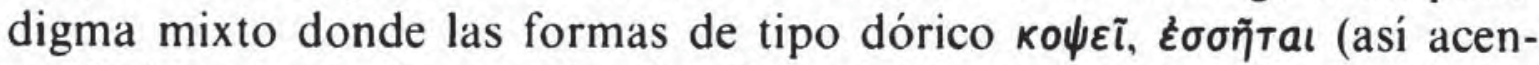

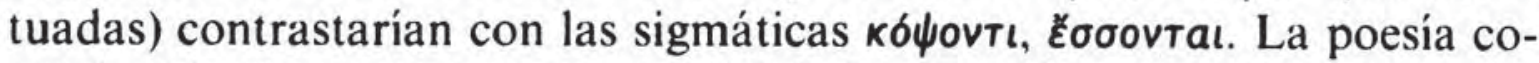
ral de Alcmán sería un trasunto fiel de la situación en el dialecto de Esparta a fines del siglo vII, que habría perdurado en Heraclea.

Tomando como base estos datos, Ruijgh (1986: pp. 456-457) reconstruye la siguiente evolución del paradigma de futuro en los dialectos dóricos. En una primera fase, conservada en Alcmán y en Heraclea, las formas de $2 .^{a}$ y $3 .^{a}$ persona del singular y $2 .^{\text {a }}$ del plural, con vocal temá-

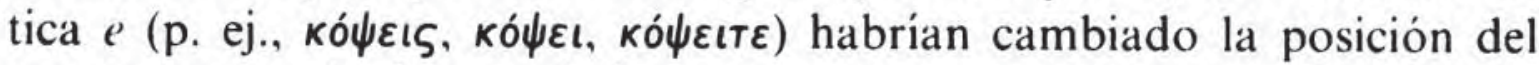
acento por analogía con el tipo contracto $\mu \varepsilon v \varepsilon \tilde{i}(\varsigma), \mu \varepsilon v \varepsilon \tilde{\tau} \tau \varepsilon$. Tal cambio no habría afectado aún a la $1 .^{a}$ persona del singular y plural y a la $3 .^{\text {a }}$ del plural con vocal temática $o$. Como resultado encontraríamos un pa-

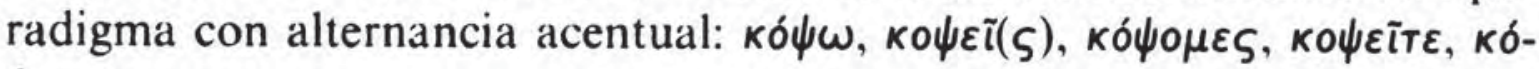

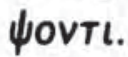

En un segundo estadio (atestiguado, según Ruijgh, en siracusano y en la koiná doria, variedades ambas que derivarian del corintio), las formas contractas se habrian generalizado: $\kappa \circ \psi \tilde{\omega}, \kappa \circ \psi \varepsilon \tilde{i}(\varsigma), \kappa \circ \psi \circ \tilde{\mu} \mu \varepsilon \varsigma$,

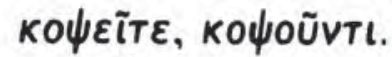

Finalmente, en la mayor parte de los dialectos dorios, las formas sin contracción se habrían introducido para la $1 .^{a}$ pers. sg. y pl. y la $3 .^{\text {a }}$

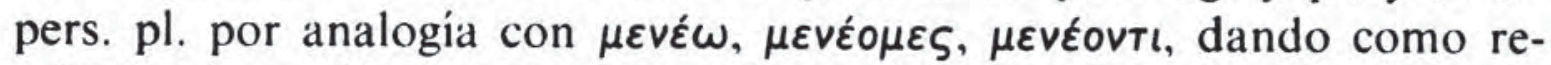

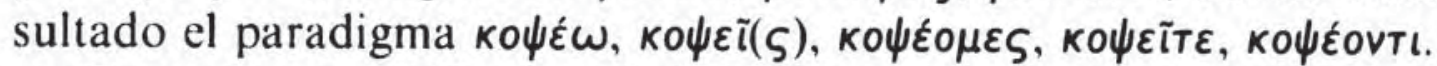

Esta reconstrucción es más ingeniosa que convincente. El cambio de posición en el acento que habría puesto en marcha la remodelación del paradigma, carece de auténtica motivación. Según Ruijgh, el hipotético

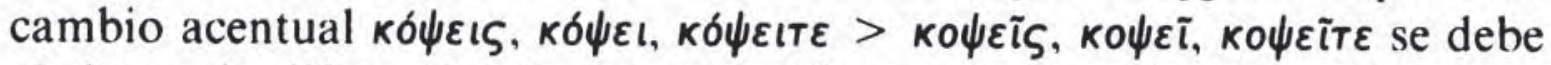
al deseo de diferenciar formas homófonas en el subjuntivo del aoristo sigmático de vocal breve. Pero la existencia de un subjuntivo de estas características en el dialecto de Heraclea está por demostrar.

A la idea de un paradigma mixto con formas en -se- y en -s- se opuso con razón Buck (1955: $\$ 42.5,141$ b); cf. también Uguzzoni (1968: p. 34) y Ortega Villaro (1990: p. 204). Según Buck, quien retoma la expli-

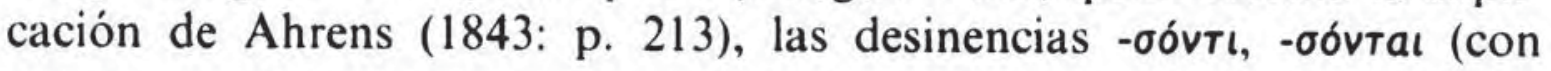

con valor de futuro y con un alargamiento secundario de - $a$ - parece remota. Nótese

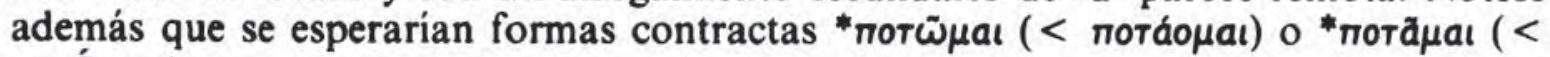
пота́оนаı). 
acento sobre la vocal temática) son el resultado fonético regular de las

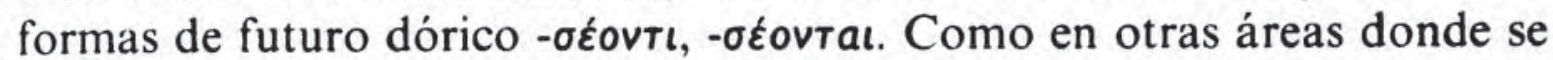
atestigua ese tratamiento (Creta, Argólide, Delfos, Mesenia, Quíos), la secuencia /eo/ habría evolucionado a [o] por hiféresis en sílaba traba$d a{ }^{69}$, pero a $\langle\iota \omega\rangle$ en sílaba libre.

Sin embargo, esta solución tropieza con una dificultad insalvable: no hay el menor rastro de tal hiféresis en otros ejemplos en que /eo(:)/

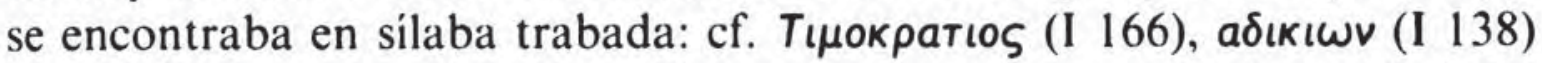

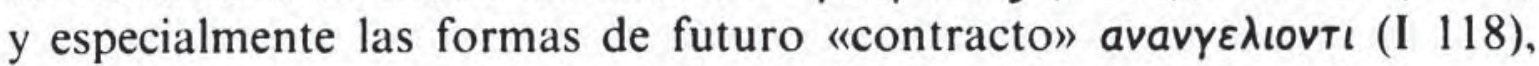

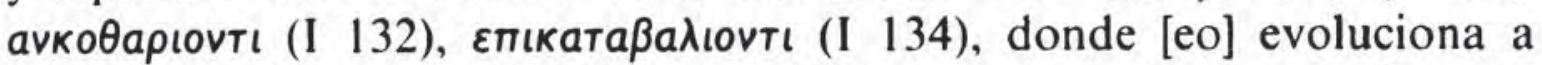
$\langle 10\rangle$ en un contexto absolutamente idéntico al que Buck postula para la hiféresis ${ }^{70}$.

7.2. Las hipótesis expuestas conducen inexorablemente a caminos sin salida. Nuestra hipótesis de la sinizesis es capaz de dar cuenta de los datos sin necesidad de forzar su interpretación. Como se dijo más arriba, [eo] evolucionó a [eoo(:)] (con alargamiento en sílaba abierta) y posteriormente a [io(:)]. Si, como acabamos de ver, el contexto posterior a la secuencia [eo] no permite explicar el cambio, habrá que pensar en tomar en consideración el contexto que la precede inmediatamente. Pese a Solmsen (1893: p. 546: «dem $\sigma$ die schuld für die abweichende behandlungsweise in die schuhe zu schieben, berechtigt uns nicht»), las

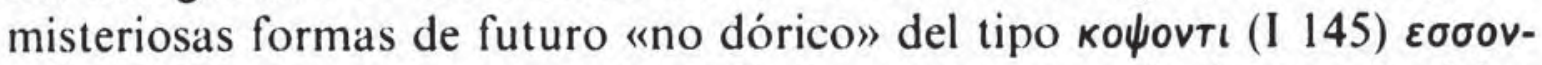
raı (I 100, 159), etc., se explican fácilmente por un fenómeno fonético

${ }^{69}$ Una curiosa variante de este tratamiento se registra en las recientemente publicadas tablillas de Entela (SEG XXX 1117-1123, XXXII 914; ¿300-250?) donde /eo/

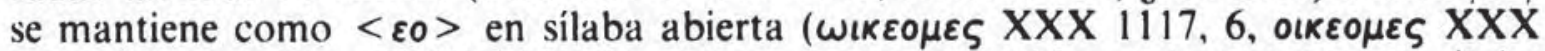
$1117,10$, Ueodvroy $\mathrm{XXX} 1120,2)$, pero aparece contraido en $/ 0: /<o u>$ en sílaba trabada: nolouvtı (XXX 1117, 11; 1118, 13-14), opoy[o]ouvtas (XXX 1119, 5-6),

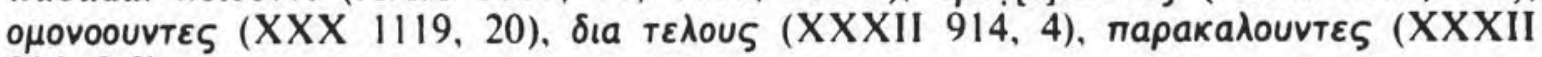
914, 8-9).

70 De hecho, Buck (1955) entra en contradicción y admite simultáneamente como regulares en sílaba trabada los resultados $\langle 10\rangle(\S 42.5 \mathrm{~b})$ y $\langle 0\rangle(\S 42,5 \mathrm{~d})$. Arena (1971: p. 113, n. 15) esgrime contra Buck el testimonio de [n]aprioopes y formas análogas en Alcmán con $\langle 0\rangle$ en sílaba abierta, pero el argumento no es vinculante ya que nada se opondría a que las formas de Heraclea y las de Alcmán hayan surgido independientemente y respondan a motivaciones diversas. Uguzzoni (1968: p. 35), seguida por Ortega Villaro (1990: p. 204), sugiere que -เ- se ha conservado en las

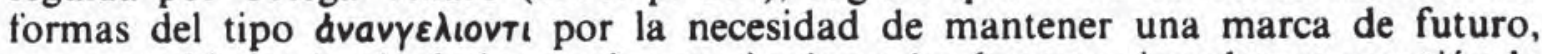
pero esta hipótesis, de dudoso valor en sí misma (en los tres ejemplos en cuestión la

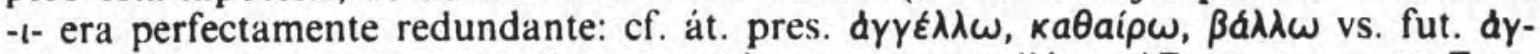

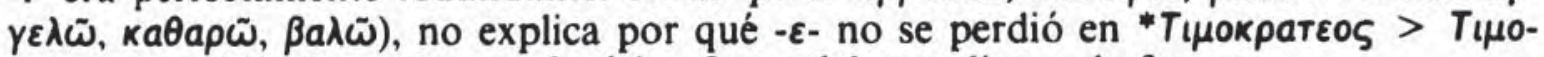
крarios, en idéntico contexto fonético fuera del paradigma de futuro. 
trivial bien documentado en griego en distintas áreas y épocas: la absor-

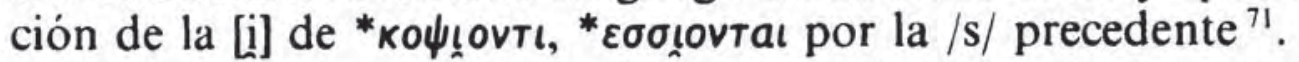

El siguiente cuadro recapitula las evoluciones aquí reconstruidas:

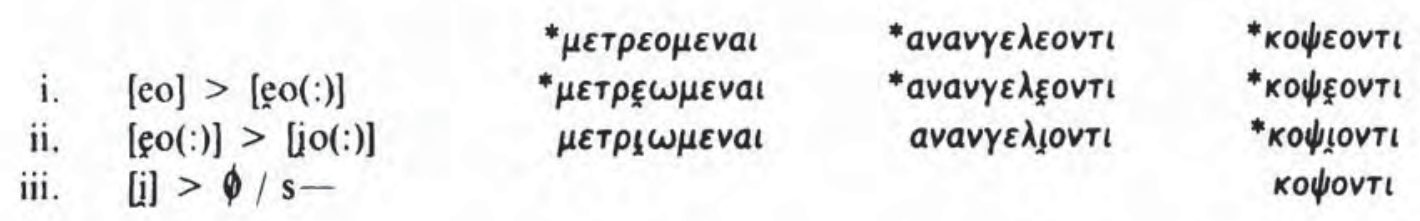

El contraste observable entre los resultados de *[seV], donde la sinizesis ${ }^{*}[\mathrm{seV}]>{ }^{*}[\mathrm{sj} \mathrm{V}]$ ha conducido a la absorción de yod, y los de

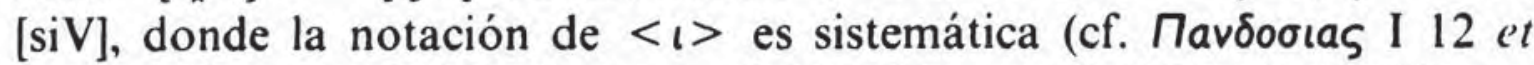

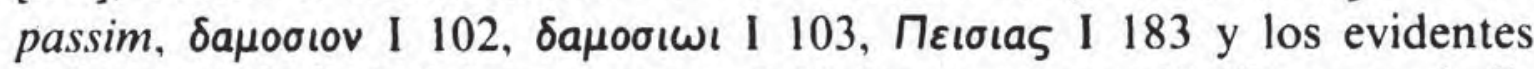

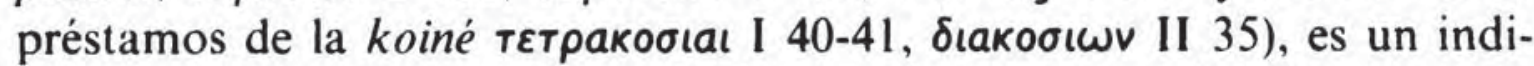
cio palpable de que ${ }^{*}[\mathrm{eV}]$ no llegó a confundirse con $[\mathrm{iV}]^{72}$. Esto concuerda con un hecho al que ya hemos aludido: en griego, las secuencias $/ \mathrm{iV} /$ (sc. [iiV]) ofrecían mayor resistencia que $/ \mathrm{eV} /$ a la sinizesis.

Para terminar el análisis de los datos del heracleota, cabe añadir un

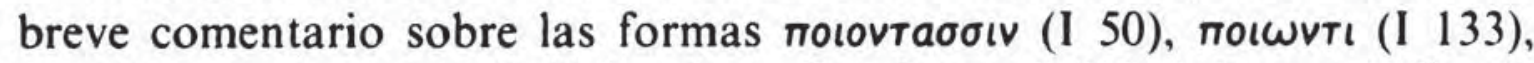
etc. Aunque, como se indicó más arriba, la posibilidad de una hiféresis

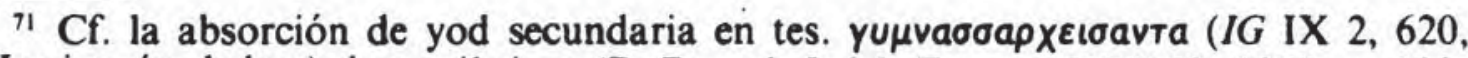
3; Larisa, ép. helen.), beoc. Kaфıбa (P. Roesch-J. M. Fossey, ZPE 29, 1978, p. 132. n. 9, II. 3-4; Queronea, fin. s. III; gr. clás. трıакбola, olayóviov > gr. mod. тракббa, бayóvt; múltiples ejemplos en Scheller (1951: pp. 107-110, 118-120). Cf. tambièn esp. confesionario $>$ confesonario, fisiognomia $>$ fisonomia; igl. suit [s(i)u:t], assume [es(i)u:m]. Incidentalmente, los datos del griego moderno y del español muestran bien a las claras que, contra una opinión bastante extendida, la absorción de yod _.. sobre todo si se trata de una [s] apico-alveolar - no presupone una palatalización de [s] en [ $\left.\int\right]$ como la del japonés.

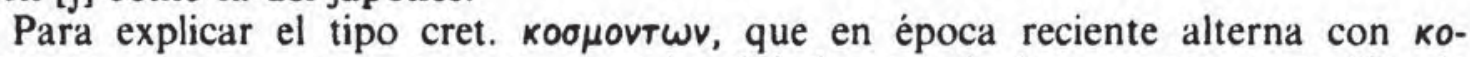

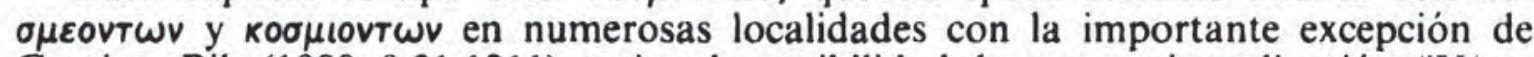
Gortina, Bile (1988: § 21.1211) sugiere la posibilidad de una semivocalización $/ \mathrm{iV} / \rightarrow$ [iV] "avec non-notation de cette articulation" (cf. también Brixhe y Bile 1991: $\S 2.3 .3)$. Pero, aparte de los problemas asociados con el cambio /eo/ > [io] que resulta en sí mismo problemático, quedan varios puntos por aclarar: (a) no parece posible admitir una pérdida fonética dado que la ausencia de $\langle\imath\rangle$ se detecta en contextos poco 'absorbentes'; (b) la "no notación" de [i] es gratuita; (c) como Brixhe y Bile (1991: $§ 2.3 .1)$ reconocen, no hay razón para que el fenómeno se produjera exclusivamente en silaba trabada por $/ \mathrm{n} /$. Dado que este resultado $\langle 0\rangle$ aparece en formas de verbos contractos en - $\varepsilon \omega$ (en su gran mayoría participios), cabe pensar que el fenómeno no sea fonético, sino que represente una hiperkoinización

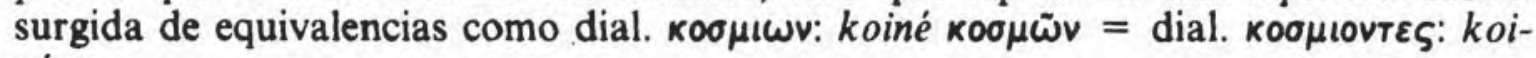
né $\mathrm{x}$.

${ }^{72}$ Por lo mismo, sería de esperar que en sílaba abierta las secuencias [io] primarias apareciesen como $\langle 10\rangle$ y no como $\langle\jmath \omega\rangle$ con SINIZ. + AC. Desgraciadamente en las Tablas de Heraclea, el único ejemplo de hiato en sílaba abierta, $\Delta$ ıovuowı (I 7 et passim), es reciente (cf. mic. Diwonusoyo) y, por lo tanto, irrelevante. 
de /e/ no es absolutamente desechable ${ }^{73}$, estas formas se pueden explicar mediante una evolución regular [oieo] $>$ [oieje] $>$ [oiio] ${ }^{74}$. La secuencia [ii] resultante recibe la notación convencional $\langle 1\rangle^{75}$.

Descartada la presencia de formas de futuro «no dóricas» en Heraclea, falta ahora examinar los datos que apoyarian la existencia del supuesto paradigma mixto en laconio. A mi entender, ni los futuros

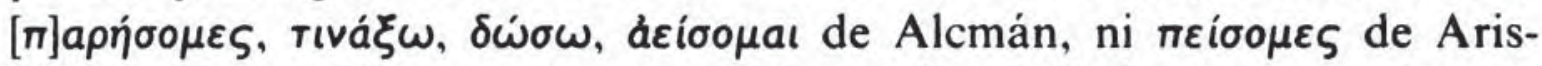
tófanes son pruebas consistentes en favor de tal hipótesis. Los primeros podrian ser formas tomadas de la épica jónica (por necesidad métrica

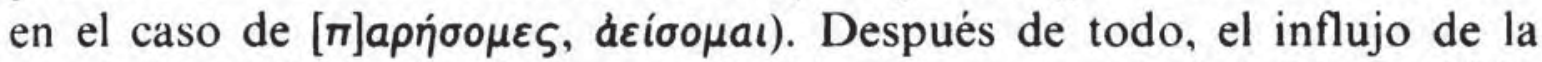
poesía homérica sobre la lengua de Alcmán es notable (cf. Risch 1954). La presencia de un aticismo en el laconio de Aristófanes tampoco puede escandalizar a nadie.

Con todo, el recurso al influjo externo es innecesario. Detrás de tales formas se esconden con entera seguridad futuros dorios con sinizesis

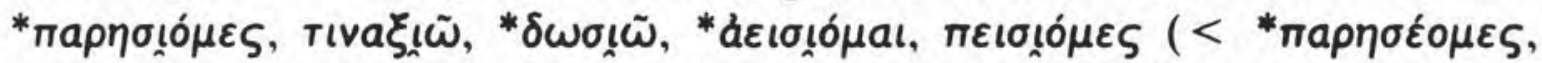

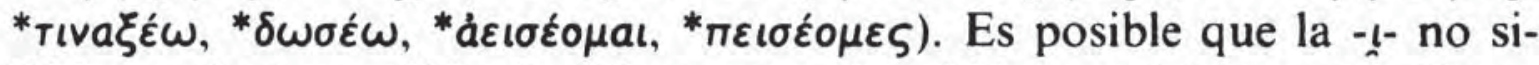
lábica se haya perdido fonéticamente absorbida por /s/ como en Heraclea, pero es mucho más probable que hayan sido los propios copistas, que por error escandian - $\sigma \omega \omega$ y $-\sigma \iota 0_{-}$como _ -.., $\_$, en dos sílabas, quienes han eliminado esta - - -, métricamente inerte (cf. hom. пótva por пótvı́a; Chantraine 1958: $\S 65)^{76}$. En cualquiera de los dos supuestos,

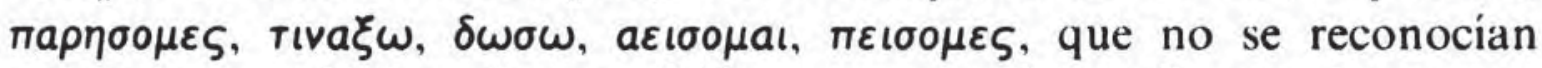
como formas dóricas, han recibido por parte de escribas antiguos, copistas de época medieval o editores modernos la acentuación convencional de los futuros sigmáticos.

Teniendo en cuenta el testimonio combinado de los resultados $\pi \rho 0-$

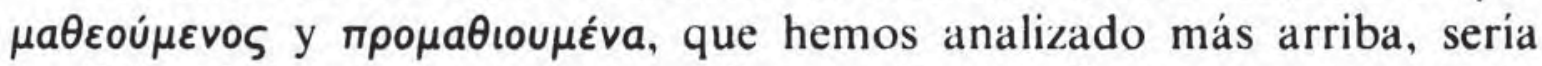
posible aplicar el mismo razonamiento a algunas formas aparentemente contractas de Epicarmo ${ }^{77}: \theta \omega \kappa \eta \sigma \tilde{\omega}, \lambda \varepsilon \xi \circ \tilde{u} \mu^{\prime}$ fr. $99,1 C F G=$ fr. 83,8 $(G F P) ; \theta \omega \kappa \eta \sigma \tilde{\omega}, \theta \omega \sigma o \tilde{\mu} \varepsilon \theta a$ fr. 139 CGF; cf. también $\lambda \tilde{\omega} v \tau \iota$ fr. 35,12 $C G F, \phi$ Oovoú $\mu \varepsilon v o \varsigma$ fr. $285 C G F$.

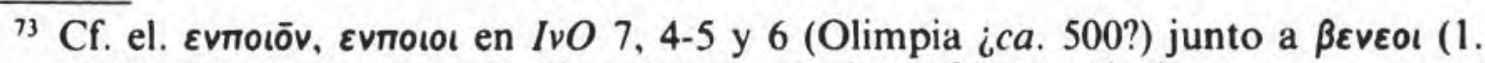

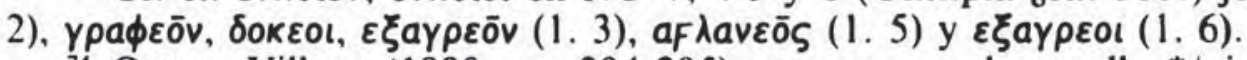

${ }_{74}$ Ortega Villaro (1990: pp. 204-205) propone un desarrollo*/oieo/ > */oiio/ > /oio/ con cierre de /e/.

${ }^{75}$ Quizá no sea necesario adoptar la misma explicación para yaıwvas (I 136) dado que puede tratarse de un derivado formado directamente sobre ya (I 32 et pas-

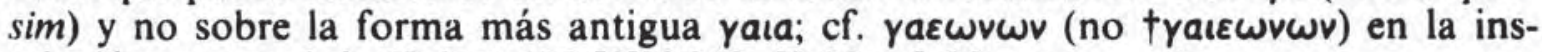
cripción catastral de Halesa (IG XIV 352 , II 83 y I 85 ; com. s. II).

${ }_{76}$ Cf. también las formas contractas en Lys. $981 \lambda \tilde{\omega}, 1162 \lambda \tilde{\omega} \mu \varepsilon \varsigma$ Bentley $(\lambda \tilde{\omega}-$ $\mu \varepsilon \sigma \theta^{\prime}$ R), $1259 \sigma \kappa \varepsilon \lambda \tilde{\omega} v$, que pueden encubrir resultados $\lambda_{\underline{l}} \tilde{v}$, liaṽêt, skeliñ̃n.

77 Debo esta sugerencia a Martin Peters. 
8. A modo de recapitulación, he aquí las principales conclusiones de nuestro estudio:

1) La MC jónico-ática no constituye un cambio fonético con entidad propia como quiere la doctrina recepta. La supuesta transferencia de la cantidad de una vocal larga a otra breve no cuenta con paralelos fuera del griego, ni es capaz de explicar determinadas características del proceso. La motivación de la MC hay que buscarla en la pérdida de silabicidad de /æ:, $\varepsilon$ :, e:/, que provoca el alargamiento compensatorio de la vocal contigua. Esta hipótesis, que se apoya en el testimonio de procesos de este tipo en las más diversas lenguas, explica por qué la "metátesis" no afecta indiscriminadamente a todas las secuencias $/ \mathrm{V}: \mathrm{V} /$ y resuelve el falso enigma de por qué los resultados de la metátesis son monosilábicos con una regularidad casi categórica en la épica homérica.

2) Un proceso de sinizesis con alargamiento compensatorio de características similares se documenta en el dialecto de Heraclea. Aqui la sinizesis actúa sobre /e/ breve y conduce a un cierre de la semivocal [e] $>$ [i]. El alargamiento compensatorio sólo tiene lugar en sílaba abierta.

3) Las presuntas formas de futuro en -s-, que alternarian con otras de futuro "dórico" en -se- en las Tablas de Heraclea y en el laconio literario de Alcmán, se explican como resultado de la sinizesis y cierre de /e/ antevocálica (-se- $>$-sę- $>-$ si -) con absorción fonética de la yod resultante $(-s i->-s-)$ en el caso del heracleota y con pérdida de una $\langle\imath\rangle$ que no contaba métricamente, en el caso de Alcmán.

Julián Méndez Dosuna

\section{REFERENCIAS BIBLIOGRÁFICAS}

Ahrens, Ludwig H. (1839): «Conjecturen zu Alcaeus, Sappho, Corinna, Alcman", $R h M$ 6, pp. 226-239.

Ahrens, Ludwig H. (1843): De Graecae linguae dialectis. II. De dialecto Dorica. Gotinga, Vandenhoeck \& Ruprecht.

Allen, William Sidney (1987): Vox Graeca. A Guide to the Pronunciation of Classical Greek ${ }_{3}$ [1." ed. 1968]. Cambridge, University Press.

Arena, Renato (1971): Note linguistiche a proposito delle tavole di Eraclea. Roma, Ateneo.

Bechtel, Friedrich (1923): Die griechischen Dialekte. 2. Band. Die westgriechischen Dialekte. Berlín, Weidmann. 
Bechtel, Friedrich (1924): Die griechischen Dialekte. 3. Band. Der ionische Dialekt. Berlin, Weidmann.

Bile, Monique (1988): Le dialecte crétois ancien. Étude de la langue des inscriptions. Recueil des inscriptions postérieures aux IC. Atenas, Ecole Française d'Athènes.

Brixhe, Claude, y Monique Bile (1991): «Le dialecte crétois. Unité ou diversité?», Cl. Brixhe (ed.), Sur la Crète antique. Histoire, écriture, langues, pp. 85138. Nancy, Presses Universitaires de Nancy.

Bowie, Angus M. (1981): The Poetic Dialect of Sappho and Alcaeus. Nueva York, Arno Press.

Buck, Carl Darling (1955): The Greek Dialects. Grammar, Selected Inscriptions, Glossary. Chicago, The University of Chicago Press.

Calame, Claude (1983): Alcman. Introduction, texte critique, témoignages, traduction et commentaire. Roma, Ateneo.

Catford, J. C. (1977): Fundamental Problems in Phonetics. Edimburgo, University Press.

Chantraine, Pierre (1958): Grammaire Homérique. Tome I. Phonétique et morphologie (troisième tirage). Paris, Klincksieck.

Christ, Wilhelm (1879): Metrik der Griechen und der Römer [2." ed.]. Leipzig, Teubner.

Clements, Nick (1986): "Compensatory lengthening in LuGanda», L. Wetzels, E. Sezer (edd.), pp. 37-77.

Crespo, Emilio (1977): "La cronología relativa de la metátesis de cantidad en jónico-ático", CFC 12, pp. 187-219.

Demiáńczuk, Ioannes (1912): Suppleme'ntum comicum. Cracovia [repr. Hildesheim, Olms, 1967].

Descroix, J. (1931): Le trimètre äamhique des iambographes à la comédie. Mâcon, Protat Frères.

Devoto, Giacomo (1928): «Il dialetto delle iscrizioni cirenaiche», $R F I C$ 56, pp. 365-403.

Donegan, Patricia J. (1985): On the Natural Phonology of Vow's. Nueva YorkLondres, Garland.

Donegan, Patricia J., y David Stampe (1979): "The study of natural phonology", Daniel A. Dinnsen (ed.), Current Approaches to Phonological Theory, pp. 126-173. Bloomington, Indiana U.P.

Dressler, Wolfgang U. (1985): Morphonology: the Dynamics of Derivation. Ann Arbor, Karoma Publishers.

Fernández Álvarez, M." Pilar (1981): El argólico occidental y oriental en las inscripciones de los siglos VII, VI y V a.C. Salamanca, Universidad.

Gallavotti, Carlo (1986): "Il timbro vocalico nella grafia di Nicandra e in iscrizioni arcaiche delle Cicladi", A. Etter (ed.), o-o-pe-ro-si. Festschrift für Ernst Risch zum 75. Gehurtstag, pp. 231-240. Berlin-Nueva York, De Gruyter.

Gentili, Bruno (1961): Reseña de E. Lobel et al. (1959), Gnomon 33, pp. 331344.

Harlow, Raymond Berry (1972): Eine Dialektanalyse der koischen Asylieurkunden. Dunedin, John McIndoe Ltd.

Henderson, Jeffrey (1987): Aristophanes. Lysistrata (edited with introduction and commentary by --). Oxford, Clarendon Press. 
Hiersche, Rolf (1970): Grundzüge der griechischen Sprachgeschichte bis zur klassischen Zeit. Wiesbaden, Dr. Ludwig Reichert Verlag.

Hock, Hans Heinrich (1986): «Compensatory lengthening: In defense of the concept 'mora'", Folia Linguistica 20, pp. 431-460.

Hoekstra, A. (1965): Homeric Modifications of Formulaic Prototypes. Studies in the Development of Greek Epic Diction. Amsterdam, Noord-Hollandsche Uitgevers Maatschappij.

Hualde, José Ignacio (1990): "Vowel lengthening in Basque», Folia Linguistica 24 , pp. $269-288$.

Hualde, Pilar (1989): "Acerca de los genitivos singulares en $\langle\omega\rangle$ de temas masculinos en $-\bar{a}$ en el dialecto jonio". Comunicación (inédita) presentada en el XIX Simposio de la SEL (Salamanca, 18-20 de diciembre de 1989).

Kaibel, Georgius (1899): Comicorum graecorum fragmenta. I. Fasc. 1. Doriensium comoedia, mimi, phlyaces. Berlin [2." ed. con addenda de Kurt Latte, Berlin, Weidmann, 1958].

Kieckers, Ernst (1932): Handbuch der griechischen Dialekte (Erster Teil. Von Albert Thumb. Zweite erweiterte Auflage von E. Kieckers). Heidelberg, Winter.

Landi, Addolorata (1979): Dialetti e interazione sociale in Magna Grecia. Lineamenti di una storia linguistica attraverso la documentazione epigrafica. Nápoles, Giannini.

Lejeune, Michel (1972): Phonétique historique du mycénien et du grec ancien. París, Klincksieck.

Lobel, E., E. G. Turner y R. P. Winnington-Ingram (1959): The Oxyrhynchus Papyri, XXV. Londres, The Egypt Exploration Society.

Lo Porto, Felice Gino (1987): «Due iscrizioni votive arcaiche dai dintorni di Taranto", PP 132, pp. 39-50.

Martinet, André (1969): "Qu'est-ce que le 'e muet'», Le français sans fard, pp. 209-219. París, Presses Universitaires de France.

Masson, Olivier (1990): "Variétés chypriotes syllabiques», Kadmos 29, pp. 144156.

Masson, Olivier y Terence B. Mitford (1986): Les inscriptions syllabiques de Kouklia-Paphos. Konstanz, Universitätsverlag Konstanz GmbH.

Méndez Dosuna, Julián, en prensa: "El cambio de $\langle\varepsilon\rangle$ en $\langle\imath\rangle$ ante vocal: ¿una cuestión zanjada?», Actas del II Coloquio Internacional de Dialectología Griega, Miraflores de la Sierra (Madrid), 19 de junio de 1991.

Mickey, K. (1981): "Dialect consciousness and literary language: an example from Ancient Greek», TPhS 1981, pp. 35-66.

Miller, D. Gary (1976): "Glide deletion, Attic reversion and related problems in Ancient Greek phonology", Die Sprache 22, pp. 137-156.

Miller, D. Gary (1982): Homer and the Ionian Epic Tradition. Some Phonic and Phonological Evidence Against an Aeolic 'Phase'. Innsbruck, IBS.

Miranda, Rocky V. (1990): "Temporal compensation and phonetic change: Two phonetic developments in Hindi», Lingua 81, pp. 221-239.

Mühlestein, Hugo (1956): "L'adjectif mycénien signifiant 'en or'. Essai de chronologie phonétique prémycénienne», M. Lejeune (ed.), Études mycéniennes. Actes du Colloque International sur les Textes Mycéniens (Gif-sur-Yvette, 3-7 avril 1956), pp. 93-97. Paris, Centre National de la Recherche Scientifique.

Nyman, Martty (1978): "Lexicalization out of casual speech. The Greek-Latin 
synizesis». Four Linguistic Studies in Classical Languages, pp. 65-95. Helsinki, University of Helsinki, Department of General Linguistics.

Olivieri, Alessandro (1930): Frammenti della commedia greca e del mimo nella Sicilia e nella Magna Grecia. Nápoles, Luigi Loffredo.

Ortega Villaro, Begoña (1990): «Los grupos /eo(:)/ y /ea(:)/ en el dialecto de Tarento y Haraclea», PP 45, pp. 199-205.

Page, Denys L. (1951): Alcman: The Partheneion. Oxford, Clarendon Press.

Peters, Martin (1980): Untersuchungen zur Vertretung der indogermanischen Laryngale im Griechischen. Viena, VÖAW.

Peters, Martin (1989): «Sprachliche Untersuchungen zur Bestimmung der Heimat Homers. Prolegomena", Sprachliche Untersuchungen zum Frühgriechischen, pp. 1-158. Tesis de habilitación (inédita), Universidad de Viena.

Poser, William J. (1986): «Japanese evidence bearing on the compensatory lengthening controversy", L. Wetzels, E. Sezer (edd.), pp. 167-186.

Risch, Ernst (1954): "Die Sprache Alkmans», $M H$ 11, pp. 20-37 [= A. Etter, M. Looser (edd.), Kleine Schriften, pp. 314-331. Berlin-Nueva York, De Gruyter, 1981].

Rix, Helmut (1976): Historische Grammatik des Griechischen. Laut- und Formenlehre. Darmstadt, Wissenschaftliche Buchgesellschaft.

Rohlfs, Gerhard (1966): Grammatica storica della lingua italiana e dei suoi dialetti. Fonetica. Turín, Einaudi [trad. it. rev. de Historische Grammatik der italienischen Sprache und ihrer Mundarten, Band I: Lautlehre. Berna, A. Francke, 1949].

Ruijgh, Cornelis J. (1957): L'élément achéen dans la langue épique. Assen, van Gorcum.

Ruijgh, Cornelis J. (1968): "Observations sur la 'metathèse de quantité», Lingua 21 , pp. 382-399.

Ruijgh, Cornelis J. (1985): "Le Mycénien et Homère», A. Morpurgo Davies, Y. Duhoux (edd.), Linear B: a 1984 Survey, pp. 143-190. Lovaina la Nueva, CABAY.

Ruijgh, Cornelis J. (1986): Reseña de Fernández Álvarez (1981), Mnemosỵne 39 , pp. $452-459$.

Ruijgh, Cornelis J. (1989): Reseña de Calame (1983), Mnemosyne 42, pp. 163170.

Scheller, Meinrad (1951): Die Oxytonierung der griechischen Substantiva auf -lä. Zurich, Leemann.

Scherer, Anton (1959): Handhuch der griechischen Dialekte (Zweiter Teil. Von Albert Thumb. Zweite erweiterte Auflage von E. Kieckers). Heidelberg. Winter.

Schmidt, Volkmar (1968): Sprachliche Untersuchungen zu Herondas (mit einem kritisch-exegetischen Anhang). Berlin, De Gruyter.

Schmidt, Volkmar (1978): "Ein vermutetes Epicharm-Fragment bei Galen», ZPE 30, pp. 13-17.

Schulze, Wilhelm (1934): Kleine Schriften. Gotinga, Vandenhoeck \& Ruprecht.

Schwyzer, Eduard (1939): Griechische Grammatik. I. Allgemeiner Teil. Lautlehre, Worthildung, Flexion. Munich, Beck.

Solmsen, Felix (1893): "Der übergang von $\varepsilon$ in 1 vor vocalen in den griechischen mundarten", $K X$ 32, pp. 513-553. 
Sommerstein, Allan H. (1986): "Notes on the text of Aristophanes" Peace», $C Q$ 36 , pp. 353-362.

Szemerényi, Oswald (1956): "The genitive singular of masculine $-\bar{a}$-stem nouns in Greek», Glotta 35, pp. 195-208.

Thumb, Albert (1909): Handbuch der griechischen Dialekte. Heidelberg, Winter.

Tichy, Eva (1981): "Beobachtungen zur homerischen Synizese», MSS 40, pp. 187-222.

Uguzzoni, Arianna (1968): "Analisi linguistica», A. Uguzzoni y Francesco Ghinatti, Le tavole greche di Eraclea, pp. 7-79. Roma, "L'Erma» di Bretschneider.

Wackernagel, Jacob (1916): Sprachliche Untersuchungen zu Homer. Gotinga, Vandenhoeck \& Ruprecht.

Wathelet, Paul (1970): Les traits éoliens dans la langue de l'épopée grecque. Roma, Ateneo.

Wells, J. C. (1982): Accents of English. Cambridge, University Press.

West, M. L. (1974): Studies in Greek Elegy and Iambus. Berlín, De Gruyter.

West, M. L. (1982): Greek Metre. Oxford, Clarendon Press.

Wetzels, Leo (1986): "Phonological timing in Ancient Greek», L. Wetzels, E. Sezer (edd.), pp. 297-344.

Wetzels, Leo y Engin Sezer (edd.) (1986): Studies in Compensatory Lengthening. Dordrecht, Foris.

Wilamowitz-Moellendorff, Ulrich von (1927): Aristophanes. Lysistrate (erklärt von -). Berlin, Weidmann [repr. fotomecánica, 1958]. 